\title{
The Role of Small Specimen Creep Testing within a Life Assessment Framework for High
} Temperature Power Plant.

\section{A. Morris ${ }^{a}$, B. Cacciapuoti ${ }^{b}$, W. Sun ${ }^{b}$}

a EDF Energy (UK), Coal Gas and Renewables, Central Technical Organisation, Barnwood, Gloucester GL4 3RS UK

b Department of Mechanical, Materials and Manufacturing Engineering, University of Nottingham, Nottingham NG7 2RD UK

\begin{abstract}
The safe operation of components operating at high temperature and pressure faces numerous challenges associated with ageing materials and maintaining commercial viability whilst economies transition to a lower carbon future as part of their climate change commitments. Due to these challenges the plant operator faces increasing pressure to ensure that any capital or operational expenditures are optimised and must ensure that they duly recognise plant age, condition, operating regime and ultimately the planned closure date.
\end{abstract}

This review, for the first time, describes how small specimen creep testing can be applied within a practical and deployable life assessment framework and in conjunction with other assessment techniques. The current state of the art for small specimen creep testing is critically reviewed; this also includes a review of traditional techniques used on site for the metallurgical assessment of material condition, with examples from site investigations and assessment campaigns in both conventional and nuclear plant applications.

In order to enhance the current practice for assessing the condition of creep ageing components this review proposes the more proactive use of small specimen testing methods for the in-service condition assessment of power plant materials, notably earlier in the plant lifecycle and within a holistic life assessment framework. This is intended to provide a means of calibrating the time dependent response of the component or system being monitored, thereby providing a key reference in-service strain rate measurement, or material property evaluation, that can subsequently be used with other traditionally deployed assessment methods to define a more targeted and cost-effective forward inspection plan. The review describes how small specimen creep testing methods and other complementary tools can be use in a new and structured approach to life management.

The current status of small specimen testing methods, for both conventional and nuclear applications, is described along with a detailed discussion on current practice for in-service creep life assessment, with a case study used to illustrate the main principals. A case study is presented for ageing $\mathrm{CMV}(0.5 \% \mathrm{Cr} 0.5 \% \mathrm{Mo} 0.25 \% \mathrm{~V})$ main steam pipework due to the extensive amount of through life data available, which highlights the particular challenges associated with the interpretation of various types of site outage inspection data, in conjunction with on-load plant operational data. The current approach to the assessment of component condition follows well established inspection based practices defined in various industry good practice guides, with expert elicitation and experience used to judge the condition of the component, system and operational risk on return to service.

This review proposes a new approach to the holistic life assessment of high temperature plant, with a particular emphasis on more proactive use of small specimen testing. In addition, the review has 
highlighted other aspects of the current approach to in-service condition assessment that could be improved to support the plant owner. This specifically refers to the potential to develop and implement novel life assessment models that can take advantage of the significant amount of site data currently routinely acquired during plant outage overhauls. There is a clear need to provide the plant owner with more reliable and effective life prediction tools, based on earlier and more rigorous assessment of life consumption. The proposed application of small specimen testing described in this paper is equally applicable to both conventional and nuclear plant applications and a range of components, from static pressure systems to high temperature turbine rotors.

\section{Nomenclature}

\begin{tabular}{|c|c|}
\hline$A, B, C, \ldots, I$ & Coefficient in parametric equation \\
\hline$A^{\prime}$ & Material constant \\
\hline$a^{\prime}$ & Elliptical ring half-axis \\
\hline$a_{p}$ & Receiving hole radius in small punch creep test \\
\hline $\boldsymbol{b}$ & Length of impression creep test specimen \\
\hline $\boldsymbol{b}^{\prime}$ & Elliptical ring half-axis \\
\hline$b_{T}$ & Two-bar specimen width \\
\hline$d$ & Width of impression creep test indenter \\
\hline$d^{\prime}$ & Thickness of the ring in the axis direction \\
\hline$d_{0}$ & Thickness of the ring in the radial direction \\
\hline$d_{T}$ & Two-bar specimen thickness \\
\hline$D_{T}$ & Diameter of the loading pins \\
\hline $\boldsymbol{h}$ & High of impression creep test specimen \\
\hline$h^{\prime}$ & Cut depth \\
\hline $\boldsymbol{k}$ & Length of the loading pins supporting end \\
\hline$K_{S P}$ & Correction factor \\
\hline$L_{T}$ & Initial bar length \\
\hline$n$ & Material constant \\
\hline$\overline{\boldsymbol{p}}$ & Mean indenter pressure \\
\hline$P$ & Applied load \\
\hline $\boldsymbol{R}$ & Radius of the circular ring \\
\hline $\boldsymbol{R}_{S}$ & Punch radius \\
\hline$t, t_{f}$ & Current and fracture thickness of small punch specimen \\
\hline$w t$ & Wall thickness \\
\hline$t_{0}$ & Initial thickness of small punch creep test specimen \\
\hline $\boldsymbol{w}$ & Width of impression creep test specimen \\
\hline$\alpha$ & Stress multiplier \\
\hline $\boldsymbol{\beta}$ & Conversion factor \\
\hline$\Delta, \Delta_{f}$ & Creep displacement and creep displacement at fracture \\
\hline$\dot{\Delta}$ & Creep displacement rate \\
\hline$\varepsilon$ & Strain at the contact boundary \\
\hline$\varepsilon_{s s}^{c}$ & Creep strain in the steady-state \\
\hline$\dot{\varepsilon}_{\min }^{s s}$ & Minimum creep strain rate \\
\hline$\eta$ & Conversion factor \\
\hline$\sigma_{m}$ & Membrane stress \\
\hline$\sigma_{M D H}$ & Mean diameter hoop stress \\
\hline$\sigma_{R}$ & Rupture stress \\
\hline
\end{tabular}




\begin{tabular}{|c|c|}
\hline$\sigma_{r e f}$ & Equivalent uniaxial stress \\
\hline$\phi$ & Outer diameter \\
\hline
\end{tabular}

\section{Introduction}

Power stations are designed and maintained to operate for long periods safely and reliably in accordance with statutory requirements. In the UK these statutory provisions are detailed in the pressure systems safety regulations (PSSR) [1], which are applicable to both conventional and civil nuclear generating plant. Further to the PSSR, UK civil nuclear advanced gas cooled reactor (AGR) generating plant is subject to licence conditions stipulated by the office for nuclear regulation (ONR) [2]. The aim of these regulations is to prevent injury from the hazard posed by high stored energy systems as a result of a failure.

Subsequent pressure system inspections must be undertaken by competent persons in accordance with written schemes of examination that identifies the systems or components requiring inspection and takes into account the relevant degradation and ageing mechanisms, asset condition including past inspection, assessment history and intended future operation. The inspection periodicity between major statutory outages on UK conventional fossil fired generating plant is every 4 years, with a short interim outage scheduled after 2 years. Typically, AGR generating plant is subject to a periodic pressure systems outage inspection every 3 years. Understanding residual life (and critically the mode of failure and rate of deterioration) is essential to maintain safety and to enable the utility to plan for any repair or replacement activities in a timely and cost-effective manner.

The operational duty of the high temperature and pressure steam circuits differ considerably between an AGR plant and a conventional fossil fired plant. Large conventional fossil fired plant are operated far more flexibly and at higher temperatures than AGR plant (design temperature of $568^{\circ} \mathrm{C}$ for conventional fossil fired plant vs. $540^{\circ} \mathrm{C}$ for AGR plant), but with similar maximum pressures of $\sim 170 \mathrm{bar}$, which reflect conditions as the steam exits the boiler.

There are other high temperature components aside from pressure systems in operation that could equally benefit from the use of small specimen creep testing, such as high pressure (170 bar) and intermediate pressure (40 bar) steam turbine rotors. The potential use of small specimen creep testing on these components is however considered more difficult due to limited access, since periodic overhauls typically occur every 12 years and with the turbines removed from berth. On these rotors access to the most relevant locations for material sampling is more restricted, for example the turbine disc steeples are of great interest, however these locations are precision machined and a sample could not be feasibly extracted without undertaking a costly repair to the disc head. Hence, the use of small specimen creep testing of material extracted from these components is more likely to be a practical choice on a rotor that has been retired from service, where the information obtained from the test could be used to provide a more informed view on the condition of other rotors in-service.

The review published by Hyde et al [3] in 2007 focussed on the use of small specimen testing methods to satisfy data requirements. This review is applicable to both conventional and nuclear plant applications and is focussed on providing a review of the current state-of-the-art of small specimen creep testing but with a focus on plant applications. Subsequently the review emphasises the following;

- Techniques currently used to assess the residual creep life of in-service plant, 
- A proposal is presented for the more pro-active use of small specimen testing methods to improve the approach to creep life expiry and subsequent run-repair-replace decisions.

Examples of in-service inspection data and a detailed case study based on high temperature and pressure pipework on conventional fossil fired plant operation is used to illustrate the above points. Pipework systems are chosen for the case study because of the extensive amount of through life inspection data available as well as extensive research studies related to material creep behaviour and modes of failure.

Understanding the contribution of prior service duty to creep life consumption and a prediction of the future rate of ageing is essential if a utility is to optimise its generating output and return on investment, with respect to both maintenance and capital infrastructure costs.

Figure 1 shows historical operating data from two 2000MW fossil fired conventional power stations presented as unit operating hours divided by unit starts; the data presented for each station has been averaged across all of the units on each site. This shows a dramatic variation in operating hours-tostarts ratio ranging from $>500$ during the early operational years, which reflects significant operation at constant (base) load to a dramatic change in the mid 1990's, to around 25. This significant reduction in hours-to-starts ratio indicates a move to more flexible plant operation, which is driven by the demands of the commercial market. Figure 2 shows specific unit average operating hours and starts for station ' $\mathrm{A}$ '. If all eight $500 \mathrm{MW}$ units operating in stations ' $\mathrm{A}$ ' and ' $\mathrm{B}$ ' are considered the range of unit operating hours is from $250 \mathrm{Khr}$ to $280 \mathrm{Khr}$ and the range of unit operating starts is from 2500 to 4100 . To put this operational data into context particular reference is made to a UK parliamentary study on UK energy policy [4], which describes the significant impact associated with these operational figures as a result of the privatisation of the central electricity generating board (CEGB) in 1990.

Both current and future operation is greatly influenced by legislation regarding environmental compliance. As a consequence of this legislation it is anticipated that stations ' $A$ ' and ' $B$ ' will from 2016 onwards revert to limited annual operational hours and unit starts (up to $2000 \mathrm{~h}$ and 100-200 starts). This shows the challenges associated with optimal deployment of small specimen testing methods (or any other monitoring or life assessment approach); these methods have to account for a wide range of operating duty throughout the stations operational life.

In the UK, the approach to managing the integrity of the high pressure and temperature pipework systems and components on conventional fossil fired plant is based primarily on an inspection based assessment (IBA) approach. This IBA approach is implemented in line with the statutory outage inspection periodicity and consequently it has no specific requirement to provide longerterm predictions of component degradation rates.

For the utility the goal of optimised life management would be realised with the following:

- Timely replacement of life expired components (maximising the useful service life), allowing the utility to budget and plan for cost-effective replacement,

- Continual optimisation of inspection plans during unit shutdowns; making the best use of all available condition monitoring and outage overhaul data,

- The more timely use of on-load monitor data and outage inspection findings to update and manage the plant risk profile within acceptable levels,

- Avoidance of significant unplanned and costly outages. 
In this context, the development and more proactive use of small specimen creep testing methods for the assessment of the integrity of high temperature and pressure systems provides a significant opportunity to reach this goal, but in conjunction with other complementary assessment tools that are outlined in this review.

\section{Specialised Small Specimen Creep Testing}

In the last 20 years small specimen creep testing techniques (SSTT) have been increasingly developed to evaluate creep properties for materials relevant to components operating at high temperature in power plant applications, to assess their remaining life and avoidance of premature failures [5]. A way forward to establish this key material data is considered to be the use of standard size uniaxial creep tests, which are well-standardised mechanical test techniques, but requiring a large amount of material to be sampled from the operating components. Furthermore, it is often needed to perform analyses on critical locations on operating components, e.g. the heat-affected zone of welds, or to risk rank the most vulnerable operating components within a larger population. In order to avoid these particular difficulties, innovative non-invasive testing techniques, such as the small punch, impression, small two-bar and small ring creep tests, have been investigated by several authors, because of the relatively small volume of material they require. In practice, these nondestructive techniques have been used to provide a ranking of material creep strength, thereby assigning a suitable inspection priority that has been adopted during a plant outage [6]. Furthermore, small punch creep testing has found applications in the nuclear field, especially for the characterization of irradiated materials (see Section 5.4).

\subsection{Scoop sampling}

In order to manufacture miniature specimens from in-service components, scoop sampling techniques are currently used for industrial procedures [7, 8]. Rolls-Royce produced the SSamTM-2 sampler for the extraction of material samples (Figure 3); the machine has a length of $420 \mathrm{~mm}$ and presents a hemispherical shell cutter of $50 \mathrm{~mm}$ in diameter, which can remove a "button" shaped sample of material, that is, typically, $25 \mathrm{~mm}$ in diameter and $4 \mathrm{~mm}$ thick [8]. Rolls-Royce has also designed two other smaller samplers, one able to fit within a $38 \mathrm{~mm}$ diameter tube bore and the second within a $30 \mathrm{~mm}$ annulus [8]. Scoop sampling techniques are such that the wall thickness of the component does not become smaller than the design wall thickness after some material has been removed [9]. Nevertheless, an increase of the creep strain rate in the sample area has been observed by finite element (FE) analyses of drum, steam pipes and turbine rotor bore. This is due to the increase in stress at the bottom of the of the excavation, which is up to 1.2-1.5 times greater than the stresses in the intact wall in the same depth from the external surface of the component $[10,11]$. In order to assess the creep damage due to this stress increment caused by the scoop sampling, Klevtsov and Dedov carried out FE analyses of a steam pipe with an outer diameter, $\phi$, of $325 \mathrm{~mm}$ and a wall thickness, $w t$, of $30 \mathrm{~mm}$, and creep cavity count on three bends steam pipes of $12 \mathrm{Ch} 1 \mathrm{MF}$ and 15Ch1M1F [11]. Two important conclusions can be deducted from their research: after 23-27 $\mathrm{khr}$ of service, the analysed components presented the same creep damage in the region under the scooping area and at a distance of $10 \mathrm{~mm}$ from that; also tensile properties of the materials remained the same during the service and were independent of the excavation location and of the specimen typology [11].

Brett carried out 170 impression creep tests, scoop sampled by using the SSamTM-2 on CrMoV main steam and hot reheat pipes, which had a wall thickness of $60-65 \mathrm{~mm}$ and $30-35 \mathrm{~mm}$ respectively [12-15]. He found that the scoop technique can be considered to be 'non-destructive' since it does not require the repair stage as long as the maximum excavation depth does not exceed $10 \%$ of the wall thickness of the main steam pipe; for the hot reheat pipe a depth bigger than $10 \%$ of the wall thickness is acceptable only over a restricted area in the centre of the excavation [15]. 
Rouse et al. investigated the effects of scoop sampling on the creep response of straight pipe sections with different geometries, for a range of cut depths from 1 to $5 \mathrm{~mm}$ and for different load conditions, for the material $0.5 \mathrm{Cr} 0.5 \mathrm{Mo} 0.25 \mathrm{~V}$ at $640^{\circ} \mathrm{C}$ [16]. They found that the presence of the excavation generates a localized stress around the base of the excavated notch. In the case of a static application of the load to the pipe, the condition is considered safe if the stress at the base of the excavation concentration does not exceed the magnitude of the stress at the inner surface. This condition is achieved only when the depth of the excavation, $h^{\prime}$, is $1 \mathrm{~mm}$ for a pipe section with $\phi=360 \mathrm{~mm}$ and $w t=60 \mathrm{~mm}$. Rouse at al. also propose a parametric equation which can estimate the scoop sample riser effect for a wide range of materials and pipe geometries, here given in equation (1), where $A, B, C, \ldots, I$ are fitting constants [16]. Future study is needed on the effects of scoop sampling on the sampled component under the effects of cyclic load conditions.

$$
\begin{aligned}
\frac{\sigma_{R}}{\sigma_{M D H}}\left(\frac{\phi}{w t}, h^{\prime}\right) & =A \frac{\phi^{4}}{w t}+B \frac{\phi^{3}}{w t}+C \frac{\phi^{2}}{w t}+D h^{\prime 2}+E\left(\frac{\phi^{2}}{w t}+h^{\prime 2}\right)+F \frac{\phi}{w t}+G h^{\prime} \\
& +H\left(\frac{\phi}{w t}+h^{\prime}\right)+I
\end{aligned}
$$

These studies on the effect of the scoop excavation suggest that a degree of prior assessment is required before a sampling exercise is conducted to consider the excavation depth, component geometry, material type, its condition and the operational duty of the plant. The study by Rouse et al [16] considers operating temperatures at $640^{\circ} \mathrm{C}$, which is much higher than the typical plant operating temperatures $\left(\sim 570^{\circ} \mathrm{C}\right)$ that Brett's study alludes to. This emphasises the need to measure on plant or estimate by analysis, the operating temperature related to a proposed sampling location due to the temperature.

For practical purposes a scoop sample location would be identified as a location on a future inspection schedule, noting that the additional cost and effort for the inspection of scoop sample locations typically is insignificant when compared to the full inspection scope during an outage. Ideally all scoop sample locations would be accessible for repair should the need be foreseen.

\subsection{Reference Stress Method}

A major concern in the evaluation of test data of small specimen creep testing techniques is their correlation with uniaxial creep data. The approach currently used for data conversion is the reference stress method [17, 18]. For materials obeying the Norton creep law, here reported in equation (1), where $A^{\prime}$ and $n$ are material constants, the reference stress method consists in calculating two reference parameters, $\eta$ and $\beta$, such that a relationship between the equivalent uniaxial stress, $\sigma_{\text {ref, }}$ and the applied stress, $\sigma$, and a relationship between the creep strain rate in the steady-state, $\dot{\varepsilon}_{\mathrm{SS}}^{\mathrm{c}}$, and the creep displacement rate obtained by SSTT, $\dot{\Delta}^{c}$, are established.

$\dot{\Delta}^{c}$ can be expressed as a function of the creep material properties, the dimensions of the specimen and the applied stress, as reported in equation (2).

The reference parameter $\eta$ is defined as material independent, non-dimensional constant such that the ratio $f_{1}(n) / \eta^{n}$ is also constant with $n$. Thus, the equivalent gauge length (EGL) of the structure 
can be defined as in equation (3). It should be noted that the EGL does not vary with $n$ since none of the terms in equation (3) does.

$$
E G L=\frac{f_{1}(n)}{\eta^{n}} f_{2} \text { (dimensions) }
$$

If $s$ is a characteristic dimension of the sample, the reference parameter $\beta$ can be expressed as in equation (4) and again it should be noted that this constant is independent of $n$.

$\beta=\frac{E G L}{S}$

Finally, equations (5) and (6) represent the sought relationships for $\dot{\Delta}^{c}$ and $\dot{\varepsilon}_{\mathrm{ss}}^{\mathrm{c}}$.

$\dot{\Delta}^{c}=E G L A^{\prime} \sigma^{n}=\beta s A^{\prime} \sigma^{n}=\beta s \dot{\varepsilon}_{\mathrm{ss}}^{\mathrm{c}}\left(\sigma_{\text {ref }}\right)$

$\sigma_{\text {ref }}=\eta \sigma$

\subsection{Codes and Standards for Small Specimen Creep Testing Techniques}

Standards for small specimen creep testing techniques still do not exist, but two Codes of Practice have been released for small punch creep test by the European Committee for Standardisation in 2006 [5] and by the Standardization Administration of China in 2012 [19, 20]. Efforts in developing a standard draft for SPCT are also ongoing in Japan, but an English version does not exist yet [21]. In the USA, an ASTM Standard test method for small punch testing of ultra-high molecular weight polyethylene used in surgical implants has been released, but does not concern creep testing [22].

The European CEN CWA 15627 [5], last updated in 2007, has been accepted as a first incentive for industrial applications all through the world, even if it is far away to be a standard and certainly needs to be improved [23]. The CEN Code of Practice consists of two parts, Part A: A Code of Practice for Small Punch Creep Testing, and Part B: A Code of Practice for Small Punch Creep Testing for Tensile and Fracture Behaviour. Part A is related to specifications for the test rig, test procedure and interpretation of results for small punch test designed for material characterisation [5]. Part B is focused on the test rig, test procedure, test specimen preparation, interpretation of results and methods for deriving the yield strength, the ductile-to-brittle transition temperature (DBTT) and the fracture toughness from SPCT $[5,23]$. Hurst and Matocha published a critical review on the CEN CWA 15627 also suggesting some potential improvements of the code [23]. One of their concerns is related to the Shear Punch test, which is not included in the code, even if it has been proven to be a reliable technique for the evaluation of tensile properties $[23,24]$.

An open problem regarding SPCT is the correlation between the load level to be applied to the small disc specimen and the stress induced in a conventional uniaxial creep test which exhibits the same time to rupture. Some equations for data interpretation have been proposed in the CEN CWA 15627 and are here reported in section 2.4 .2 , but the procedure is still not totally accepted for industrial applications and further investigation on the complex behaviour of the specimen during testing is ongoing [25]. 


\subsection{Currently Used Test Methods}

Reliable bulk behaviour can be obtained if at least 8 grains are contained through the specimen thickness. Among the small specimens described in this section, the smallest dimension of the samples is the small punch disc thickness, equal to $0.5 \mathrm{~mm}$. So, the materials generally used in power plant have at least 20 grains through such a thickness, allowing consisted results to be obtained.

\subsubsection{Impression Creep Test}

In the impression creep test (ICT) a steady constant load, $\mathrm{P}$, is applied to a flat-ended indenter in contact with the specimen at a fixed temperature. The test output is the variation of the indenter displacement with time, which is related to the creep properties of the small volume of material in the contact region between the specimen and the indenter. Figure 4-a shows the typical test geometry. If the indenter is rectangular, the reference stress approach can be used to establish the

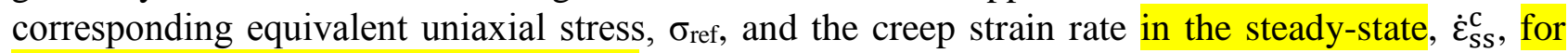
materials obeying the Norton creep law[26]. Equations (7) and (8), where $d$ is the indenter width, express the relationships between them and the mean indenter pressure, $\bar{p}$, and creep displacement rate, $\dot{\Delta}$. The reference stress parameter, $\eta$ and $\beta$, do not depend on the impression depth, if the creep displacement $\Delta$ is relatively small compared to the specimen thickness.

$$
\begin{aligned}
& \sigma_{r e f}=\eta \bar{p} \\
& \dot{\varepsilon}_{s S}^{c}=\frac{\dot{\Delta}}{\beta d}
\end{aligned}
$$

Once $\dot{\Delta}^{c}$ is known, for example by FE analyses, for different values of $n$, it is possible to calculate $\beta$ through equation (9), by using assumed values for the stress multiplier, $\alpha$ [26]. The value of $\alpha$ such that $\beta$ does not vary with $n$, is the reference stress parameter $\eta[26]$.

$\beta=\frac{\dot{\Delta}}{d A^{\prime}(\alpha \sigma)^{n}}$

The $\eta$ and $\beta$ values for the recommended geometry $(\mathrm{w} \times \mathrm{b} \times \mathrm{h}=10 \times 10 \times 2.5 \mathrm{~mm})$ are $\eta=0.43$ and $\beta$ $=2.18$, for an indenter width of $\mathrm{d}=1 \mathrm{~mm}$ [26]. A typical set of data obtained from such tests for a high temperature CMV $(0.5 \% \mathrm{Cr} 0.5 \% \mathrm{Mo} 0.25 \% \mathrm{~V})$ steel is shown in Figure 6. Impression creep test data lie on the same straight line of uniaxial test data, confirming the reliability of the ICT. The slight fluctuations in the data observed are mainly caused by temperature variations within the furnace and laboratory. However, it can be seen in Figure 6-a that these variations are typically well within $\pm 1 \mu \mathrm{m}$ [27].

\subsubsection{Small Punch Creep Test}

The small punch creep test (SPCT) consists of the application of a constant load, P, to a hemispherical indenter in contact with a disc specimen clamped between an upper and lower die containing the receiving hole. Figure 4-b shows the sketch of typical specimen and punch, while a schematic cross section of the test rig is given in Figure 7-a.

The European Committee for Standardisation has released a Code of Practice which provides standard dimensions of both test rig and samples to be tested [5]. According to that, the disk diameter has to be between 3 and $10 \mathrm{~mm}$, the specimen thickness, $t_{0}$, between 0.2 and $0.5 \mathrm{~mm}$, and 
the punch radius, $R_{s}$, between 1 and $1.50 \mathrm{~mm}$. Li and Sturm [28] found a third order polynomial based on Chakrabarty's membrane theory [29] and valid for $R_{s}=1.25 \mathrm{~mm}$ and $a_{p}=2 \mathrm{~mm}$ (receiving hole diameter), which correlates the strain, $\varepsilon$, at the contact boundary between the punch and the disc and the central displacement of the punch, $\Delta$, as shown in equation (10). An empirical relationship between the applied load and the membrane stress, $\sigma_{\mathrm{m}}$, is also given in the CEN Code of Practice and is here reported in equation (11) [5].

$\varepsilon=0.17959 \Delta+0.09357 \Delta^{2}+0.0044 \Delta^{3}$

These relationships are only valid when bending deformation of the specimen is negligible and thus the deformation mode can be assumed to be governed by membrane stretching. This happens when large deformations are exhibited by the specimen during the test, that is, from an engineering estimation, when $\Delta>0.8 \mathrm{~mm}$ [5]. However, according to many researchers, during small punch creep test the specimen deformation is caused by bending prior to membrane stretching [30-32] and a recent study, confirming this theory, suggests upper limits to $\Delta$, depending on the specimen and the punch dimensions [33], as shown in Table 1.

Table 1. Conditions for the applicability of Chakrabarty's theory for small punch data interpretation from Ref. [33].

$$
\left\{\begin{array}{ccc}
0.8<\Delta<0.95 \mathrm{~mm} & \text { if } & 1.04 \leq R_{s}<1.25 \mathrm{~m} \\
0.8<\Delta<1.15 \mathrm{~mm} & \text { if } & 1.25 \leq R_{s}<1.50 \mathrm{~m} \\
\Delta>0.8 \mathrm{~mm} & \text { if } & R_{s}=1.50 \mathrm{~mm}
\end{array}\right.
$$

Another empirical relationship, always derived by Chakrabarty's membrane theory, is reported in an annex of the Code of practice [5], and can be used to derive the load to be applied for the SPCT, here given in equation (12), where $K_{S P}$ is a correction factor depending on the tested material.

$$
P / \sigma_{m}=3.33 K_{S P} R_{S}^{-0.2} a_{p}^{1.2} t_{0}
$$

In order to find $K_{S P}$, at least five small punch creep tests are necessary as well as a comparison with a conventional creep test $[5,34]$. This parameter generally ranges between 1 and 1.5 [35]. An additional difficulty in SPCT data interpretation is the not negligible variation of the reference parameters due to large deformations involved in the test [34] and, although it is still possible to define $\eta$, as in equation (13), in virtue of equation (10) a constant EGL, and thus a constant $\beta$, cannot be determined [36].

$\eta=\frac{0.6 \pi}{K_{S P}}\left(\frac{a_{p}}{R_{S}}\right)^{0.2}$

Figure 7-b shows typical small punch creep test data output, in terms of displacements versus time, for a P91 steel at $600{ }^{\circ} \mathrm{C}$, while Figure 7-c shows converted creep rupture data (using equation (11), with $K_{S P}=1.275$ ), obtained from a SPCT on a P91 steel at $650{ }^{\circ} \mathrm{C}$, compared with corresponding uniaxial data. SPCT data are in good agreement with uniaxial data.

\subsubsection{Small Ring Creep Test}

Figure 4-c shows the typical specimen and loading system of the small ring creep test method that involves diametrically loading in tension a circular or elliptical ring. The test output is the deformation versus time curve, and similar to the impression creep test, this needs to be related to the data obtained from a standard uniaxial creep test, using the reference stress approach. An 
analytical solution for the load-line displacement rate of the elliptical ring in the secondary region of the creep curve has been developed at the University of Nottingham in 2009 by assuming as the main hypotheses the effects of the shear stresses to be negligible, bending as the governing deformation mode, and material obeying Norton's creep law [36]. The solution is given in equation (14), where $a^{\prime}$ and $b^{\prime}$ are the ellipse half-axes and $b_{0}$ and $d^{\prime}$ are the thicknesses in the radial and axis directions, respectively, $P$ is the applied load, while $I n t_{2}$ is defined in equation (15), where $\theta$ is the angular coordinate of the small ring system, as shown in Figure 5, and $\theta^{\prime}$ the value of $\theta$ for null bending moment, $M$. If the ring is circular $a^{\prime}=b^{\prime}=R$, where $R$ is the radius of the ring.

$$
\dot{\Delta}=\left(\frac{2 n+1}{n}\right)^{n} \operatorname{Int}_{2}\left(n, a^{\prime} / b^{\prime}\right) \frac{4 a^{\prime} b^{\prime}}{d^{\prime}} A^{\prime}\left(\frac{P a^{\prime}}{b_{0} d^{\prime 2}}\right)^{2}
$$

$$
\begin{aligned}
\operatorname{Int}_{2}\left(n, \frac{a^{\prime}}{b^{\prime}}\right)= & -\int_{0}^{\theta^{\prime}}\left\{\left(\cos \theta-\cos \theta^{\prime}\right)^{n}(1-\cos \theta) \sqrt{\left[\left(\frac{a}{b}\right)^{2} \sin ^{2} \theta+\cos ^{2} \theta\right]}\right\} d \theta \\
& +\int_{0}^{\theta \prime}\left\{\left(\cos \theta^{\prime}-\cos \theta\right)^{n}(1-\cos \theta) \sqrt{\left[\left(\frac{a}{b}\right)^{2} \sin ^{2} \theta+\cos ^{2} \theta\right]}\right\} d \theta
\end{aligned}
$$

By virtue of the reference stress method, the equivalent uniaxial creep stress and the equivalent uniaxial creep strain rate for the load-line deformation rate, $\dot{\Delta}$, are given in equations (16) and (17) $[36,37]$. For the full mathematical treatment refer to Ref. [36].

$\sigma_{\text {ref }}=\eta \frac{P a^{\prime}}{b_{0} d^{2}}$

$\dot{\varepsilon}^{c}\left(\sigma_{\text {ref }}\right)=\frac{d^{\prime}}{4 a^{\prime} b^{\prime} \beta} \dot{\Delta}$

Large deformations involved during the test do not significantly affect the conversion parameter $\eta$, the thickness in the radial direction, $b_{0}$, and the thickness axis direction, $d$ '; while they affect $a$ ', which decreases during the test as well as $\sigma_{\text {ref }}$; the conversion parameter $\beta$ also varies with the ratio $a^{\prime} / b$ ' at each instant of time $[36,37]$. As a consequence, the creep curve still shows primary and secondary regions, but the latter is characterised by a finite curvature rather than a constant rate [37]. In other words, with this test, a constant strain rate is not quite achieved, but it is still possible to calculate the equivalent uniaxial data by using the method proposed by Hyde et al., which consists in calculating the instantaneous values of $a^{\prime} / b^{\prime}, \eta, \beta, \sigma_{\text {ref }}$ and $\dot{\varepsilon}^{c}$ at many intervals in the secondary region; the average of the calculated values of $\sigma_{\text {ref }}$ and $\dot{\varepsilon}^{c}$ can be then assumed to be the equivalent uniaxial data [37]. In order to obtain a better defined steady-state, Hyde et al. are developing a software capable of varying the load during the test according to equation (16) as the specimen shape changes [37].

The test results for circular $\left(a^{\prime} / b^{\prime}=1\right)$ and elliptical $\left(a^{\prime} / b^{\prime}=2\right)$ rings, with $R / d^{\prime}=5$, for a P91 steel at $650^{\circ} \mathrm{C}$, with a range of equivalent uniaxial stresses, are shown in Figure 8-a in terms of displacement, $\Delta$, versus time, and in terms of minimum creep strain rate versus the applied stress in Figure 8-b, from which it can be observed that the method proposed by Hyde et al. in ref. [37] allows highly accurate secondary creep properties to be obtained, since the small ring data are on the same straight line as the uniaxial data. 


\subsubsection{Small Two-Bar Creep Test}

Another small specimen experimental technique which has been recently developed at the University of Nottingham by Hyde et al. is the two-bar specimen (TBS) test [38]. Figure 9-a shows the typical test rig, while Figure 9-b shows the typical two-bar specimen, which consists of two relatively slim bars connected by supporting ends. The sample is creep tested by applying a constant load to the supporting ends through the use of two pins (Figure 9-a). The specimen geometry comprises of the initial bar length, $L_{T}$, which is the distance between the centres of the loading pins, the length of the loading pins supporting end, $k$, the specimen thickness, $\mathrm{d}_{T}$, the diameter of the loading pins, $D_{T}$, and the bar width, $\mathrm{b}_{T}$ [38]. Hyde et al. recommended $L_{T} / \mathrm{b}_{\mathrm{T}}=4.5, D_{T} /\left(2 \mathrm{~b}_{\mathrm{T}}\right)=1.25, \mathrm{k} /$ $D_{T}=1.3$ [38] and a bar length, $L_{T}$, of $26 \mathrm{~mm}$, which is larger than the diameter of the small punch creep test specimen recommended in the CEN Code of Practice [5], i.e. $8 \mathrm{~mm}$, and of the impression creep test specimen recommended in ref. [26]. The equivalent uniaxial creep stress and the equivalent uniaxial creep strain rate are again defined through the reference stress method and here given in equations (18) and (19), where $\eta$ and $\beta$ are determined by FE analyses, as for impression creep test, and their values are 0.9866 and 1.456 , respectively [38]. However those values were obtained by the use of Norton's law, thus the FE analyses could well predict the primary and secondary region of the creep curve, but not the tertiary region. Consequently, further investigation in determination of the reference stress parameters is ongoing [39].

$\sigma_{\text {ref }}=\eta \frac{P}{2 b_{T} d_{T}}$

$\dot{\varepsilon}^{c}\left(\sigma_{\text {ref }}\right)=\frac{\dot{\Delta}}{L_{T} \beta}$

During the test, the creep deformation of the specimen is essentially due to stretching under uniaxial stress, as well as the rupture of the bars. Bending occurs in the area of the contact between the sample and the pins, but it has be proven not have a significant effect on the failure mode and on creep deformation [39]. This behaviour of the specimen is also observed by FE analysis results, as shown in the contour plot presented in Figure 10, where the specimen failure of P91 steel at $600{ }^{\circ} \mathrm{C}$ and applied stress of $170 \mathrm{MPa}$ is achieved when the damage variable, $\omega$, approaches unity. The twobar test is very close to the uniaxial test and this is also the reason why $\eta$ is almost 1 .

Typical small two-bar creep test data output and the corresponding correlation with uniaxial tests are shown in Figure 11. TBS data are in good agreement with uniaxial data, as their MSR trend is still on the same straight line of the uniaxial data, as well as for impression and small ring creep tests data.

\subsection{Evaluation of Current Test Methods}

The selection of a small specimen creep test technique is dictated by factors such as, economics, the type of data required, e.g. creep rupture data or creep strain rate data, material to be tested and the test conditions [40].

In practice, the impression creep test method is easy to perform and it gives accurate output in terms of minimum creep strain rate, particularly at relatively high stresses and in the heat affected zones of welds. This technique appears to be useful in power plant component life assessment [6], and has been deployed in-service to support decisions to continue operation as opposed to undertaking immediate repairs. Despite these advantages, the test has some limitations, e.g. the indenter creep resistance needs to be two or three order higher in magnitude than that of the specimen. Also, tertiary creep behaviour cannot be obtained, because of the compressive stress field in the specimen 
which does not allow the material to exhibit creep damage [41]. The deformations involved during the test are very small, of the order of $\mu \mathrm{m}$, requiring very accurate data acquisition and temperature control systems. Furthermore, FE analyses of this test are complicated by the contact interaction between the indenter and the specimen. The same problem is observed in numerical simulations of small punch creep test, where the contact is also non-linear.

The small punch creep test potentially allows the entire characterisation of material behaviour up to failure, because the specimen is taken to rupture and it can also be used to perform focused analyses on critical locations of operating components. Despite these advantages the interaction of several non-linearities, such as large deformations, large strains, non-linear material behaviour and nonlinear contact interactions between the specimen and the punch, induces a complex multi-axial stress field in the specimen which also evolves in time [42-45]. This affects the SPCT fracture mechanism and introduces several challenges into the identification of a robust correlation to convert SPCT data into respective standard uniaxial creep test data [34, 46]. Another major concern is the non-repeatability of the testing method, since the experimental results depend on the set up geometry [5]. For this reason, a well-established and universally accepted method for data interpretation still does not exist.

\begin{abstract}
Progresses in the understanding of the complex behaviour of the specimen have been made through FE analyses and microstructural studies. In particular, the implementation in a commercial FE code of the Liu and Murakami damage model [47], by the use of a subroutine, leads to good simulation of the crack propagation in the small punch specimen, as shown in Figure 12, where a comparison between SEM images of interrupted tests and FE results of P91 steel is proposed. Figure 12 also confirms Chakrabarty and other researchers' statement that the necking occurs at a certain distance from the specimen centre due to friction $[29,31,33,48]$ and that the zone affected by the maximum damage spread from the bottom of the specimen through the thickness in the necking area, as reported in the open literature $[32,49,50]$. The creep mechanism characterising the deformation of the specimen, that is represented by dislocation creep in the secondary creep regime and intergranular cavitation when the tertiary creep stage is reached, is not affected by the different temperature values of the test, $600{ }^{\circ} \mathrm{C}$, and of that assumed for the material properties in the numerical simulations, $650{ }^{\circ} \mathrm{C}[33,51]$. Figure 13 shows the typical uniaxial creep test output in terms of strain versus time, and illustrates that the crack propagation starts in the tertiary region of the creep curve. By comparing Figure 7-b, Figure 12 and Figure 13 the different behaviour of the small punch specimen with respect to the uniaxial specimen is evident. In fact, the crack propagation in the small punch disc starts in the secondary region of the creep curve instead of the tertiary region, as observed for the typical uniaxial specimen.
\end{abstract}

Difficulties in obtaining good agreement between FE analyses and small punch test output are due to the effects on the specimen time to failure of punch load misalignments, of initial plasticity, and of the approximation of the friction formulation used in the FE analyses for the interactions between the specimens and the testing machine components [33]. An increase of the failure life has been found to be up to 10 times when initial plastic deformation is included in the model [30]; the time to failure can also increase up to 8 times when the friction coefficient between the specimen and the punch varies from 0 to 0.5 [51-53]. Punch load misalignments can also increase the time to failure by up to 1.49 times, in the worst possible situations [54].

The small ring creep test method is able to provide accurate minimum creep strain rates, especially at relatively low equivalent uniaxial stresses with a unique application of this test type being for creep resistant materials. During the creep test, the small ring specimen is subjected to relatively large deformations, from which relatively small strains are obtained with a lower equivalent stress 
than that applied to other miniature specimens. As shown in Figure 8-b, the minimum creep strain rate data obtained from circular and elliptical ring creep test at stresses between 50 and $65 \mathrm{MPa}$ lie on the same straight line as the uniaxial data obtained at higher stresses, between 70 and $100 \mathrm{MPa}$. The slight deviation of the elliptical ring data from the straight line is less or equal than the typical scatter of creep tests, which is of $8 \%$. Future development involves the establishment of timedependent geometric correction functions to compensate for the effects of geometry changes during the deformation process [36, 37].

The small two-bar creep test allows production of full uniaxial creep curves, but further experimental data and validation are necessary. With this technique, the pins must be made of a material characterised by higher creep strength than that of the specimen, therefore there is a limitation in the range of materials which can be potentially tested. In the case of testing high creep strength materials, e.g. Nickel based super-alloys for turbine blades, using the two-bar specimen, careful consideration of the specimen design should be given. Relatively larger diameter pins and smaller cross-sectional areas of the test sections of the two-bar specimen should be adopted to reduce the mean contact stresses between the pins and the specimen. In such a case, the material for the pins can be chosen to have a similar creep strength as that of the test material. The contact between the pins and the specimen induces a bending deformation in the extreme regions of the specimen, while the stress distribution in the bars is almost constant [39]. In view of this feature, the reference stress parameters for this specimen type are almost one, as the stress field in the effective section of the structure is considerably similar to that found in conventional uniaxial creep test specimen. Furthermore, the specimen is taken to failure, therefore contrary to the impression creep and the small ring creep tests, the tertiary creep region of the material can be characterised and the failure behaviour identified.

In conclusion, good agreement between small specimen creep data and uniaxial creep data have been obtained with all of the techniques described so far, particularly with good correlation against minimum creep strain rates. Both small punch and small two-bar creep tests are able to predict the specimen failure life, but difficulties in data interpretation of small punch data have not been overcome yet, while, methods for data interpretation of the two-bar test are still under investigation, even though this test has already been validated for steel materials and a nickel-based super-alloy material. Impression and small ring creep tests are both suitable for the determination of the steadystate creep properties. The noise in the impression creep test output can be of the same order of the output itself, since very small deformation occur during the test. An opposite problem has been observed for the small ring creep test, during which the specimen shape varies, making the reference stress to change as well. As a final consideration, small specimen creep testing techniques look very promising for determining creep properties and providing information about failure, even though further experimental and numerical investigations are needed.

The current status of the techniques can be summarised as;

- Provide estimates of minimum creep strain rate that show good comparison to uniaxial data, (can we differentiate to comment on which test is better for low and high stress tests - in this context 'low' implies plant stress levels, so circa 40-70MPa)

- Impression creep specimens have been used to support operational run-repair-replace decisions on components,

- The small two-bar creep test specimen is the only method considered to be capable of providing a full uniaxial creep curve,

- There is currently no agreed standard for the application of small specimen testing, although the definition of a SPCT standard is the most advanced. (are there any major differences between CEN, Chinese and Japanese codes of practice?) 
- Material is typically sampled from the surface of a component, which confers the following opportunities;

- Correlation against other current methods for assessing the condition of the bulk component, such as surface creep replicas, hardness tests,

- Provides component specific data on the in-service creep strain rate, which can be compared against the response from a representative structural model, thereby allowing a more objective assessment of component condition,

- Sampling the material from the surface also presents similar issues faced by other surface techniques such as creep replicas and hardness testing, since the through section stress state is not directly accounted for. However, the use of a structural model that can account for the stress state provides a means of eliminating some of the current shortfalls associated with interpretation of surface creep replicas and hardness data.

\section{Industry Practice for Condition Monitoring and Life Management}

A range of non-destructive inspection based assessment techniques and surveys are routinely used during a statutory plant shutdown to support an evaluation of the creep damage accumulated in a component operating at high temperature. These techniques do not provide a direct measure of accumulated creep damage (life consumption); however they support the subsequent residual life assessment by reference to similar components and systems on sister plant. The current assessment approach requires extensive data mining and review of large quantities of site metallurgical data, from a number of different power stations and at different times in their lifecycle. A range of inspection and metallurgical assessment techniques are routinely used to assess the condition of components during a plant outage, such as; surface replication, surface hardness, ultrasonic inspection, magnetic particle inspection and physical dimension measurements using calipers and micrometers. The selection and use of these techniques is influenced by a host of considerations such as cost, perceived risk, familiarity and confidence with the techniques, plant access, accuracy, reliability, regulator preference and tradition. In addition, on-load monitoring of pressure and temperature conditions can be used to provide a generally conservative estimate of the residual creep life. This involves using sampled operational steam or metal temperature data coupled with steam pressure data, with an appropriate creep rupture expression to determine the residual creep life; this is illustrated in more detail in section 3.1.2.

It is standard practice to use multiple assessment techniques, such as outage overhaul inspections and on-load monitoring to evaluate component condition. This is necessary because of the intrinsic scatter in the material creep properties and uncertainty in some of the load components, such as loads from fixed supports and reaction loads from adjacent components and systems, which can also vary as the plant is cycled on and off load. It should be noted that modern plant design can limit the ability (access) to deploy some of these traditional techniques.

For example, heat recovery steam generators (HRSGs) are designed so that it is not possible to use traditional diametral strain measurements on the steam headers. This provides a requirement to consider the use of the novel techniques to assess creep life consumption such as optical strain gauges [55], Alternating Current Potential Drop [56] and small specimen testing techniques such as impression creep, small punch and ring specimens $[3,36]$.

With respect to the use of the non-destructive techniques, on-line strain rate measurement offers great potential to the Utility, from the perspective of being able to use the information to proactively manage the integrity of plant throughout the whole life cycle of the plant. The ultimate aim is to use the strain rate data iteratively in pipework or component specific computational models, where the system or component model response would be calibrated against specific strain 
rate information, and balanced against other relevant condition assessment data obtained during the plant outage. This would demonstrate a truly holistic approach and is considered to be the ultimate aim for optimal plant integrity management. Figure 14 shows a schematic of the current integrity management approach. Particular reference is made to the two following aspects; 1) miniature specimen testing, which could provide significant benefits to the utility with respect to maintaining safe operation, maximizing availability and optimising operational and capital costs, and 2) more proactive use of on-load data assessment.

\subsection{Inspection Planning and Reporting}

The inspection planning process is driven by the need for the utility to demonstrate compliance with PSSR requirements [1] and is applicable to both conventional and nuclear AGR pressure systems. The inspection plans are developed by a 'competent body' that can demonstrate that its staff are suitably qualified and experienced.

It is common practice in the UK for large conventional fossil fired stations to prepare a technical review document about three months before the statutory outage. This gives an overview of the previous operational history, maintenance, replacement, inspection and assessment history of all the pressure systems for the Unit. Operating AGR plants are subject to additional licence requirements [2], which for example define requirements for sites to produce periodic safety reviews in support of the stations risk management process.

There is a statutory requirement for the 'competent person' to compile a written report of the outage examination within 28 days of return to service, which is agreed with site representatives and the technical inspection body. Subsequently, detailed component and system specific integrity assessment reports and safety cases follow on after return to service.

\subsubsection{Off-load: Outage Works}

The following outage inspection techniques are applicable to both conventional and AGR high temperature and pressure systems. None of these techniques are used as systematic input into a predictive creep life assessment model of the piping system or other high temperature components.

\section{Pipe movement}

Pipe movement is obtained via hot and cold surveys of pipe work hanger positions, an example of one type of pipe hanger set-up is shown in Figure 14. In this arrangement there are two spring loaded pipe hanger supports either side of the main steam pipe, with connections to structural steelwork above and connections to the main steam pipe via a ring (trunnion) clamp below (out of the image). This arrangement is designed to ensure that a constant load is imposed on the pipe as it moves up or down with normal plant operation. These hot and cold surveys provide information on pipework operational loads (between cold condition and full load hot operation), which can be compared against the design basis and prompting readjustment of hangers as required.

\section{Passive strain measurement}

Bow gauge micrometers, Figure 15, are typically used for headers and pipework for diameters up to about $600 \mathrm{~mm}$ with a precision of $0.01 \mathrm{~mm}$, especially when used with a more accurate locating method such as non-oxidising creep pips. It has been shown [57] that safe management of plant can be achieved with well controlled and managed diametral surveys, coupled with interrogation of other outage and operational plant data. However, a review of large datasets from periodic 
conventional fossil fired plant diametral surveys show much greater than expected variability and emphasises the need for good procedural control on site if such methods are to be relied on.

More recent developments to improve the accuracy and reliability of passive strain measurement include the ARCMAC high temperature optical strain measurement system [58, 59]. The ARCMAC system uses stud-welded optical targets attached to the component in a bi-axial arrangement, which is illuminated from a light source within a purpose designed camera system with a telecentric lens and beam splitter arrangement. The attachment if the stud-welded optical gauge is facilitated by the use of a purpose designed gauge carrier that allows consistent gauge installation, along with the installation of a suitable protective cover. The optical arrangement and illumination ensures that accurate measurements of strain can be captured even if the camera system is not located precisely normal to the target gauge. The strain measurement resolution is $\sim 60$ micro-strain with an error of $<10 \%$. Gauge images captured during subsequent shutdown periods enables the creep strain rate to be deduced. The author has un-published data from validation tests at $600^{\circ} \mathrm{C}$ and a period of that $20 \mathrm{Khr}$ operation, (with test periodically interrupted to obtain gauge images and thereby simulate intended use on site), which shows strain resolution and repeatability that is in very good agreement with the laboratory creep test extensometer instrumentation. Further extensions to these optical strain measurement techniques have been developed using surface speckle coatings and digital image correlation techniques to provide a non-contact surface strain distribution (across a weldment), with reference images from an adjacent ARCMAC gauge to provide a calibration strain reference $[60,61]$.

\section{Surface Creep replicas}

These are targeted at regions considered to be more prone to creep damage accumulation, such as weldments, pipe penetrations (fillet welds), attachment welds, pipe bends and pipe terminal positions. The requirement for creep replicas is dependent on the age of the plant and the perceived risk, which may be influenced for example by adverse readings from routine passive strain measurement campaigns or known periods of mal-operation evident from reviews of operational data. It is not unusual for several hundred replicas to be taken during an outage on a single Unit.

The surface replica technique involves capturing the surface features on a film that can subsequently be examined under a microscope. This involves careful surface preparation by grinding the surface with progressively finer abrasive papers, with final polishing. This process should be undertaken with great care to avoid removing the creep damaged surface and also to ensure that any surface oxidation and decarburised layers are removed. The prepared surface for replica assessment typically covers a surface area of $25 \times 50 \mathrm{~mm}$ is then etched with a dilute acid such as Nital to reveal the microstructure. A soft cellulose acetate strip is then pressed onto the surface and allowed to dry before spraying with a matt black paint. This provides a contrast under white light when the replica is removed and examined under the microscope. 0Carefully applied this process should reveal creep cavities that can subsequently be counted per $\mathrm{mm}^{2}$ and classified, which is described in further detail in section 4 . It should be noted that different types of steel may require a modified process to the above in order to obtain the best quality surface replica.

Figure 17 illustrates a surface replica of a CMV main steam line weld, taken after grinding to a depth of $5 \mathrm{~mm}$ from the outside surface. Two photomicrographs are shown at x200 and x500 magnification, in this example a high creep cavity count was assessed at 842 cavities $/ \mathrm{mm}^{2}$. In this case the material had been in operation on one of the EDF Energy's conventional fossil fired power stations for circa $260 \mathrm{Khr}$ before retirement and subsequent examination. 
The repair or return to service decision is invariably supplemented by experiential knowledge, as indicated in the current condition assessment route, Figure ; usually with a recommendation to further inspect at the next interim or major outage. The importance of experiential knowledge should not be underestimated in the decision process due to the significant differences in creep degradation characteristics of power plant materials in widespread use such as CMV and modified 9\% Cr steels (P91).

\section{Surface Hardness}

These outage measurements are targeted at regions considered to be more prone to creep damage accumulation, with the key aspect being the change in surface hardness captured at successive inspections. It is custom and practice to cross-check these results against periodic trends from surface creep replicas obtained from an adjacent location.

This is essentially a similar approach to surface creep replication and is frequently used during an outage to provide a large amount of data, with the key feature of the subsequent assessment being the change in surface hardness at a repeat location between periodic inspection intervals. It is custom and practice to cross-check with other site metallurgical techniques, such as surface creep replicas obtained from an adjacent location on the component.

There are a range of portable site hardness test tools available, either using ultrasonic contact impedance, direct measurement or dynamic rebound, such as the Equotip system, which uses the impact and rebound velocities to determine the surface hardness value. It is necessary to prepare the surface before testing (to remove hard scale), and these methods are frequently used on site during the outage. Various industrial studies associated with the performance (accuracy and repeatability) of these techniques have been undertaken. For the dynamic rebound systems the characteristics are (assuming trained and competent operators and for specimens in the range 180300HB);

- Low standard deviation,

- Error typically 5\%,

- Error is significantly influenced by the hardness of the specimen, with the error increasing with softer materials),

- Results can be influenced by the angle of the probe.

Again, decisions on repair or return to service options that use hardness data is typically based on rate of change in hardness and experiential knowledge from hardness trends associated with other similar components, material, service age and duty. This information is not used in a predictive life assessment model.

\section{Material composition checks}

This standard practice confirms that the correct materials have been installed on plant. In some instances rogue materials have been identified, hence composition checks are recommended good practice. For on-site composition checks portable x-ray flourescence analysers are typically used.

\subsubsection{On-load: Use of Operational Data}

The Utility routinely records steam temperature and pressure data at selected key points in the process system. The decision on the sampling interval is influenced by the stability of operation; if 
the Unit is prone to temperature instability then the sampling interval should be reduced. These techniques are applicable to both conventional and AGR high temperature pressure systems.

In addition, most Stations will invariably have installed additional surface mounted or deep drilled thermocouples on key components or on components being monitored as part of a safety case. This data is stored in the plant historian and various data sampling frequencies can be defined. Typically if a plant transient is being monitored the thermocouple sampling interval may be as frequent as every 15-30 seconds. For longer term creep temperature monitoring the sampling interval could be relaxed to several minutes. With respect to creep temperature monitoring the decision on the sampling interval is influenced by the stability of operation; if the unit being monitored is prone to temperature instability then the sampling interval should be reduced. Hence, some judgement and experience is needed in order to define the required sampling interval prior to any computation being undertaken.

Once this data is collected the utility evaluates what is termed as the creep effective temperature (CET); defined as the average temperature at which all of the creep damage (over the monitored period) can be equated to. This approach typically uses the design pressure in the computation, although it is possible to also use the measured operational pressure. However, for the purposes of the CET calculation the design pressure is usually sufficient. For UK conventional plant designs $0.5 \% \mathrm{Cr} 0.5 \% \mathrm{Mo} 0.25 \% \mathrm{~V}(\mathrm{CMV})$ steels are typically used for main steam line construction.

The creep rupture life calculation, using CET, gives a value of creep rupture life, which is dependent upon stress and temperature. Equation (5) is used to estimate the creep rupture life of CMV material and is based on the Manson-Brown $4^{\text {th }}$ degree polynomial formula.

$\frac{\log t_{r}-f}{(T-g)^{h}}=a+b \log \sigma+c(\log \sigma)^{2}+d(\log \sigma)^{3}+e(\log \sigma)^{4}$

\section{Where;}

$\sigma=1.25 \times$ Creep Reference Stress $(\mathrm{MPa})$

$a=-0.10086133$

$b=0.2521769$

$c=-0.27441233$

$d=0.12751693$

$e=-0.02218978$

$f=8.659$

$g=650$

$h=0.95$

$t_{r}=$ predicted time to creep rupture $(\mathrm{h})$

$T=$ temperature in Kelvin.

For a main steam line the Creep Reference Stress is equivalent to the mean diameter hoop stress in equation 6. 
Where;

$P=$ Operating Pressure

$D_{0}=$ Pipe Outside Diameter

$t=$ Wall Thickness

Figure 18 shows the effect of changes in operating temperature from $568^{\circ} \mathrm{C}$ to $578^{\circ} \mathrm{C}$ against the minimum creep rupture life, for two operating stress levels of 42 and $47 \mathrm{MPa}$ of a typical main steam line based on nominal dimensions of $360 \mathrm{~mm}$ outside diameter, $60 \mathrm{~mm}$ wall thickness with an operating pressure of $168 \mathrm{bar}$. The subsequent mean diameter hoop stress is $42 \mathrm{MPa}$ and it can be observed that an increase in operating temperature of $\sim 5^{\circ} \mathrm{C}$ or an increase in stress of $\sim 10 \%$ results in a reduction in creep rupture life of $\sim 20 \mathrm{Khr}$. Information presented later in this section provides examples of plant temperature data trends that show that abnormal operating temperatures are not uncommon; in addition practical experience during periodic plant overhauls regularly shows evidence of the biasing of observed creep damage around pipework sections due to in-service system loading effects.

The above example is significant for the following reasons:

1. Relatively modest increases in operating conditions (temperature and stress) result in a significant reduction in creep rupture life.

2. The reduction in creep rupture life of $\sim 20 \mathrm{Khr}$, due to variation in temperature or stress is approximately equivalent to a typical 4-year operating period for a large conventional fossil fired power station.

3. Stations would prefer to be able to plan future outage scope and replacement strategies with more certainty for budgetary purposes; the example presented shows the dilemma that Stations face as Unit operation nears the end of practical commercial life.

From the perspective of the station operator the sensitivity to modest increases in operating conditions makes planning the scope of subsequent outages or replacement exercises fraught with uncertainty. This uncertainty triggers a natural response to conduct more sampling inspections at subsequent outages and may result in premature replacement of large sections of pipework systems, driven by an inspection scope that in reality is out of step with real material condition.

Figure 19 shows an example of a typical steam temperature trace obtained at the final superheater outlet from a boiler on a 500MW conventional unit, with temperatures plotted from two of the four outlet steam legs (A1 and B1) during a run-up to full load. In this example, steam temperature is sampled at one minute intervals. Since there are four main steam lines exiting the boiler on a typical 500MW unit it is not unusual to find each of the four steam outlet legs operating at different CET's. In this example there are a number of temperature excursions that significantly exceed the $568^{\circ} \mathrm{C}$ design temperature. Hence, the primary use of the CET computation is to provide a systematic process to identify operational issues and to prompt a correction. In addition, historical CET computations on units and across steam systems and components can be used to support the definition of the inspection scope prior to the next statutory outage.

It should be noted that on current UK conventional fossil fired stations the steam outlet design conditions are nominally $568^{\circ} \mathrm{C}$ and $168 \mathrm{bar}$. However, from experience it is not unusual for steam 
temperatures to cycle beyond $600^{\circ} \mathrm{C}$, which is the limit of the CMV creep rupture in equation 5 . In such cases, the use of the CET data is problematical and a consequence of such adverse operation is that more 'inspection sampling' during an outage is usually stipulated in order to determine if the operational instability has manifested itself as an unexpected accumulation of creep damage or the initiation of damage (metallurgical or physical macro-cracks) at weldments. Hence, unstable temperature excursions as illustrated in Figure 19 above should be avoided wherever possible. Unstable operation of can also result in severe (rapid) thermal transients occurring on plant, which can result in the initiation of fatigue cracks in weldments and for high temperature systems propagation via creep crack growth through wall [62].

Figures 20 and 21 show the design of steam headers, which are another significant class of high temperature thick sectioned components installed in a boiler. These components are subject to very similar outage inspections and on-line CET assessments as described for main steam pipes, however these are considered to be more complex to assess due to the numerous penetrations in the header shell and difference in stiffness between the relatively rigid header shell and the thin interconnecting boiler tubes. Steam headers ensure proper distribution of steam across the boiler space, with the boiler tubes providing the heat transfer surface within the furnace of a conventional boiler. There are many different designs of steam header (material and geometry) within a typical conventional fossil fired boiler. With respect to the use of small specimen testing the critical areas on the header are usually the inter-ligament positions between boiler stub tube connections. The photograph in Figure 21 shows the limited access available on this particular design for material extraction. For this situation the approach would be to take a reference small specimen sample from the adjacent and accessible header shell, providing a reference data set. This reference data would then be supplemented by a computational model of the header, which uses on-line temperature and pressure measurements to determine the theoretical residual life at the interligament positions. Reference to the process outlined in Figure 14 indicates how the small specimen testing and on-line data analysis would be used interatively over an extended period of service to establish the residual life, along with periodic inspection data acquired during periodic overhauls.

\subsection{Holistic Condition Assessment}

The main objective of the owner of a large power station is to maximise plant availability and profitability, whilst maintaining safety. In order to achieve this objective the station must be able to understand, with good certainty, the remaining life of the assets at any time during the operation of the asset so that it can cost-effectively plan future inspections, refurbishments and replacements as required.

This requirement to understand with certainty the remaining life becomes ever more acute in commercial electricity generation where the profitability is marginal, whether caused by government or environmental policy, market prices, taxation or other factors. At the time of writing this paper these factors are all significantly influencing the profitability of large scale conventional plant generation in the UK.

From a technical perspective the current approach to arriving at a 'holistic' view of the condition of the generating assets is achieved by the assimilation and deductive assessment of information gleaned from the activities described in Sections 3.1.1 and 3.1.2. The process of deduction is strongly based on the experience of the assessment engineers, who ideally will have also conducted investigations on other similar types of generating plant (likely of different age and condition). This deductive assessment process is highly interactive amongst the engineering teams involved in order 
to arrive at an agreed view of the condition of the asset and any needed future monitoring or changes in future inspection scope.

Hence the current approach is defined as 'inspection based' and usually results in an incremental increase to future inspection sample size to contain a perceived emerging threat. This current approach is outlined in Figure 14.

However, the current 'holistic' condition assessment process does not;

- Stipulate predictive life assessments beyond the next major statutory outage, which in the UK occurs every 4 years,

- Seek to integrate the various disparate data sets obtained from the plant outage or on-load monitoring.

Figure 14 seeks to illustrate two significant missing activities, namely 1) miniature specimen testing and 2) on-load condition assessment, which could fruitfully be exploited to provide a more predictive life assessment approach and thereby satisfy the main objectives of the plant owner outlined at the beginning of this section.

The following case study illustrates how creep life assessments and decisions are currently achieved.

\section{Case Study: Ageing Main Steam Pipework}

The data presented in this case study is based on conventional plant operation and focused on information and techniques currently used to assess the remaining creep life and hence decide on replacement.

The through life integrity of main steam CMV butt welded pipework systems has been dominated by the condition of the weldments, which have typically been addressed by means of periodic inspection, weld repair or pipe spool replacement. Most of the integrity issues associated with the weldments have manifested as circumferentially distributed creep cavitation or subsequent circumferential cracking. This damage is affected by pipework system loads and it is not uncommon to find the observed weld damage biased (creep cavitation or depth of cracking) around the circumference of the pipe weld. Invariably at the latter stages of a stations life the location and condition of all the major welds has been established and procedures are in place to implement any needed repair and replacement activities.

However, the failure of parent material is more likely to occur due to the acting pipe hoop stress, which can potentially initiate longitudinal cracking. It is very difficult to comprehensively identify those parent material regions close to creep life expiry, noting the large volume of parent material in typical pipework systems. As the pipe system enters the later stages of life conducting piecemeal butt weld replacement by the insertion of new pipe spools becomes more difficult due to the aged condition of the cut faces of the original pipe section, which is typically assessed by on-site surface replication and hardness testing. This 'test' of the parent material condition, when conducting pipe spool replacements, is often used as an opportunistic indicator of parent material condition (through thickness).

Firstly some background related specifically to the case study pipework example. During the 2005 outage on a unit on Station 'A', Figure 2 (Unit operating history $221.8 \mathrm{Khr}$ and 2846 starts), high levels of surface creep damage were identified in a number of main steam bends and straight pipe sections, most significantly on steam leg B2. Subsequently creep rupture and creep crack growth 
tests were conducted on material extracted from straight pipework sections removed from service, which indicated a minimum creep life of between $250-275 \mathrm{Khr}$. Consequently in 2009 some partial replacement of main steam CMV pipework was undertaken; at the time of the replacement the unit had accumulated $242.5 \mathrm{Khr}$ and 3552 Unit starts.

This case study considers one of the straight pipework sections removed from steam leg B1 and the subsequent laboratory examination to investigate the distribution of creep cavitation damage on the surface and through wall. This pipe sections (and others) were removed to reduce operational risk; having been sanctioned as life expired based on surface replication results during the 2009 outage that showed moderate to high levels of creep damage. The nominal design information for this main steam pipework is

- Outside Diameter

- Wall Thickness

- Design Pressure

- Design Temperature $568^{\circ} \mathrm{C}$.

\subsection{In-Service Inspection History}

During service the CMV pipework system had been subjected to the standard outage examinations and periodic in-service CET analyses. These analyses had been undertaken regularly since 1993, typically based on a 6-month block of steam temperature data from the monitored steam leg. Table 2 shows a sample of this CET data for all four steam legs (A1, A2, B1, B2) on the unit. The data presented in Table 2 is determined using the approach described in section 3.1.2. Data blocks of more or less than 6-months could be used to expedite the calculation. The noted step in CET values between the monitored dates is quite normal for a large conventional stations and is driven by the change in operation, for example base load to flexible operation, and other factors such as extracting more MW from each unit. This just reflects the very real commercial pressures affecting operation.

Table 2. Steam Leg CET values.

\begin{tabular}{|c|c|c|c|c|}
\hline Year & $\mathbf{A 1}\left({ }^{\circ} \mathbf{C}\right)$ & $\mathbf{A 2}\left({ }^{\circ} \mathbf{C}\right)$ & $\mathbf{B 1}\left({ }^{\circ} \mathbf{C}\right)$ & $\mathbf{B 2}\left({ }^{\circ} \mathbf{C}\right)$ \\
\hline 2009 & 565.2 & 562.6 & 562.7 & 560.3 \\
\hline 2005 & 567.4 & 565.8 & 563.7 & 563.2 \\
\hline 2003 & 567.3 & 568.0 & 564.7 & 561.2 \\
\hline 2001 & 566.0 & 568.0 & 563.2 & 561.5 \\
\hline 1999 & 554.4 & 565.4 & 560.7 & 561.1 \\
\hline 1997 & 567.8 & 566.4 & 566.3 & 566.5 \\
\hline 1995 & 566.1 & 564.3 & 565.7 & 565.3 \\
\hline 1993 & 568.5 & 567.2 & 568.0 & 568.7 \\
\hline
\end{tabular}


The CET data collated over a number of years of service shows that each steam leg operates at creep effective temperatures that can be as much as $5{ }^{\circ} \mathrm{C}$ different (omitting the suspiciously low 1999 CET data for leg A1). Such relatively modest differences in creep effective temperature can result, if sustained for a long enough period of time, in significant differences in creep rupture life from leg-to-leg on a unit. Figure shows this leg-to-leg variation with temperature, noting that practical plant control is further complicated when the units are subjected to a high number of starts, as illustrated by past station operation in Figure 2 (a). Another standard approach taken during the outage is to take diametral strain measurements. Typically, these are taken over installed stellite grade 6 creep pips (reference measurement points) on the outer diameter; for the case of the unit on Station ' $A$ ' the pipework creep pip locations were towards the boiler stop valve at the $160 \mathrm{ft}$ level in the boiler, as well as at the $100 \mathrm{ft}$ and $60 \mathrm{ft}$ levels. Various diametral strain measurements had been taken over installed creep pips during successive outages dating back to 1993 (unit operation at $161 \mathrm{Khr}$ and 321 starts) and including the 2009 outage. Table 3 shows the pipe diametral measurements taken at the $160 \mathrm{ft}$ level on leg B1 and leg B2 between 1993 and 2005 for comparison. Four diametral measurements are taken across the eight installed creep pips around the pipe circumference.

Table 3. Diametral Measurements, Main Steam Legs B1 and B2.

\begin{tabular}{|c|c|c|c|c|c|c|c|}
\hline \multicolumn{3}{|c|}{$\begin{array}{l}\text { Measurement } \\
\text { Location }\end{array}$} & \multicolumn{5}{|c|}{ Measurement over creep pips corrected to $20^{\circ} \mathrm{C}(\mathrm{mm})$} \\
\hline Leg & $\begin{array}{l}\text { Boiler } \\
\text { Level }\end{array}$ & Axis & $\begin{array}{c}1993 \\
(161,643 \mathrm{~h})\end{array}$ & $\begin{array}{c}1997 \\
(187,116 \mathrm{~h})\end{array}$ & $\begin{array}{c}1999 \\
(196,583 \mathrm{~h})\end{array}$ & $\begin{array}{c}2001 \\
(203,010 \mathrm{~h})\end{array}$ & $\begin{array}{c}2005 \\
(221,799 \mathrm{~h})\end{array}$ \\
\hline \multirow[t]{5}{*}{ B1 } & \multirow[t]{5}{*}{$160 \mathrm{ft}$} & $\mathrm{N}-\mathrm{S}$ & 364.31 & 364.62 & 364.77 & 364.82 & 364.98 \\
\hline & & E-W & 364.03 & 364.46 & 364.64 & 364.69 & 365.03 \\
\hline & & NE-SW & 364.44 & 364.79 & 364.97 & 365.02 & 365.27 \\
\hline & & SE-NW & 365.23 & 365.61 & 365.79 & 365.81 & 366.11 \\
\hline & & Average & 364.50 & 364.87 & 365.04 & 365.09 & 365.35 \\
\hline \multirow[t]{5}{*}{$\mathrm{B} 2$} & \multirow[t]{5}{*}{$160 \mathrm{ft}$} & $\mathrm{N}-\mathrm{S}$ & 368.27 & 368.58 & 368.71 & 368.73 & 368.89 \\
\hline & & E-W & 365.61 & 366.04 & 366.24 & 366.27 & 366.64 \\
\hline & & NE-SW & 367.11 & 368.02 & 367.64 & 367.69 & 368.83 \\
\hline & & SE-NW & 368.07 & 368.38 & 368.53 & 368.50 & 368.77 \\
\hline & & Average & 367.26 & 367.75 & 367.78 & 367.80 & 368.28 \\
\hline
\end{tabular}

The pipe diametral measurements show a generally steady increase in pipe outside diameter, with only a small number of measurement anomalies evident. Hence, the average strain rate over the period 1993 to $2005(60,000 \mathrm{~h})$ is $\sim 4 \times 10^{-8} \mathrm{~h}^{-1}$, which equates to a minimum operational creep life of $\sim 300,000 \mathrm{~h}$. The strain rate is determined by evaluating the diametral strain between periods and correcting for the temperature at which the measurement was taken and micrometer zero (offset) errors. Pipe diametral measurements can sometimes be taken directly across the pipe outer 
diameter, if this is the case additional corrections would be required to account for oxide film growth over the time period between successive measurements. The subsequent site diametral measurements are assessed using conservative residual life formulae, which are derived from strain measurements taken from a series of physical internal pressure creep rupture tests undertaken by the UK's former central electricity generating board.

Interestingly, comparing the CET and diametral data for legs B1 and B2; Leg B1 shows a lower average strain rate, but a higher CET trend when compared with leg B2. It might have been expected that the higher CET trend on leg B1 over the extended period of measurements would have led to a higher diametral strain rate. This shows the current difficulty interpreting such measurement data in isolation and the reason why other more invasive methods such as surface replication are used to assess material condition.

During the 2009 outage the original CMV straight pipe section (SM14) was removed from leg B1 for further laboratory examination; based on observed 'High Orientated' creep replica results. The adjacent pipe section immediately upstream from this removed section was left in service, with only 'Very Isolated' replica assessment on the parent material.

\subsection{Post-Service Laboratory Examination}

Both surface creep cavity and through section creep cavity mapping was carried out to industry procedures described in GENSIP guidance [63]. GENSIP refers to the UK 'Generators Safety and Integrity Programme', which is a member self-funded utility collaboration tasked with ensuring best practice is shared across the industry. The creep cavity damage levels indicated are classified in accordance with the definitions in Table 4. These classifications are provided by the technical service provider and enable them to compare observed creep damage and hence recommend a suitable course of action. The surface creep cavity mapping was taken at various axial and circumferential positions on the examined specimen (SM14 from Leg B1), and is illustrated in Table 5.

Table 4. Creep Cavity Damage Level (Technical service provider classification).

\begin{tabular}{|c|l|l|}
\hline Level & \multicolumn{1}{|c|}{ Description } & Abbreviation \\
\hline 0 & Clear & $\mathrm{C}$ \\
\hline 1 & Isolated & $\mathrm{I}$ \\
\hline 2 & Isolated/low orientated & $\mathrm{I} / \mathrm{LO}$ \\
\hline 3 & Low orientated & $\mathrm{LO}$ \\
\hline 4 & Low orientated/mid orientated & $\mathrm{LO} / \mathrm{MO}$ \\
\hline 5 & Mid orientated & $\mathrm{MO}$ \\
\hline 6 & High orientated & $\mathrm{HO}$ \\
\hline 7 & High orientated/grouped & $\mathrm{HO} / \mathrm{G}$ \\
\hline 8 & Grouped & $\mathrm{G}$ \\
\hline 9 & Aligned & $\mathrm{A}$ \\
\hline
\end{tabular}




\begin{tabular}{|c|l|l|}
\hline 10 & Micro cracking & MC \\
\hline 11 & Cracking & Crack \\
\hline
\end{tabular}

With reference to the pictorial representation and definitions in Figure 13, the technical service provider classification in Table 4 is interpreted as follows; Isolated (Level 2-3), Aligned (Level 89), Microcracking (level 10). In addition, Figure 17 shows a photomicrograph from a section of retired CMV pipework, with a creep cavity count of 842 cavities $/ \mathrm{mm}^{2}$ in this case the classification would be judged at level 5-6 mid to high orientated. This exhibits quite a high creep cavity count and would be expected to progress to grouped and aligned in the short term if left in service.

Table 5. Creep Cavity Surface Damage Levels; CMV Straight Section SM14, leg B (Technical service provider classification).

\begin{tabular}{|c|c|c|c|c|c|c|c|c|c|c|c|}
\hline $\begin{array}{c}\text { Angular } \\
\text { Position } \\
\text { Around } \\
\text { Ring }\end{array}$ & \multicolumn{10}{|c|}{ Distance along pipe (m) } \\
\cline { 2 - 16 } & 0.5 & 0.75 & 0.8 & 0.85 & 0.9 & 0.95 & 1 & 1.4 & 1.5 & 1.6 & 2 \\
\hline $0^{\circ}$ & & & & & 1 & & & & & & \\
\hline $45^{\circ}$ & & 3 & 7 & 4 & 5 & 7 & 6 & & 1 & & \\
\hline $90^{\circ}$ & & & & & 3 & & & & & & \\
\hline $135^{\circ}$ & 2 & 3 & 3 & 6 & 7 & 6 & 1 & 6 & 5 & 6 & 3 \\
\hline $180^{\circ}$ & & & 6 & 5 & 5 & & 4 & & 3 & & \\
\hline $225^{\circ}$ & & 7 & & 5 & 3 & 7 & & 3 & 6 & 7 & \\
\hline $270^{\circ}$ & & & & & 1 & & & & 7 & & \\
\hline $315^{\circ}$ & & 3 & & 6 & 3 & 2 & & 3 & 7 & 7 & \\
\hline
\end{tabular}

The German VGB guideline [64] provides a revision of the Neubauer-Wedel creep cavity classification [65] and is reproduced in Table 6.

Table 6. VGB Guideline Classification [64].

\begin{tabular}{|c|l|}
\hline $\begin{array}{c}\text { Assessment } \\
\text { Class }\end{array}$ & \multicolumn{1}{|c|}{ Structural and Damage Conditions } \\
\hline 0 & As received, without thermal service load \\
\hline 1 & Creep exposed, without cavities \\
\hline $2 \mathrm{a}$ & Advanced creep exposure, isolated cavities \\
\hline $2 \mathrm{~b}$ & $\begin{array}{l}\text { More advanced creep exposure, numerous cavities without preferred } \\
\text { orientation }\end{array}$ \\
\hline $3 \mathrm{a}$ & Creep damage, numerous orientated cavities \\
\hline $3 \mathrm{~b}$ & Advanced creep damage, chains of cavities and, or grain boundary separations \\
\hline 4 & Advanced creep damage, microcracks \\
\hline
\end{tabular}




\begin{tabular}{|l|l|}
\hline 5 & Large creep damage, macrocracks \\
\hline
\end{tabular}

ECCC recommendations [66] on residual life and microstructure references investigations undertaken to correlate the VGB damage classification [64] against residual life for low alloy steels in the heat-affected zone of a weld. In this particular investigation VGB damage level 3 correlates to an expended life fraction of 0.691 .

With reference to the ex-service SM14 straight specimen surface replication (Table 5); three angular positions $(135,225$ and 315 degrees) at distance $1500 \mathrm{~mm}$ along the pipe were selected for through section creep void mapping. Table 7 shows an example for the 315 degree position. Each of the through section samples was carefully aligned with the corresponding surface replica position (Table 5). A series of replicas were taken at through section depth increments of approximately every $4 \mathrm{~mm}$ until the bore was reached. At each 'depth' position surface replicas were taken horizontally across the width of the extracted through wall specimen, resulting in a sample of approximately 15 per 'depth' position. These replicas were commenced at a distance of $2 \mathrm{~mm}$ from the cut face to avoid any damage from specimen preparation.

Table 7. Through section creep cavity count distribution $\left(1500 \mathrm{~mm}\right.$ and $\mathrm{Circ} / 315^{\circ}$ Position) (Technical service provider classification).

\begin{tabular}{|c|c|c|c|}
\hline $\begin{array}{c}\text { \% Through Wall } \\
\text { (from outside } \\
\text { surface) }\end{array}$ & $\begin{array}{c}\text { Cavity Count } \\
\text { (Cavities/mm2) }\end{array}$ & Category & $\begin{array}{c}\text { Classification } \\
\text { number }\end{array}$ \\
\hline 0.00 & 115 & LO & 3 \\
\hline 9.23 & 75 & LO & 3 \\
\hline 18.46 & 50 & LO & 3 \\
\hline 27.69 & 60 & LO & 3 \\
\hline 36.92 & 55 & LO & 3 \\
\hline 46.15 & 45 & LO & 3 \\
\hline 55.38 & 25 & I & 1 \\
\hline 64.62 & 13 & I & 1 \\
\hline 73.85 & 10 & I & 1 \\
\hline 83.08 & 0 & C & 0 \\
\hline 100.00 & & & \\
\hline
\end{tabular}

The results show a trend of reducing cavity count through the section, peaking at the outer surface position. It's possible to further summarise and compare the through wall cavity count distributions in Table 7 as follows, based on the classifications in Table 4 (Technical service provider) and Table 6 (VGB): 
- Outer $10 \%$ of the wall section:

Classification $>=5: \quad($ VGB 3)

- Intermediate $60 \%$ of the wall section:

Classification 2-3:

(VGB 2)

- Inner $30 \%$ of the wall section:

Classification $<=1: \quad($ VGB 1$)$

This illustrates the somewhat subjective nature of the cavity count classifications and the importance of where possible having a clear understanding of the origin of the cavity count classification being used during an in-service inspection and the subsequent residual life.

\subsection{Comments}

The following points are evident considering the site inspection history and subsequent examination of the ex-service life expired CMV straight pipe section SM14:

- Leg B1 shows a lower average strain rate based on diametral measurements compared to leg B2, but operates at a higher temperature (CET),

- There are significant operational temperature differences between the four main steam legs exiting a 500MW conventional boiler,

- Through section creep cavity mapping on straight pipe section SM14 (Table 7) shows a wide range of damage levels, peaking at the outer surface, which infers a significant residual life for the bulk of the parent material.

These results emphasise why the current inspection and sentencing approach requires expert deduction and elicitation of various data sets in order to provide advice on future inspection plans, monitoring schemes and eventual repair and replacement options.

The case study illustrates some of the more subjective aspects of the current approach to life assessment of ageing components at high temperature. The importance of the experts view on the condition of component under examination should not be underestimated and the need for comparison against other similar components elsewhere (possibly older with respect to service duty) is evident. The case study shows that the current life assessment process would benefit from more synergistic use of the data routinely collected during an outage. In addition, life assessment would greatly benefit from the more pro-active use of in-service monitoring data along with the use of more predictive models of assessing residual life, which would subsequently allow more intelligent optimisation of future plant operation.

\section{The Role and Application of Small Specimen Creep Testing}

Small specimen creep testing techniques are currently applied for ranking the strength of power plant components, in order to establish repair strategies and supporting life assessment. They are also used in nuclear applications and for fatigue life evaluation.

\subsection{Strength Ranking}

Power Plant materials age during high temperature service and periodic structural integrity assessments are needed to quantify their permissible service life. Implementing an inspection priority for welds that are subject to in-service creep damage and fatigue cracking is standard practice, with suitable inspection and repair methods being readily available to the utility. 
However, identifying a suitable and cost-effective inspection priority for ageing parent material is of concern due to the extensive amount of material that may be affected, and the difficulty in identifying the optimum locations and inspection sampling regime required. Understanding system or component specific creep degradation rates will enable more quantitative life predictions to be made that truly reflect the ageing of the material (weld or parent) operating under service loads and ideally should enable timely changes to operation and hence optimise serviceable life. Figure 14 emphasises the importance of the need for timely feedback on factors affecting condition of the assets to the plant operator.

The use of small specimen testing is intended to provide information on component strength ranking and the rate of creep life consumption to improve targeting of subsequent outage inspections and operational improvements, resulting in a reduction in the rate of damage accumulation. If these methods are implemented on parent materials, as recommended in this review, the expectation is that there will also be a commensurate reduction in the creep damage accumulation rate at welds. The greater use of on-line monitoring, highlighted in Figure 14, is an important complement to the use of small specimen testing.

The use of small specimen creep testing provides an alternative technique that has merit when compared to conventional creep testing, due to the less invasive procedures, which don't require a significant amount of material to be removed from in-service components and subsequent weld repair [67].

\subsection{Decision on Improved Inspection, Replacement and Repair Strategy}

In the open literature, many examples of plant component strength ranking have been considered in case studies [13-15]. In the 1990's, RWE npower carried out impression creep and small punch tests on scoop samples from two Grade 91 headers which were considered close to premature Type IV weld failures. As a reference material, a weak Grade 91 bar section was creep tested by using both small specimen and standard testing methods. By plotting the impression creep strain rates obtained from the headers samples against the strain rate of the reference material, it was found that the creep strength was similar for both materials, as shown in Figure 16. In the same plot were also reported the strain rates for a prematurely failed endplate and two other samples taken from plant items with no known problems. Cross-weld specimens were also creep tested from the reference material, specifically welded, in order to acquire Type IV data. The test results led to an early inspection of the headers, one of which was found to be widely cracked, while the other header cracked a few years later. Hence, deployment of the non-conventional small specimen creep testing methods avoided costly failure in service and associated unplanned outage time and allowed life extension of the headers $[14,67]$.

Other tests were carried out by RWE npower by sampling main steam pipework components with the intention to identify the damage at an early stage, the results of which are plotted in Figure 17 that shows impression creep strength ranking for CMV. The ISO lower bound line intersects a sample which parallel conventional uniaxial testing has shown possesses a strength equivalent to the lower bound (mean-20\%) ISO value for this material in the as-received condition [15, 67]. By testing a significant number of ex-service CMV samples an empirical correction factor was found as well, in order to compare components of very different plant ages. The histogram in Figure 18, shows the CMV data corrected for operating hours at the time of sampling to reflect strength at the start of life, is helpful in placing any other CMV sample within the creep strength scatter band [67]. Although small specimen testing techniques have been proved to be extremely useful in the creep strength ranking, their standardization is still required and the effects of the scoop sampling on the creep response of components still needs to be investigated [67]. 


\subsection{Small Specimen Creep Data Correlated with Hardness Data for Life Assessment}

The research of a correlation between room temperature hardness data and time temperature parameters is ongoing since 1943 [68, 69], but any physical link nor any explicit relationship between them have been found. Many researchers have related creep life evaluation and hardness data through the Larson-Miller parameter, but this approach only allows a first assessment of the damage if the initial hardness, at a time of 0 hours of creep, is known [70-77]. Unfortunately, it is very rare for a utility to have record of this initial hardness data and as a consequence, the method is suitable only to provide an initial idea of the component damage. Currently, hardness data continues to be collected because of the simplicity of the test method in contrast to the evaluation of the minimum creep strain rate, but more research is needed to evaluate the benefits.

Creep and hardness data are not correlated by any mathematical model because of the different parameters they are related to, since creep life is a function of the operating temperature and stress, while hardness, after prolonged service, is mostly related to the thermal aging at the operating temperature [6]. Nevertheless, Brett [12] found that by plotting the variations of minimum creep strain rates obtained by both uniaxial and impression creep tests at $600{ }^{\circ} \mathrm{C}$ and at a stress of 155 $\mathrm{MPa}$, against room temperature hardness for Grade P91 steels (with different service histories) the samples with the lowest minimum creep strain rates have the highest hardness (Figure 19-a). Brett [12] also plotted the time to failure against the hardness (Figure 19-b), and found that the samples with the highest hardness have the longest time to failure as well, where the time to failure for the impression test samples were calculated by using the Monkman-Grant relationship [6, 74].

Hence material hardness data, which is routinely captured on ageing materials during statutory outages, is a characterising parameter that should be further researched in order to establish if it could be more deeply integrated into a life prediction model. The variability associated with site acquired hardness data should be considered in such research.

Figure 24 provides an illustration of the correlation between Hardness (Hv) and creep replica assessment level obtained during an outage on 200,000 h old CMV parent material, and is taken from two main steam lines (legs A1 and A2) exiting the boiler on a conventional fossil fired unit operating at a design temperature of $568{ }^{\circ} \mathrm{C}$ and pressure of 170 bar. This sample comprises 79 assessment locations from leg A1 and 113 from leg A2, with a mean hardness of 123 on leg A1 and 126 on leg A2, which compares to a start of life mean hardness of $170 \mathrm{Hv}$. In this data sample the creep replica is assessed at seven defined levels as defined in Figure 24; these assessment level definitions are from the same source as those outlined in Table 4. The data has been obtained from a range of locations on the main steam pipe system and from a mixture of pipe bends and straight sections, but predominantly straight sections, hence these locations will be exposed to a range of inservice stress levels and temperature histories (Ref Figure 19). Inspection of hardness data at creep replica assessment levels 2, 3 and 4 reveals very similar mean $\mathrm{Hv}$ values of between 123-125 for these datasets. Section 3.1.1 outlined that typical Hv measurement accuracy of $\sim 5 \%$ can be expected but with an increasing error on softer material. Hence, it is evident from this sample of data collected from ageing CMV parent material that there is no definitive correlation between the surface replica assessment levels and Hv. Cursory inspection of the data presented for leg A1 in Figure 24 could be interpreted as indicating a potential reduction in hardness with increasing creep cavity count, however this is not evident in the data presented for leg A2.

\subsection{Applications for Irradiated Materials}

Understanding the effects of neutron irradiation on the performance of materials used in the construction of nuclear power stations is a challenge when considering the requirements for life extension of existing reactor designs and future advanced fusion reactor technologies. The use of 
small specimen testing to characterise materials behaviour has many advantages in this respect due to the small volumes of irradiated material required. The ASTM symposium [78++] in 1983 provided an initial milestone for the development of these methods for irradiated specimens. This highlighted some of the important considerations that have influenced the development of the testing methods, such as limited space in hot test cells, the effect of neutron fluence gradients across the reactor components, personnel dose levels in post-irradiation testing and the development of materials suitable for use in high energy $(\sim 14 \mathrm{MeV})$ nuclear fusion reactors.

The following sections review the more prevalent uses of small specimen testing on irradiated materials and related to fracture strength, material property evaluation, behaviour and condition monitoring of in-service reactors.

\subsubsection{In-Service Condition Monitoring}

Currently the SP testing technique has gained an important role for monitoring nuclear power plant operation and critical areas, such as the heat affect zone of welds. In particular, the material state of all Slovak reactor pressure vessels is monitored through SP testing (several thousand material samples) as part of the advanced surveillance specimen programs, which aims to extend the reactor pressure vessels life in the WWER-440 pressurised light water reactors by at least 20 years [78A, $78 \mathrm{~B}$ ], with typical operating conditions at $297^{\circ} \mathrm{C}$ and $123 \mathrm{bar}[78 \mathrm{C}]$. The focus of this surveillance program is to provide a through life assessment of the tensile strength and ductile-brittle transition temperature at various locations within the reactor, with material extracted using the Rolls-Royce SSamTM-2 device with comparison against reference material blocks. Sampling locations are defined with care so that there is no requirement for subsequent repair or monitoring.

Some of the small specimens have been irradiated in the Halden research reactor at a fluence of $4.02 \times 10^{23} \mathrm{n} / \mathrm{m}^{2}$ [78D], which showed an expected increase in the tensile and yield stress properties. Comparisons between the fracture appearance transition temperature (FATT) values obtained from the SP tests and standard charpy tests provided good agreement between material in the initial state and the irradiated condition. This application of SP testing provides the Slovak regulatory authorities with contemporary information on the change in material properties due to inservice operation and irradiation levels.

This application of SP testing is similar to the use of impression creep testing applied to ageing conventional power plant materials subject to thermal creep, Brett et al [12-15]. Importantly the examples provided by these investigators show practical examples of the techniques use to assess the condition of operating plant, driven by regulatory and safety requirements.

\subsubsection{Material Properties}

Hyde at al [3] produced a comprehensive review of the use of miniature specimen testing for mechanical and creep material properties. This importantly concluded that viable test methods exist; however there is no single specimen design that can cater for all data requirements. It is evident that commercial objectives has driven the development of some of these techniques, such as SP and impression creep and on specific materials of interest on operating plant, such as CMV and P91 steels on conventional stations. Hyde's [3] review provided a perspective on future requirements and emphasised the need for greater standardisation of experimental test methods, which is still apparent as discussed in section 2.3 in this current review.

Small specimen testing is perceived as a key approach for obtaining critical information on the mechanical properties, deformation and fracture behaviour of candidate materials in support of the ongoing design and development of fusion reactors. The challenges associated with the 
development of the international fusion materials irradiation facility (IFMIF) to test reactor materials at high fluxes of $14 \mathrm{MeV}$ and temperatures in the range $250-550^{\circ} \mathrm{C}$, is described by Kastner et al [78E]. This test facility is expected to be ready and available to use within 10 years from project approval and is constrained for test volumes of up to $500 \mathrm{~cm}^{3}$. A range of small specimens have been irradiated as part of the engineering validation and engineering design activities (EVEDA) phase, with subsequent tests related to tensile data, fracture toughness, creep and fatigue crack growth, thereby demonstrating the practical set-up of the irradiation capsules. However, one of the major challenges cited by Kastner to overcome is ensuring adequate validation of the derived irradiated properties to the regulatory bodies. This again emphasises the need for accepted standards and codes of practice for all the deployed small specimen test methods and in readiness for the high flux IFMIF facility once constructed.

Lucas et al $[78 \mathrm{~F}]$ provides some examples of the developments required related to improve understanding of the fracture, fatigue and deformation behaviour. Fracture toughness tests on a range of specimen sizes on candidate reduced activation ferritic-martensitic EUROFER97 steel are described, with the use of correction factors derived with finite element simulations of crack tip stress fields to address specimen size effects. These tests show the requirement for close scrutiny of the mechanics of the testing process coupled to the observed material behaviour. Kastner et al [78E] emphasised the ultimate requirement for validation of material properties derived from small specimen tests in support of the design of fusion reactors. The challenge is to establish material behaviour models that use the measured parameters and observed behaviour of the materials tested. These material behaviour models must be demonstrably scalable to account for the size of the reactor components and expected in-service loading, such as neutron fluence and thermal gradients and environmental factors such as the presence of helium produced by the fusion process, which will influence the fracture behaviour $[78 \mathrm{~F}]$. Examples of the potential to SP tests with a finite element element simulation is provided, with respect to the evaluation of the deformation behaviour obtained in conjunction with hardness testing, although the potential effects of thermal, environmental ageing or stress state effects are not explicitly captured. Hardness data is routinely acquired during periodic inspections of ageing conventional plant and is usually interpreted in conjunction with a metallurgical evaluation via creep replicas. There are some material models in use on conventional plant that couple surface hardness data with the von-mises stress to evaluate time to creep rupture. These models typically are used to supplement safety case assessments on operating plant and hence are necessarily used in conjunction with several other methods. Nonetheless, it is evident that such hardness models (possibly in conjunction with other measured parameters) may be able to be further developed to a position where a practical forward looking lifing model can be routinely implemented on operational plant. Various options for modifying Liu and Murakami's [78G] constitutive creep models are currently being investigated by the authors of this review paper for CMV and P91 steels that account for the change in surface hardness and the stress state. The hardness data is based on experimental tests and examination of periodic hardness data collected over several inspection campaigns on operational plant.

The assessment framework in Figure 14 illustrates how small specimen testing should be used in conjunction with data acquired from existing inspection procedures and material or component behaviour models that utilise in-service operational data. The authors of this review paper and coworkers in the EPRSC sponsored Flex-E-Plant consortium are actively developing these integrated models for conventional plant applications and on materials such as P91 steel which is similar to materials being evaluated for fusion reactor applications.

Reduced activation ferritic martensitic steels such as $\mathrm{F} 82 \mathrm{H}$ are candidates for use in fusion reactors $[78 \mathrm{H}]$ and have been developed from modified 9Cr-1Mo steels (by replacing Mo and Nb with W and Ta), which are used extensively in modern conventional power stations. In 2014, Bruchhausen 
et al. [78I] assessed the behaviour of ferritic-martensitic oxide dispersion steels by use of the SP testing at $650^{\circ} \mathrm{C}$ complemented by uniaxial creep tests. Importantly the SP tests were conducted in accordance with the current CEN SP code of practice [5]. The SP failed specimens were extracted from a material block in the transverse and longitudinal directions and the micrographs of the failed specimens exhibited very different crack patterns, which are indicative of the anisotropic alloy microstructure.

The evident strong anisotropy is considered due to scatter in the steady state creep response and influenced by the biaxial stress field active in the SP test and variability in the alloy's microstructure; which was also evident from other uniaxial creep tests on conventional specimens. These results illustrate again the requirement for comprehensive modelling-simulation studies of the $\mathrm{SP}$ and other small specimen tests in order to inform the relevant code of practice. It is important adapt this integrated test-modelling approach to the situation of in-service components and the inevitable regulatory requirement to demonstrate fitness-for-service in a production reactor. The requirement for integrated small specimen experimental designs to provide fundamental material behaviour models is reiterated in Odette et al's review on innovations in small specimen testing [78J].

One of the challenges of demonstrating the validity of selected materials used in a production fusion reactor is to account for the effects of the neutron fluence and thermal gradients in the structural components. Gilbert et al [78K] have reviewed some of the factors influencing material behaviour such as neutron flux gradients, component size and helium production on the design of a proposed demonstration fusion power plant (DEMO). The study shows an expected spatial variation of the neutron flux across various structural components, which is also evident in other reactor designs associated with naval pressurised water reactors. For these naval reactor designs the through life effects on material behaviour due to the spatial variation in irradiation creep and swelling is accounted for by measuring the deformation of representative fuel coupons irradiated in research reactors, supplemented by measurements of end of life fuel deformation of spent reactor fuel modules. These experiences with the effects of spatial variation of neutron flux in naval reactors, coupled with the very high energy levels expected in production fusion reactors only further emphasise the need for standardised small specimen codes of practice.

On conventional power plant an analogy is made with respect to the change to flexible operation in the 1990's (see Figure 2a and the significant increase in annual unit starts). This resulted in large periodic thermal stress gradients acting across thick-sectioned components, resulting in critical integrity problems [62]. The older conventional stations are still suffering from the effects of this type of operation, which coupled with the long running hours has driven the development and field application of small specimen testing methods described in this review.

\subsubsection{Fracture}

Understanding the long-term fracture behaviour is critical to ensure the integrity of irradiated structures. The SP testing technique has undeniable advantages due to the small irradiated specimen volume and availability of a recognised code of practice [5]. Material properties of the heat affected zone of welds, and the ductile-to-brittle transition temperature (DBTT) can be determined by the use of the SP testing technique $[78,79]$.

SP testing technique was first used by Baik et al. in 1983, who evaluated the DBTT of a Ni-Cr steel and established a linear relationship between small punch and standard Charpy V-Notch test results in terms of DBTT $[80,81]$. Mao and Kameda, by observing SP test data, found that neutron 
irradiation significantly increases the DBTT in Fe based alloys doped with $\mathrm{Cu}$ [82], while Wakai et al. proved that the production of helium can cause the shift of DBTT in F82H steels [83].

According to Kasada et al. [85], the master curve (MC) methodology, developed by the American Society for Testing and Materials [86], has been successfully used by employing small specimens in the assessment of the drop in fracture toughness caused by neutron irradiation. More recently, Martínez-Pañeda et al. have proposed a novel methodology which involves a notched small punch specimen for the evaluation of the fracture toughness [87]. In particular, they determined a linear relationship between the notch mouth opening displacement and the vertical displacement of the SP, and a critical value of the notch mouth opening displacement of the SP, that can be compared with the corresponding parameter in conventional fracture tests [87].

\subsection{Other Applications}

There are a variety of other applications to note such as, screening of materials, assessment of hydrogen embrittlement, supporting fatigue studies and investigating very high temperature performance of materials such as single crystal alloys used in gas turbine applications. These are all derivatives of the methods discussed previously as discussed briefly as follows. One of the other aspects to note in this review is that many of these small specimen tests require the development of novel measurement techniques due to factors such as specimen size and geometry, requirements for hot cells in nuclear applications or for testing in combustion atmospheres for fossil plant applications. These may present requirements for the use of full-field optical based non-contact measurement systems such as digital image correlation, infra-red thermography, laser extensometry etc.

In 2013, Methew et al [88], by employing the SP testing technique, demonstrated the benefits of using the SP techniques to rapidly investigate the creep performance of $316 \mathrm{LN}$ stainless steel with different nitrogen content levels, using the technique as a means of differentiating the creep rupture performance between alloy heats. Although the SP technique provides the ability to undertake multiple tests quickly the study emphasised the potential for shortfalls due to the short duration of the tests, typically $<1000$ hours and the inability to assess effects due to longer-term thermal ageing and environmental factors. This is a common problem associated with small specimen tests and emphasises the opinion proposed in this paper that the application of small specimen testing in a life assessment framework requires periodic sampling as the material ages in-service.

Hydrogen embrittlement of steels is a particular concern for materials employed in hydrogenpowered vehicles and offshore platforms, as well as in power plant components [89, 90]. Furthermore, hydrogen can be added to materials during the manufacturing process [91]. Therefore, investigating the effects of hydrogen embrittlement is of great interest. One of the latest studies on this matter has been conducted by García et al., who investigated the effects of hydrogen embrittlement on the tensile properties of three different CMV steels (parent material, welding, and heat treated welding) through small punch tests [92]. They found that the yield strength of the steels can be assessed by the SP test yield load and that the technique is able to evaluate the degradation of the material tensile properties due to the hydrogen environment.

Fatigue studies are crucial in many engineering fields and especially in the design of nuclear reactors because of the temperature and neutron flux cycles they are subjected to [93, 94]. Specimen dimensions are preferred to be as small as possible due to lack of material and to danger caused by irradiation.

Hirose et al [93] and Nogami et al [94] for example describes the development of small-scale fatigue specimens, with a specimen gauge diameter of $1.25 \mathrm{~mm}$ for testing reduced activation 
ferritic-martensitic steels in nuclear applications. These cyclic load test present challenges for test machine alignment, load control and measurement of extension, especially for applications to irradiated specimens in a hot cell. Validation of these small-scale fatigue tests for full-size components is a challenge, due regard to the potential in-service load cycles (strain range and hold periods) and operating environment is required as well as the impact of thermal or environmental ageing that might be expected to occur in an operating reactor. It is envisaged that such small scale tests will be invaluable as a means of assessing for example the performance not only of the base material but also the welding fabrication process and therefore reducing the overall time and cost to develop a material that is fit for purpose. Therefore the development of new testing methods using small specimens is of great interest in current research [93-96].

Roebuck et al [96+] have developed a novel miniature specimen testing facility use for assessing the high temperature properties of Ni-base superalloys such as CMSX-4 used in the manufacture of gas turbine hot gas path components. This facility operates at temperatures above $1000^{\circ} \mathrm{C}$, includes water cooled grips and has been used to investigate flow stress dependence on strain and temperature, resistivity measurements, oxidation, pyrometry measurements and recrystallisation kinetics. The test facility also comprises an environmental chamber and is equipped to apply high heating and cooling rates and variable thermo-mechanical loads. Single crystal superalloys such as CMSX-4 are subject to very arduous operating conditions in an operational gas turbine engine and often manufactured in relatively thin sections, hence the need for miniature specimens and suitable test facilities to determine properties and characterise their behaviour.

\section{Plant Assessment Model Adopting Small Specimen Creep Testing in a Condition Based Monitoring Framework}

Section 3 and Figure 14 illustrate the current condition assessment process, which has reliably been used in the UK for many years. This approach results in an increasing inspection and assessment scope as the plant ages, until a point at which the economic life is reached and replacement is advised. The development of this staged approach to life management has been heavily influenced by the periodic inspection, condition assessment and remediation of defects and damage in welds, with the assessment of the condition of 'parent' material following later in life and primarily influenced by the utilities desire to manage their requirements for large capital spend on plant refurbishment. As an example, for high temperature CMV main steam pipes on conventional plant this staged approach is typically applied as follows:

- Stage 1: includes first weld inspections after $50 \mathrm{Khr}$ of operation,

- Stage 2: first parent material checks (bends) initiated at circa 130Khr,

- Stage 3: initiation of planned inspection of straight pipe sections at circa 190Khr, with first pass of bend inspections completed,

- Stage 4: Economic replacement scheduled at around 260Khr.

The case study presented in Section 4 shows that considerable effort from inspection bodies is required throughout the life of the plant to understand the rate at which the material deteriorates until component replacement is required.

This has shown the uncertainty that the plant owner is faced with, due to the lack of consistency in inspection data trends. In broad terms the generating plant operates on a 3 to 4-year ahead operating ticket, whereas ideally the plant operator would prefer a longer-term 8-10 year forward 
prediction of the rate of life consumption to facilitate economic decisions related to capital investment and optimisation of periodic statutory inspections. In addition, a more predictive assessment of life consumption would provide the plant operator with the opportunity to optimise operation such that the economic lifetime of the assets can be safely and cost-effectively extended. The optimisation of life consumption (to minimise outage inspection scope and prolong asset life) is worth multi-million pounds over the life of a station.

Figure 14 illustrates the current IBA procedures, with the inclusion of small specimen testing and on-load condition assessment highlighted as areas that warrant further development and implementation. The development of on-load condition assessment methods is not the main subject of this particular review paper, however the authors are involved in other complementary research to develop these approaches for plant based applications [97]. In an example of this approach for the assessment of main steam bends [98, 99], routine data assimilated during current plant monitoring and outage inspections is used seamlessly in computational models to rapidly assess current condition and predict remaining life. This methodology is being further explored and developed as practical 'tools' within the UK Flex-E-Plant research consortium related to the analysis of whole steam pipe systems.

Small specimen creep testing provides the opportunity to remove some of the uncertainty associated with the site outage inspection and assessment processes currently used, illustrated by the comparison between surface hardness and creep replica assessments in Fig 24. Based on the current maturity level of the testing techniques outlined in Section 5 it is proposed that the most practical approach to consider at the moment is the impression creep method, particularly since it has been exploited on ageing plant by Brett [13-15, 100] for purposes of condition assessment. The extensive programme of sampling undertaken on Slovakian reactors [78A, 78B, 78D] is also noteworthy and is another example of the pro-active and systematic use of these testing techniques. It's worth noting that other methods such at the two-bar creep test specimen may provide additional benefits due to the potential to model the tertiary phase of creep, however further work on miniaturisation is likely to be required.

The key point to note is that more precise information is required on the in-service rate of material ageing and any subsequent acceleration of the ageing rate that might indicate that repairs or replacements are required.

\subsection{Implementation of Small Specimen Testing}

The intention is to provide more reliable and periodic measurements of material properties throughout the operating life of the asset. This approach can be applied to both conventional and nuclear generating assets and will allow the plant operator sufficient time to implement positive corrections to operation that maximise the useful life of the asset. Data obtained from these small specimen tests can be used to:

- Amend and update relevant pipeline system and component life prediction models,

- Advise plant operators on creep strain rates and changes in material behaviour, hence allow operating conditions to be optimised with respect to the plant owner's requirements for economic asset life,

- Influence and optimise the inspection scope at subsequent statutory outages, 
- Provide a more informed view on the loads acting on complex regions such as welds, complemented by expert review of outage findings from weld inspections and metallography, thereby improving the management of weld integrity,

- Enable some current non-productive site examination methods to be gradually phased out or improved.

In order to provide useful information to the plant operator, results from small specimen testing must be acquired at a suitable time in life to enable appropriate modifications to plant operation to be implemented.

Using the current CMV life management methodology summarised previously as a reference for current practice, the following modification to the current approach is proposed for high temperature pipework. This essentially provides an earlier baseline condition assessment from targeted sample locations, supplemented by interrogation of online monitoring data. Subsequent statutory inspections provide periodic updates on the condition of the in-service ageing materials. Importantly, this modified approach gives the operator more opportunity to optimise how they can effectively manage the plant. The proposed modified approach is as follows;

- Stage 1: Develop full pipeline model(s) of a lead system, which allows estimates of creep strain rate based on design values for material creep models, hanger survey data, plant temperature and pressure monitored data. Ideally pipeline model(s) developed by $\sim 75 \mathrm{Khr}$ and used to proactively support future outage inspection planning. This essentially provides the baseline or reference model(s) for the plant.

- Stage 2: Start to acquire small specimen samples from lead pipeline(s). Specimens should be obtained from straight pipe sections that are adjacent to (upstream or downstream) from proposed bends to be first inspected at $\sim 100 \mathrm{Khr}$ and from positions that will not require subsequent repair or additional monitoring. Update pipeline model(s) accordingly and compare predictions against outage inspection findings. Review and update future periodic inspection plans.

- Stage 3: Select additional targeted small specimen samples to further assess and optimise pipeline model(s), thereby supporting continued safe operation towards end of life. The selection of suitable locations for additional material sampling would be informed by assessment of previous inspection findings. Review and update periodic inspection plans.

- Stage 4: At an economic point, plan to implement replacements.

It is important to recognise that there is a cost to implement small specimen testing, however it is anticipated that this will be offset by cost reductions elsewhere, such as:

- Reduction in the use of diametral strain measurements,

- Optimisation of outage site replica and hardness sampling and analysis campaigns,

- Proactive improvements in plant operation that result in reduced inspection scope at future outages. 


\section{Concluding Remarks}

This review paper has focussed on the application of small specimen testing methods with an emphasis on their place in a practical life assessment framework that could be applied to both conventional and nuclear generating assets. Examples have been provided on current practice associated with invasive site inspections and material condition assessment towards the end of economic life on conventional plant pipework systems. A previous review [3] has described the use of small testing methods to satisfy specific material property and data requirements.

The exacting demands associated with the use of small specimen testing methods in nuclear plant applications strongly emphasises the importance of developing agreed codes of practice and standards. The successful development and validation of alloys under consideration for fusion reactors demands the application of standardised small specimen test methods, this requirement will no doubt drive efforts towards more standardisation. Importantly, the experiences described in this review on the successful application of both SP and impression creep techniques to support operational plant gives a clear indication of their potential use in the field.

There are of course still a number of challenges to overcome before their use can be more widespread as a tool to assist the plant operator. The case study example provided shows how the current methods for assessing the condition of materials via hardness and surface replica surveys have some scope for improvement, ideally towards a position where more mechanistic material behaviour models can be applied, which would be regularly and seamlessly updated with operational and inspection data. Information from the application of small specimen testing campaigns can support this objective, but only if applied in accordance with a timely and structured approach as described in this review. The development of validated small specimen testing methods will also require complementary innovation of experimental measurement methods, facilities and data interpretation.

Developments on improving measurement methods applied to experimental tests may well result in useful applications on operating plant. The use of laser based measurement systems is now accepted and applied (for measuring component displacements) to assist plant investigations associated with premature failure of welds. High resolution high temperature optical strain measurement systems have been taken out of the laboratory and engineered for site applications [55]. Features of these high temperature optical strain measurement systems have recently been used to assist the first site application of creep damage sensors [56]. There are also examples of the first trials of non-contact full field strain measurement on high temperature plant using digital image correlation [60] and thermographic approaches for defect identification and residual stress measurement using infra-red camera systems [104+].

The power industry is facing severe challenges as the economy transitions to a low carbon future. This puts much emphasis on conventional and nuclear AGR plant continuing to operate reliably, cost effectively and life extension.

This review has presented the current practice for life management of high temperature and pressure systems and proposes that small specimen testing methods ideally should be used earlier in the plant lifecycle. The current inspection based approach for life management is unable to provide sufficiently rigorous future life predictions that allow the plant operator to efficiently optimise plant operation and reduce through life inspections costs. 
It is recognised that developing rigorous predictive life assessment models is not trivial; however targeted use of small specimen testing methods described in this paper, within a new life assessment framework that also exploits the capabilities offered by modern computational techniques, provides an opportunity to achieve this objective. To support this aim there is a critical need to better exploit the extensive plant data acquired during outages, along with on-line data routinely captured during operation.

These challenges are being addressed as part of the remit of the EPSRC funded Flex-E-Plant consortium and it should be acknowledged that some aspects of the challenge have been demonstrated in other recent research and plant trials; for example:

- Plant applications of impression creep testing for risk ranking components [34, 37],

- The development of computational models for main steam pipe bends that use plant outage inspection data as model inputs to provide forward predictions of creep life consumption based on measured operational loads [42],

- Ongoing development and trials of creep damage sensors on operating plant [17].

Hence, it is the authors' belief that the development and practical use of such predictive life assessment tools within the proposed new life assessment framework is now both cost-effective and achievable.

The ultimate aim is to develop 'point of application' material models that can seamlessly use inservice metallurgical, inspection and operational data to provide the utility operator with a timely and predictive life assessment capability. These aims are applicable to both conventional and nuclear generating stations.

Moreover, the arduous operational duty experienced by conventional generating plant provides a useful source of both metallurgical and operational experience to assist the cost-effective life management of existing nuclear AGR plants and also to support the life management of materials to be used in next generation nuclear reactors.

\section{Acknowledgments}

We would like to acknowledge the support of the Engineering and Physical Sciences Research Council (EPSRC) for their support for the project - Flexible and Efficient Power Plant: Flex-E-Plant (Grant number: EP/K021095/1). We also thank the following partners for their the valuable contributions: Alstom Power Limited, Doosan Babcock Limited, Centrica plc., EDF Energy (West Burton Power) Limited, E.ON Technologies (Ratcliffe) Limited, Goodwin Steel Castings Limited, NPL Management Limited, R-MC Power Recovery Limited, RWE Generation UK plc., Scottish and Southern Energy (SSE) plc., Siemens Industrial Turbomachinery and TWI Limited.

The authors would like to acknowledge members of the Flex-E-Plant consortium and EDF Energy for permission to publish this paper. 


\section{References}

1. Pressure Systems Safety Regulations 2000 Approved code of practice and guidance. $2^{\text {nd }}$ Edition published 2014, HSE Books, ISBN 978071766644 7. Available from www.hse.gov.uk

2. Pressure Systems Safety, Office for Nuclear Regulation Guide, NS-TAST-GD-067 Rev 0, November 2014. Available from www.onr.org.uk.

3. Hyde, T.H., W. Sun, and J.A. Williams, Requirements for and Use of Miniature Test Specimens to Provide Mechanical and Creep Properties of Materials: a Review. Int. Mater. Rev., 2007. 52(4): p. 213-255.

4. Pearson, P. and J. Watson, UK Energy Policy 1980-2010: A History and Lessons to be Learnt. 2012: The Institution of Engineering and Technology, Pub: The Parlimentary Group for Energy Studies, 2012.

5. CEN WORKSHOP AGREEMENT, Small Punch Test Method for Metallic Materials, CWA 15627: 2007, D/E/F. European Committee for Standardisation, December 2007.

6. Sun, W., T.H. Hyde, and S.J. Brett, Application of Impression Creep Data in Life Assessment of Power Plant Materials at High Temperatures. Proc. Instn Mech Engrs, Journal of Materials Design and Applications, 2008. 222(Part L): p. 175-182.

7. European Technology Development (ETD), http://www.etd-consulting.com/ourservices/engineering-services/advanced-nondestructive-evaluation/.

8. Rolls-Royce Power Engineering Plc, Scoop sampling - extraction of material samples for examination and analysis. 2010.

9. Data acceptability criteria and data generation: recommendations for creep testing of post exposed (ex-service) materials. ECCC Recommendations, http://www.ommi.co.uk/etd/eccc/advancedcreep/v3piiii4x.pdf, 18 June 2012. 3(III).

10. Dedov, A., I. Klevtsov, T. Lausmaa, and D. Neshumayev, Method of small samples for assessment of properties of power plant components: sampling devices and stress concentration in dimples, in Proc. Conference Plant Maintenance for Managing Life \& Performance BALTICA VII. 2007. p. 180-192.

11. Klevtsov, I. and A. Dedov. Impact of Small Specimens Sampling on Durability of In-Service Power Plant Components. in SSTT. Proceedings of the 2nd International Conference SSTT: Determination of Mechanical Properties of Materials by Small Punch and Other Miniature Testing Techniques. October 2-4, 2012. Ostrava, Czech Rep.

12. Brett, S.J., The creep strength of weak thick section modified 9 Cr forgings. Baltica V: Condition and Life Management for Power Plants, VTT, ESPOO, 2001: p. 35-44.

13. Brett, S.J., UK Experience with Modified 9Cr (Grade 91) Steel, in Baltica VII: International Conference on Life Management \& Maintenance for Power Plants. 2007: HelsinkiStockholm-Helsinki. p. 48-60.

14. Brett, S.J., Early Type IV Cracking on Two Retrofit Grade 91 Steel Headers, in IIW Int. Conf. on Safety and Reliability of Welded Components in Energy and Processing Industry. 2008: Graz, Austria.

15. Brett, S.J., Small Scale Sampling and Impression Creep Testing of Aged $1 / 2$ CrMoV Steam Pipework Systems, in Proc. of ECCC Conf. on Creep and Fracture in High Temperature Components - Design and Life Assessment. April 2009: Dübendorf, Switzerland. p. 10881096.

16. Rouse, J.P., W. Sun, and T.H. Hyde, The effects of scoop sampling on the creep behaviour of power plant straight pipes. Journal of Strain Analysis, 2013. 48(8): p. 494-511.

17. MacKenzie, A.C., On the use of a single uniaxial test to estimate deformation rates in some structures undergoing creep. International Journal of Mechanical Sciences, 1968. 10(5): p. 441-453. 
18. Penny, R.K. and D.L. Marriott, Design for creep, ed. 2nd. 1995, London: Chapman and Hall.

19. GB/T 29459.1-2012 Small Punch Test Methods of Metallic Materials for In-Service Pressure Equipment-Part 1: General Requirements. General Administration of Quality Supervision, Inspection and Quarantine of China/ Standardization Administration of China, 2012.

20. GB/T 29459.1-2012 Small Punch Test Methods of Metallic Materials for In-Service Pressure Equipment-Part 2: Method of Test For Tensile Properties at Room Temperature. General Administration of Quality Supervision, Inspection and Quarantine of China/ Standardization Administration of China, 2012.

21. Standard for Small Punch Creep Test -Estimation of Residual Life for High Temperature Component. The Committee on High Temperature Strength of Materials. The Society of Materials Science, September, 2012. ISBN 978-4-901381-38-3.

22. Standard Test Method for Small Punch Testing of Ultra-High Molecular Weight Polyethylene Used in Surgical Implants. 2008, ASTM International.

23. Hurst, R.C. and K. Matocha, A Renaissance in the Use of the Small Punch Testing Technique, in Proceedings of the ASME 2015 Pressure Vessels and Piping Conference. 2015: Boston, Massachusetts, USA. p. V01BT01A048-041 - V001BT001A048-016.

24. Kasiviswanathan, K.V., V. Karthik, P. Visweswaran, K. Laha, and T. Jayakumar, Small Specimen Testing - Research and Development Activities at Igcar, India, in SSTT. Proceedings of the 2nd International Conference SSTT: Determination of Mechanical Properties of Materials by Small Punch and Other Miniature Testing Techniques, K. Matocha, R. Hurst, and W. Sun, Editors. October 2-4, 2012: Ostrava, Czech Rep.

25. Hurst, R.C. and K. Matocha, Small Punch Testing - the transition from a Code of Practice to a European testing standard, in SSTT. Proceedings of the 4th International Conference: Determination of Mechanical Properties of Materials by Small Punch and other Miniature Testing Techniques, K. Matocha, R. Hurst, and W. Sun, Editors. 12-14 October 2016: Shanghai, China.

26. Hyde, T.H. and W. Sun, Evaluation of Conversion Relationships for Impression Creep Test at Elevated Temperatures. International Journal of Pressure Vessels and Piping, 2009. 86(11): p. 757-763.

27. Sun, W., T.H. Hyde, and S.J. Brett, Small Specimen Creep Testing and Application for Power Plant Component Remainig Life Assessment, in IRF2013 - 4th International Conference on Integrity, Reliability and Failure. 2013: Funchal, Portugal.

28. Li, Y.Z. and R. Sturm, Determination of Creep Properties from Small Punch Test. Proceedings of the ASME Pressure Vessels and Piping Conference, 2009. Vol 3: p. 741752.

29. Chakrabarty, J., A Theory of Stretch Forming Over Hemispherical Punch Heads. International Journal of Mechanical Sciences, 1970. 12(4): p. 315-325.

30. Cortellino, F., J.P. Rouse, W. Sun, and T.H. Hyde. A Study on the Effect of Initial Plasticity on the Small Punch Creep Test for a P91 Steel at $600{ }^{\circ} \mathrm{C}$ in SSTT - Determination of mechanical properties of materials by small punch and other miniature testing techniques. 2014. Castle Seggau - Graz (Austria): OCELOT s.r.o.

31. Dobeš, F. and K. Milička, Application of Creep Small Punch Testing in Assessment of Creep Lifetime. Materials Science and Engineering: A: Properties, Microstructure and Processing, 2009. 510(11): p. 440-443.

32. Ma, Y.W., S. Shim, and K.B. Yoon, Assessment of Power Law Creep Constants of Gr91 Steel Using Small Punch Creep Tests. Fatigue \& Fracture of Engineering Materials \& Structures, 2009. 32(12): p. 951-960. 
33. Cacciapuoti, B., W. Sun, and D.G. McCartney, A study on the evolution of the contact angle of small punch creep test of ductile materials. International Journal of Pressure Vessels and Piping, 2016. 145: p. 60-74.

34. Rouse, J.P., F. Cortellino, W. Sun, T.H. Hyde, and J. Shingledecker, Small Punch Creep Testing: Review on Modelling And Data Interpretation. Materials Science and Technology, 2013. 29(11): p. 1328-1345.

35. Li, Y.Z., R. Sturm, R.C. Hurst, and D.T. Blagoeva, Derivation of Creep Properties From Small Punch Test Small Punch Test (SPT), in International Worshop. June 27-28 2011: University of Nottingham, United Kingdom.

36. Hyde, T.H. and W. Sun, A Novel, High Sensitivity, Small Specimen Creep Test. Journal of Strain Analysis, 2009. 44(3): p. 171-185.

37. Hyde, C.J., T.H. Hyde, W. Sun, S. Nardone, and E. De Bruycker, Small Ring Testing of a Creep Resistant Material. Materials Science and Engineering: A, 2013. 586(0): p. 358-366.

38. Hyde, T.H., W. Sun, and B.S.M. Ali. A Small Creep Test Specimen for Use in Determining Uniaxial Creep Rupture Data. in SSTT. Proceedings of the 2nd International Conference SSTT: Determination of Mechanical Properties of Materials by Small Punch and Other Miniature Testing Techniques. October 2-4, 2012. Ostrava, Czech Rep.

39. Hyde, T.H., B.S.M. Ali, and W. Sun, Analysis and Design of a Small, Two-Bar Creep Test Specimen. ASME. Journal of Engineering Materials and Technology, 2013. 135(4): p. 041006-041006-041009.

40. Hyde, T.H., C.J. Hyde, and W. Sun, A Basis for Selecting the Most Appropriate Small Specimen Creep Test Type. Journal of Pressure Vessel Technology, 2014. 136(2): p. 024502-024501-024506.

41. Hyde, T.H., W. Sun, and A.A. Becker, Analysis of the Impression Creep Test Method Using a Rectangular Indenter for Determining the Creep Properties in Welds. International Journal of Mechanical Sciences, 1996. 38: p. 1089-1102.

42. Dymáček, P. and K. Milička, Creep Small-Punch Testing and its Numerical Simulations. Materials Science and Engineering: A, 2009. 510-511: p. 444-449.

43. Li, Y. and R. Šturm, Determination of Creep Properties from Small Punch Test, in ASME 2008 pressure vessels and piping conference, ASME, Editor. 2008: Chicago, Illinois, USA. p. 739-750.

44. Ling, X., Y. Zheng, Y. You, and Y. Chen, Creep Damage in Small Punch Creep Specimens of Type 304 Stainless Steel. International Journal of Pressure Vessels and Piping, 2006. 84(5): p. 304-309.

45. Wilshire, B. and M. Willis, Mechanism of Strain Accumulation and Damage Developmant During Creep of Prestrained 316 Stainless Steel. Metaallurgical and Materials Transactions A, 2004. 35(2): p. 563-571.

46. Hyde, T.H., M. Stoyanov, W. Sun, and C.J. Hyde, On the Interpretation of Results from Small Punch Creep Tests. The Journal of Strain Analysis for Engineering Design, 2010. 45(3): p. 141-164.

47. Liu, Y. and S. Murakami, Damage Localization of Conventional Creep Damage Models and Proposition of a New Model for Creep Damage Analysis. JSME International Journal Series A, 1998. 41(1): p. 57-65.

48. Kobayashi, K.I., I. Kajihara, H. Koyama, and G.C. Stratford, Deformation and Fracture Mode During Small Punch Creep Tests. Journal of Solid Mechanics and Materials Engineering, 2010. 4(1): p. 75-86.

49. Cortellino, F., R. Chen, W. Sun, and T.H. Hyde, A Microscopic Investigation on the Failure Mechanisms of Small Punch Creep Test of a P91 Steel at 873 K, in SSTT - Determination of mechanical properties of materials by small punch and other miniature testing techniques 
K. Matocha, R. Hurst, and W. Sun, Editors. 2014, OCELOT s.r.o.: Castle Seggau - Graz (Austria). p. 260-269.

50. Evans, M. and D. Wang, The Small Punch Creep Test: Some Results from a Numerical Model. Journal of Materials Science, 2008. 43(6): p. 1825-1835.

51. Cortellino, F., Experimental and numerical investigation of small punch creep test. 2015, $\mathrm{Ph}$. D Thesis, The Univeristy of Nottingham.

52. Kobayashi, K.I., M. Kaneko, H. Koyama, G.C. Stratford, and M. Tabuchi, The Influence of Both Testing Environment and Fillet Radius of the Die Holder on the Rupture Life of Small Punch Creep Tests. Journal of Solid Mechanics and Materials Engineering, 2012. 6(8): p. 925-934.

53. Dymáček, P., S. Seitl, K. Milička, and F. Dobeš, Influence of Friction on Stress and Strain Distributions in Small Punch Creep Test Models. Key Engineering Materials, 2010. 417418: p. 561-564.

54. Cortellino, F., W. Sun, T.H. Hyde, and J. Shingledecker, The Effects of Geometrical Inaccuracies of the Experimental Set-Up on Small Punch Creep Test Results. The Journal of Strain Analysis for Engineering Design, 2014. 49(8): p. 571-582.

55. Morris, A., M. Kourmpetis, I.D. Dear, M. Sjodahl, and J.P. Dear, Optical Strain Monitoring Techniques for Life Assessment of Components in Power Generation Plant. Proc. Instn Mech Engrs, Part A, Journal of Power and Energy, 2007. 221 (A8): p. 1141-1152.

56. Davies, C.M., P. Nagy, A. Narayanan, and P. Cawley, Continuous Creep Damage Monitoring Using a Novel Potential Drop Technique. 2012, AMER SOC MECHANICAL ENGINEERS. p. 35-39.

57. Thoraval, G., Creep of High Temperature Steam Piping; EDF Experience With Fossil-Fired Power Plants From 1955 to 1987. Nuclear Engineering and Design, 1989. 116 p. 389-398

58. Morris, A., C. Maharaj, M. Kourmpetis, I.D. Dear, A. Puri, and J.P. Dear, Optical Strain Measurement Techniques to Assist in Life Monitoring of Power Plant Components. Journal of Pressure Vessel Technology. 131(2): p. 024502-024502-024508.

59. Morris, A., C. Maharaj, I. Palmer, A. Puri, and J.P. Dear, ARCMAC Optical Strain Measurement for Creep Monitoring: Recent Improvements in Accuracy and Resolution, in ASME PVP 2009 Conference - Sustainable Energy for the Third Millenium. July 2009: Prague, Czech Republic, PVP200977511.

60. Morris, A., C. Maharaj, I. Palmer, A. Puri, and J.P. Dear, Developments in Combined ARCMAC and Strain Mapping Systems for Creep Measurement, in ASME PVP 2008 Conference - Nuclear Power Plant Renaissance Change in Paradigm, A.A.G. Dermenjian, L. H. eds, Editor. July 2008, PVP200861118: Marriott on Magnificent Mile Hotel, Chicago, Illinois, USA, PVP200861118.

61. Morris, A., C. Maharaj, A. Puri, M. Kourmpetis, and J.P. Dear, Recent Developments in Methods to study Creep Strain Variations in Power Station Steam Plant, in ASME PVP 2008 Conference - Nuclear Power Plant Renaissance Change in Paradigm, A.A.G. Dermenjian, L. H. eds, Editor. July 2008: Marriott on Magnificent Mile Hotel, Chicago, Illinois, USA, PVP200861119.

62. Fenton, S.T., A. Morris, and P. Mulvihill, Investigation and analysis of CrMoV Bore Cracking, in IOM 2nd International Conference "Integrity of High Temperature Welds", I. Communications, Editor. November 2003: London.

63. GENSIP Publication, CMV Pipework Management in Conventional UK Power Stations. GENSIP/GPG/PS001. Issue 1.2, August 2011.

64. VGB-TW 507, Guidelines for the Assessment of Microstructure and Damage Development of Creep Exposed Materials for Pipes and Boiler Components. VGB Technical Association of Large Power Plant Operators, 1992. 
65. Neubauer, B. and U. Wedel, Restlife Estimation of Creeping Components by Means of Replicas, in ASME International Conference on Advances in Life Prediction Methods, J.R.W. Eds. D.A. Woodford, ASME, Editor. 1983: New York.

66. Concari, S., Residual Life Assessment and Microstructure. ECCC Recommendations, 2005. 6(1).

67. Hyde, T.H. and W. Sun, Application of Impression Creep Test Data for the Assessment of Service Exposed Power Plant Components. Metallurgical Journal - Theme 3: Numerical Approach, 2010. Vol. LXIII: p. 138-145.

68. Hollomon, J.H. and L.D. Jaffee, Time-temperature relations in tempering steel. Trans. AIME, 1943. 162: p. 223-249.

69. Kohlhofer, W. and R.K. Penny, Hardness testing as a means for creep assessment. International Journal of Pressure Vessels and Piping, 1996. 66(1-3): p. 333-339.

70. Ghassemi Armaki, H., R. Chen, S. Kano, K. Maruyama, Y. Hasegawa, and M. Igarashi, Microstructural degradation mechanisms during creep in strength enhanced high Cr ferritic steels and their evaluation by hardness measurement. Journal of Nuclear Materials, 2011. 416(3): p. 273-279.

71. Sposito, G., C. Ward, P. Cawley, P.B. Nagy, and C. Scruby, A Review of Non-Destructive Techniques for the Detection of Creep Damage in Power Plant Steels. NDT \& E International, 2010. 43(7): p. 555-567.

72. Mukhopadhyay, S.K., H. Roy, and A. Roy, Development of hardness-based model for remaining life assessment of thermally loaded components. International Journal of Pressure Vessels and Piping, 2009. 86(4): p. 246-251.

73. Masuyama, F., Creep degradation in welds of Mod.9Cr-1Mo steel. International Journal of Pressure Vessels and Piping, 2006. 83(11-12): p. 819-825.

74. Furtado, H.C., B.R. Cardoso, F. Santos, C. Matt, and L.H. de Almeida, Remaining Life Evaluation of Power Plant Based on Strain Deformation Monitoring and Computational Diagnosis, in The 12th International Conference of the Slovenian Society for NonDestructive Testing: Application of Contemporary Non-Destructive Testing in Engineering. September 4-6, 2013: Portorož, Slovenia.

75. Furtado, H.C., L.H. de Almeida, J. Dille, and I. Le May, Correlation Between Hardness Measurements and Remaining Life Prediction for 2.25Cr-1Mo Steel Used in Power Plants. Journal of Materials Engineering and Performance, 2010. 19(4): p. 558-561.

76. Furtado, H.C., L.H. de Almeida, and I. Le May, Damage and Remaining Life Estimation in High Temperature Plant with Variable Operating Conditions. OMMI, Power Plant, 2008. 5: p. 1-10.

77. Larson, F.R. and J. Miller, A time-temperature relationship for rupture and creep stress. Transactions ASME, 1952. 74(5): p. 765-775.

78++ Corwin W.R., Lucas G.E., The use of small-scale speciemns for testing irradiated material, ASTM special technical publication 888, 1983, Albuquerque, USA.

78A Petzová, J., M. Březina, M. Kapusnak and L. Kupča. Application of small punch testing methods for thermal ageing monitoring at primary circuit components in nuclear power plant. In Proceedings of the 2015 ASME Pressure Vessels \& Piping Conference PVP2015. July, 19-23, 2015. Boston, USA.

78B M. Březina, Petzová, J, M. Kapusnak and L. Kupča. A. Utilization of SPT techniques for evaluation of changes in the properties of the vve-440 reactor pressure vessel steels after their radiation in the research and power reactors. In Proceedings of the 2015 ASME Pressure Vessels \& Piping Conference PVP2015. July, 19-23, 2015. Boston, USA. 
78 C Tamás János Katona (2011). Long-Term Operation of VVER Power Plants, Nuclear Power Deployment, Operation and Sustainability, Dr. Pavel Tsvetkov (Ed.), ISBN: 978-953-307-474-0, InTech, Available from:http://www.intechopen.com/books/nuclear-power-deployment-operationand-sustainability/long-termoperation-of-vver-power-plants

78 D Petzová, J., M. Březina, and L. Kupča. Evaluation of mechanical properties of the reactor pressure vessel materials changes by small punch test application. In Proceedings of the 2013 ASME Pressure Vessels \& Piping Conference PVP2013. July, 14-18, 2015. Paris, France

$78 \mathrm{E} \mathrm{J}$ Knaster et al, IFMIF, the europeran-japanese efforts under the broader approach agreement towards a Li $(d, x n)$ neutron source; Current status and future options. Nuclear Materials and Energy 9 92016), 46-54

78F G.E Lucas., G.R Odette., H. Matsui., A. Moslang., P. Spatig., J Rensman., YT Yamamoto, The role of small specimen test technology in fusion material development. Nuclear Materials 367-370 (2007) 1549-1556

78G Liu, Y.,Murakami, S., Damage localisation of conventional creep damage models and proposition of a new model for creep damage analysis, JSME International Journal Series A, 1998. 41(1): p. 57-65

78H R Klueh. Reduced activation bainitic and martensitic steels for nuclear fusion applications, Current Opinion in Solid State and Materials Science 8 (2004) 239.

78I Bruchhausen, M., K. Turba, F. de Haan, P. Hähner, T. Austin, and Y. de Carlan, Characterization of a $14 \mathrm{Cr}$ ODS steel by means of small punch and uniaxial testing with regard to creep and fatigue at elevated temperatures. Journal of Nuclear Materials, 2014. 444: p. 283-291.

78J Odette, G.R., He, H., Gragg D., Kingensmith D., Lucas G.E., Some recent innovations in small specimen testing, Journal of Nuclear Materials 307-311 (2002) 1643-1648

78K Gilbert, M.R., Dudarev, S.L., Zheng, S., Packer, L.W., Sublet, J-Ch, An integrated model for materials in a fusion power plant: transmutation, gas production, and helium embrittlement under neutron irradiation. Journal Nuclear Fusion 52 (2012) 083019

78. Nakata, T., S.-i. Komazaki, Y. Kohno, and H. Tanigawa, Development of a small punch testing method to evaluate the creep property of high Cr ferritic steel: Part I - Effect of atmosphere on creep deformation behavior. Materials Science and Engineering: A, 2016. 666: p. 54-60.

79. Petzová, J., M. Březina, and L. Kupča. Evaluation of mechanical properties of the reactor pressure vessel materials changes by small punch test application. in Proceedings of the 2013 ASME Pressure Vessels \& Piping Conference PVP2013. July, 14-18, 2013. Paris, France.

80. Baik, J.M., J. Kameda, and O. Buck, Small punch test evaluation of intergranular embrittlement of an alloy steel. Scripta Metallurgica, 1983. 17(12): p. 1443-1447.

81. Chi, S.-H., J.-H. Hong, and I.-S. Kim, Evaluation of irradiation effects of $16 \mathrm{MeV}$ protonirradiated 12Cr-1MoV steel by small punch (SP) tests. Scripta Metallurgica et Materialia, 1994. 30(12): p. 1521-1525.

82. Mao, X. and J. Kameda, Small-punch technique for measurements of material degradation of irradiated ferritic alloys. Journal of Materials Science, 1991. 26: p. 2436-2440.

83. Wakai, E., H. Ohtsuka, S. Matsukawa, K. Furuya, H. Tanigawa, K. Oka, S. Ohnuki, T. Yamamoto, F. Takada, and S. Jitsukawa, Mechanical properties of small size specimens of F82H steel. Fusion Engineering and Design, 2006. 81: p. 1077-1084. 
84. Bruchhausen, M., K. Turba, F. de Haan, P. Hähner, T. Austin, and Y. de Carlan, Characterization of a $14 \mathrm{Cr}$ ODS steel by means of small punch and uniaxial testing with regard to creep and fatigue at elevated temperatures. Journal of Nuclear Materials, 2014. 444: p. 283-291.

85. Kasada, R., H. Ono, and A. Kimura, Small specimen test technique for evaluating fracture toughness of blanket structural materials. Fusion Engineering and Design, 2005. 81: p. 981986.

86. Standard Test Method for Determination of Reference Temperature, $T_{0}$, for Ferritic Steels in the Transition Range. ASTM E 1921-02, Annual Book of ASTM Standards, 2002. 03.01.

87. Martínez-Pañeda, E., T.E. García, and C. Rodríguez, Fracture toughness characterization through notched small punch test specimens. Materials Science and Engineering: A, 2016. 657: p. 422-430.

88. Mathew, M.D., J. Ganesh Kumar, V. Ganesan, and K. Laha, Small Punch Creep Studies for Optimization of Nitrogen Content in 316LN SS for Enhanced Creep Resistance. Metallurgical and Materials Transactions A, 2014. 45(2): p. 731-737.

89. Bueno, A.H.S., E.D. Moreira, and J.A.C.P. Gomes, Evaluation of stress corrosion cracking and hydrogen embrittlement in an API grade steel. Engineering Failure Analysis, 2014. 36: p. 423-431.

90. Rehrl, J., K. Mraczek, A. Pichler, and E. Werner, Mechanical properties and fracture behavior of hydrogen charged AHSS/UHSS grades at high- and low strain rate tests. Materials Science and Engineering: A, 2014. 590: p. 360-367.

91. Magudeeswaran, G., V. Balasubramanian, and G. Madhusudhan Reddy, Hydrogen induced cold cracking studies on armour grade high strength, quenched and tempered steel weldments. International Journal of Hydrogen Energy, 2008. 33(7): p. 1897-1908.

92. García, T.E., C. Rodríguez, F.J. Belzunce, and I.I. Cuesta, Effect of hydrogen embrittlement on the tensile properties of CrMoV steels by means of the small punch test. Materials Science and Engineering: A, 2016. 664: p. 165-176.

93. Hirose, T., H. Sakasegawa, A. Kohyama, Y. Katoh, and H. Tanigawa, Effect of specimen size on fatigue properties of reduced activation ferritic/martensitic steels. Journal of Nuclear Materials, 2000. 283-287, Part 2: p. 1018-1022.

94. Nogami, S., T. Itoh, H. Sakasegawa, H. Tanigawa, E. Wakai, A. Nishimura, and A. Hasegawa, Study on fatigue life evaluation usinf small specimens for testing neutronirradiated materials. Journal of Nuclear Science and Technology, 2011. 48(1): p. 60-64.

95. Bao, C., L.X. Cai, and C. Dan, Estimation of fatigue crack growth behavior for small-sized $C$-shaped inside edge-notched tension (CIET) specimen using compliance technique. International Journal of Fatigue, 2015. 81: p. 202-212.

96. Volak, J., M. Novak, J. Kaiser, and V. Mentl, Fatigue testing by means of miniature test specimens. Journal of Achievements in Materials and Manufacturing Engineering, 2012. 55(2): p. 386-389.

96++ Roebuck. B., Cox. D.C., Reed. R.C., An innovative device for the mecyhanical testing of miniature specimens on superalloys. Journal of Superalloys, 2004

97. Rouse, J.P., W. Sun, T.H. Hyde, and A. Morris, Comparative Assessment of Several Creep Damage Models for Use in Life Prediction. International Journal of Pressure Vessels and Piping, 2013. 108-109: p. 81-87.

98. Rouse, J.P., M.Z. Leom, W. Sun, T.H. Hyde, and A. Morris, Steady-state Creep Peak Rupture Stresses in $90^{\circ}$ Power Plant Pipe Bends with Manufacture Induced Cross-Section 
Dimension Variations. International Journal of Pressure Vessels and Piping, 2013. 105-106: p. 1-11.

99. Rouse, J.P., W. Sun, T.H. Hyde, A. Morris, and W. Montgomery, A Method to Approximate the Steady-State Creep Response of Three-Dimensional Pipe Bend Finite Element Models Under Internal Pressure Loading Using Two-Dimensional Axisymmetric Models. Journal of Pressure Vessel Technology, ASME, 2013. Vol. 00: p. PVT-13-1046.

100. Brett, S.J., The Creep Strength of Weak Thick Section Modified 9Cr Forgings, in BALTICA V: Condition and Life Management for Power Plants, VTT Symposium, ESPOO, V.M.T. Seija Hietanen \& Pertti Auerkari, Editor. 2001: Hotel Haikko Manor, Porvoo, Finland. p. 35-44.

101. Hyde, C.J., T.H. Hyde, and W. Sun. Small Ring Specimen Creep Testing of a Nickel-Based Superalloy. in Determination of Mechanical Properties of Materials by Small Punch and other Miniature Testing Techniques. 2012. Ostrava, Czech Republic.

102. Sun, W., T.H. Hyde, and B.S.M. Ali, Small Tensile Bar Specimen Creep Tests for Use in Determining Creep Deformation and Rupture Properties, in SSTT - Determination of mechanical properties of materials by small punch and other miniature testing techniques K. Matocha, R. Hurst, and W. Sun, Editors. 2014, OCELOT s.r.o.: Castle Seggau - Graz (Austria).

103. Guglielmino, E., R. Pino, C. Servetto, and A. Sili, Chapter 4 - Creep damage of high alloyed reformer tubes A2 - Makhlouf, Abdel Salam Hamdy, in Handbook of Materials Failure Analysis with Case Studies from the Chemicals, Concrete and Power Industries, M. Aliofkhazraei, Editor. 2016, Butterworth-Heinemann. p. 69-91.

104+ Tighe, R.C., Howell, G.P., Tyler, J.P., Lormor. S., Dulieu-Barton, J.M, Stress based nondestructive evaluation using thermographic approaches: from laboratory trials to on-site assessment. Journal NDT\&E International 84 (2016) 76-88 


\section{Figures}

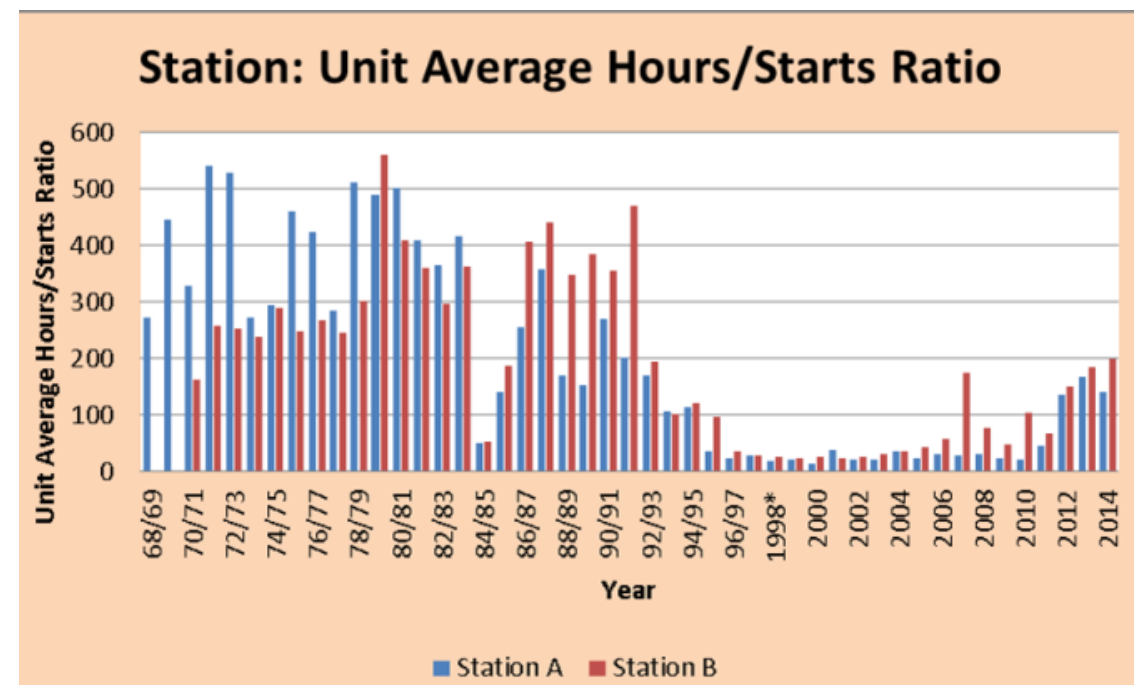

Figure 1. Unit average operating hours/starts ratio: for two 2000MW fossil fired conventional power stations, from initial commissioning until end of 2014.

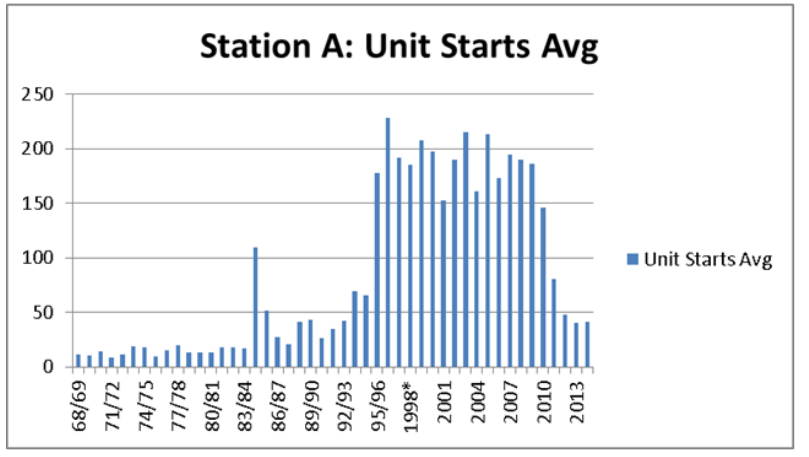

(a)

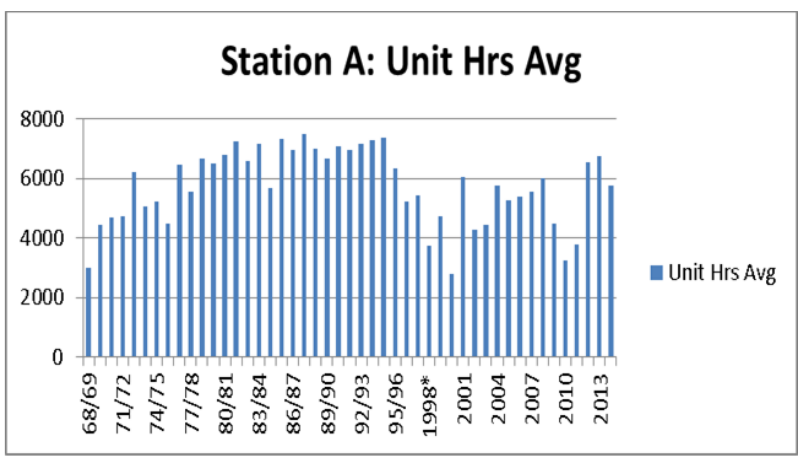

(b)

Figure 2. (a) Unit average operating starts for station A and (b) unit average operating hours for station A. 


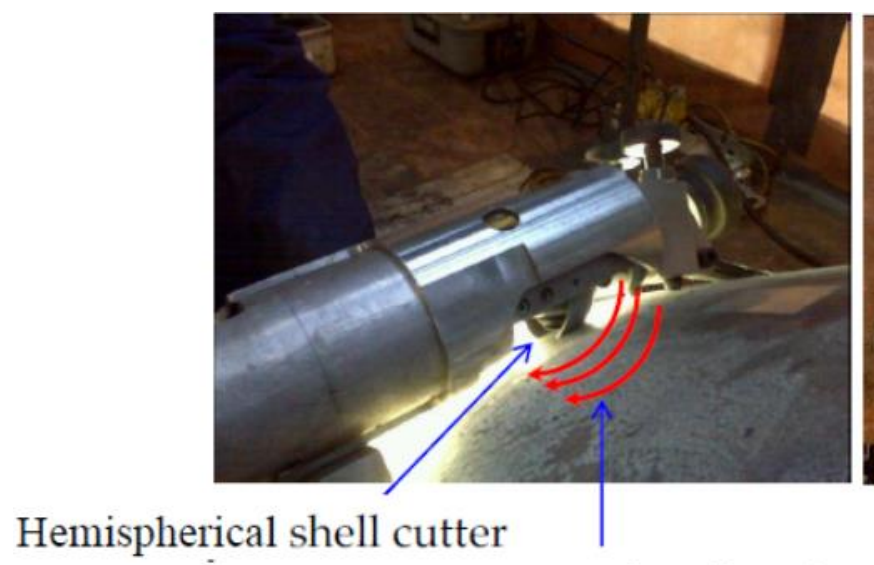

Cutting direction

(a)

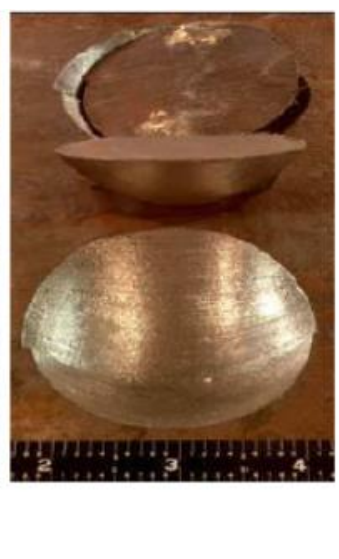

(b)

Figure 3. Photographs of (a) scoop sampling in process on pipework, and (b) a typical scoop sample, from Ref. [101].

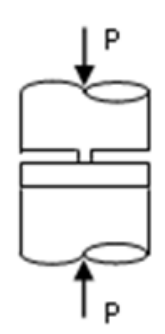

(a)

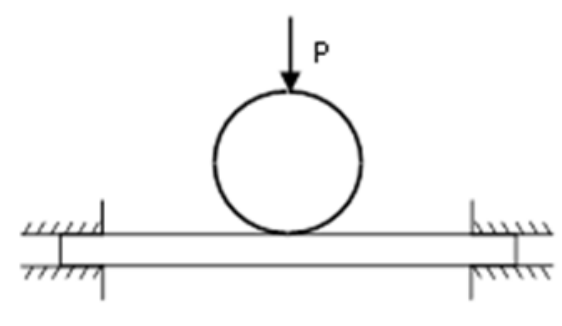

(b)

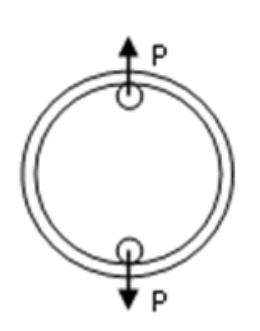

(c)

Figure 4. (a) Impression creep test specimen; (b) small punch creep test specimen; (c) small ring creep test specimen, adapted from Ref. [27].

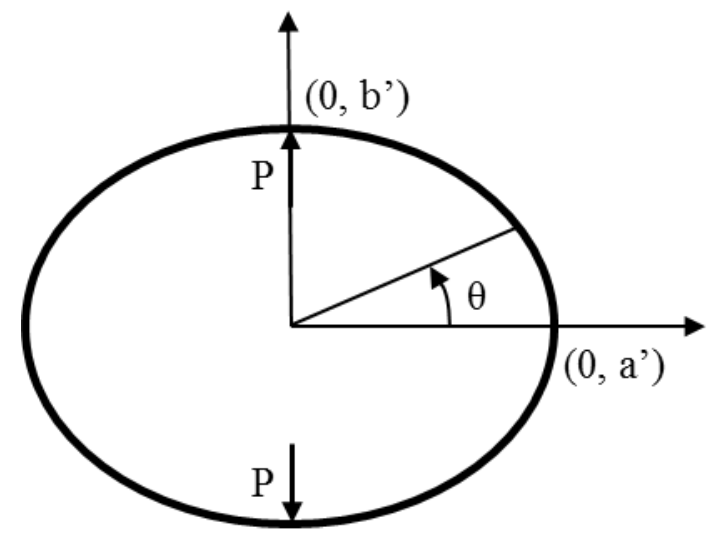

Figure 5. Reference frame of the small ring, adapted from Ref. [36]. 


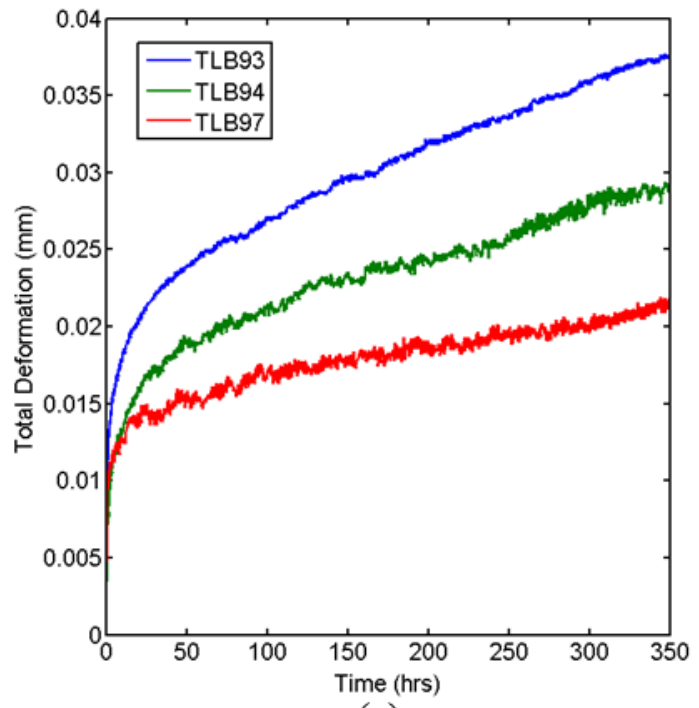

(a)

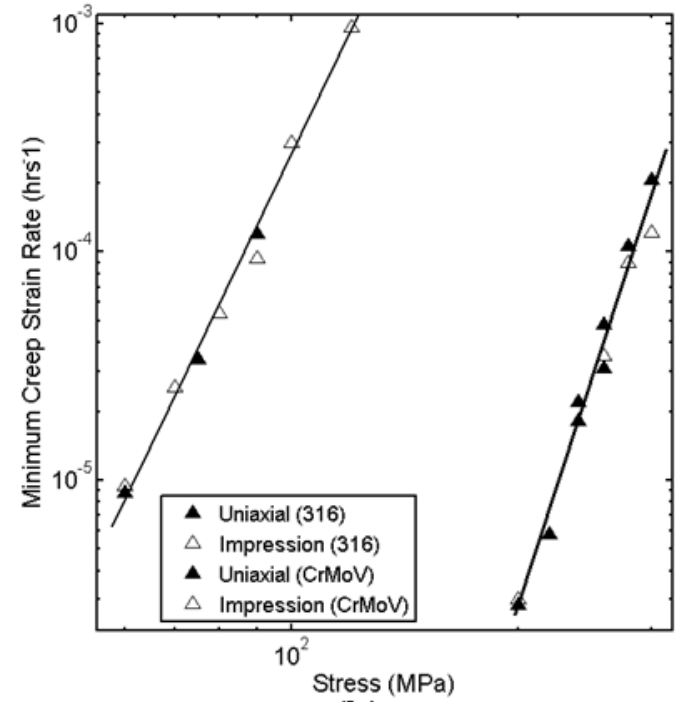

(b)

Figure 6. (a) Impression deformations with time at $90 \mathrm{MPa}$ and $600{ }^{\circ} \mathrm{C}$ obtained from ex-service CMV steam pipe samples, from Ref. [27], and (b) minimum creep strain rate (MSR) data for 316 stainless steel at $600{ }^{\circ} \mathrm{C}$ and 2-1/4Cr1Mo weld metal at $640{ }^{\circ} \mathrm{C}$, obtained from uniaxial and impression creep tests, from Ref. [27]. 


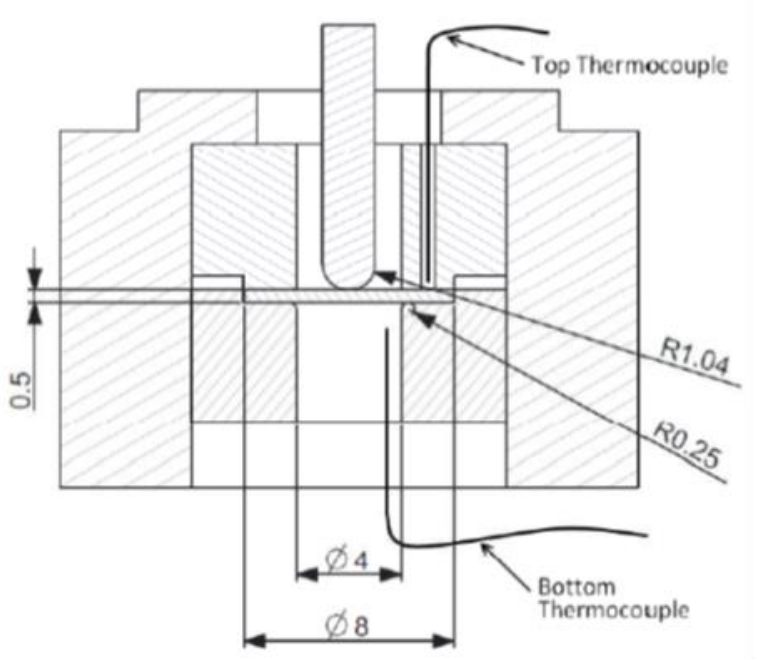

(a)

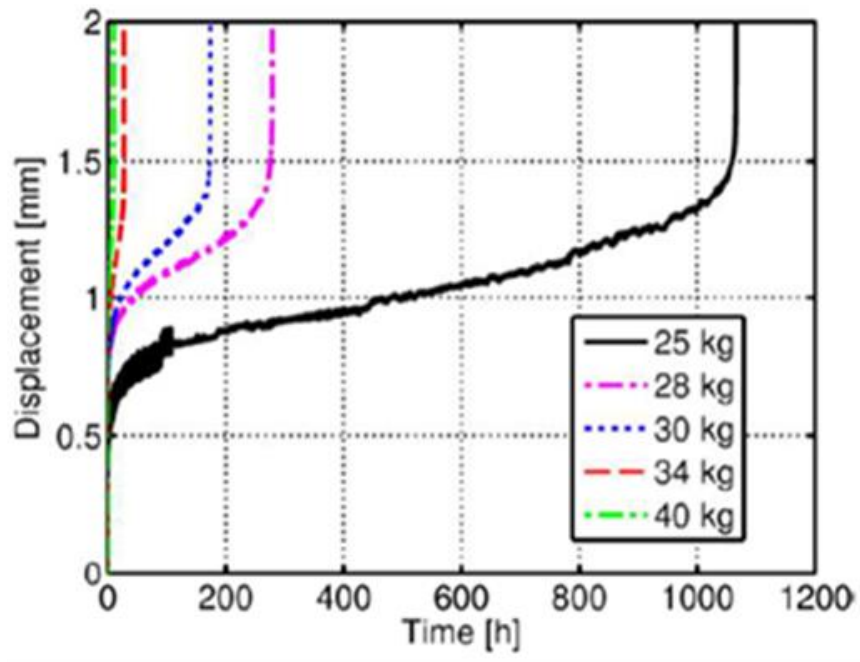

(b)

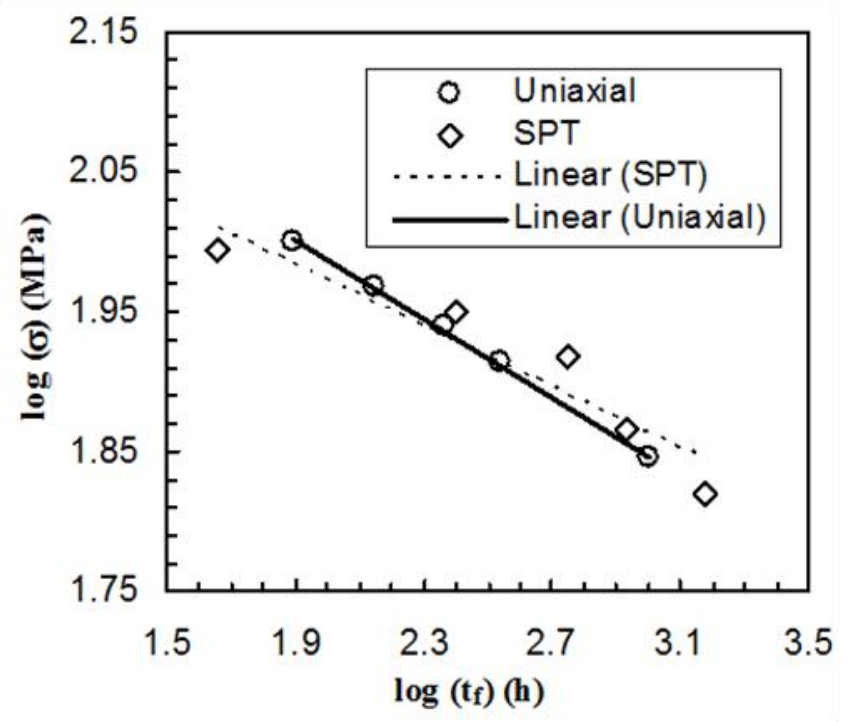

(c)

Figure 7. (a) Cross section of a typical experimental set-up used for small punch creep tests with dimensions in [mm], from Ref. [51]; (b) typical small punch creep test data output for a P91 steel at $600{ }^{\circ} \mathrm{C}$, from Ref. [49]; (c) converted creep rupture data (using equation (11), with $K_{S P}=1.275$ ) obtained from a SPCT (SPT in the graph) on a P91 steel at $650{ }^{\circ} \mathrm{C}$, compared with corresponding uniaxial data, from Ref. [40]. 


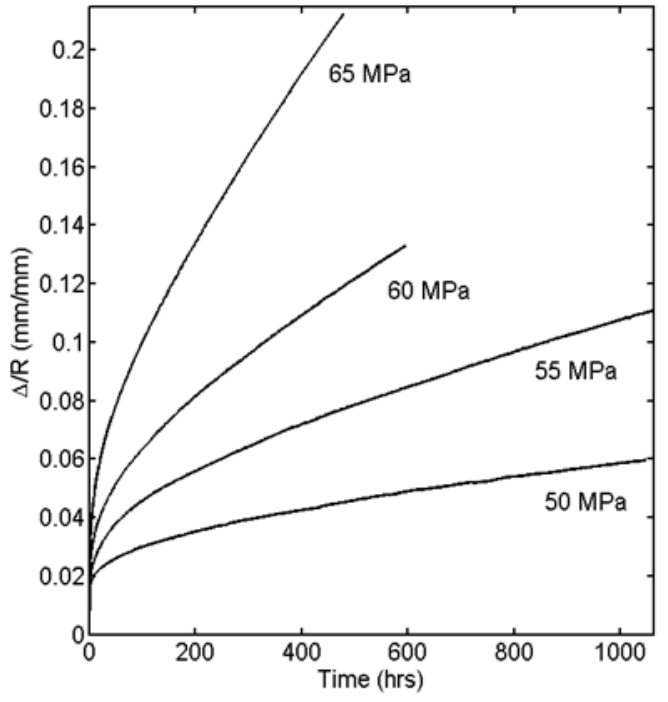

(a)

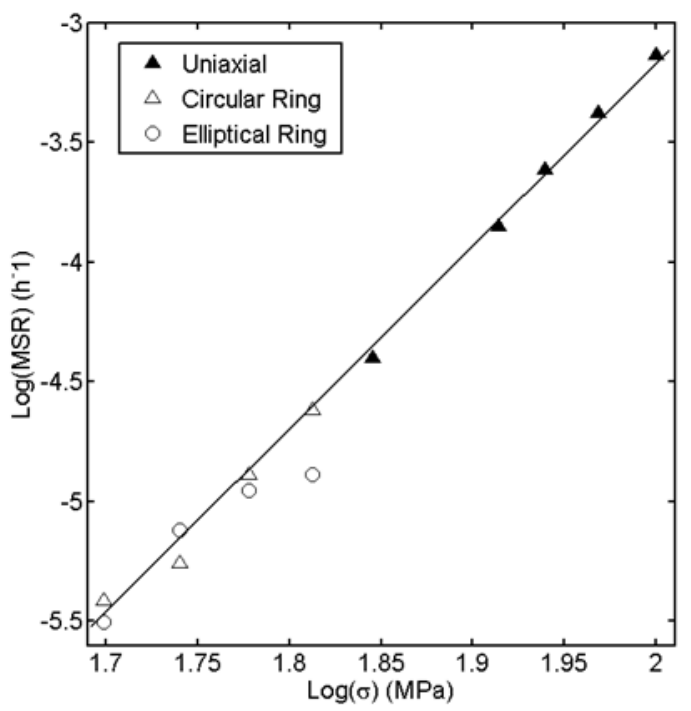

(b)

Figure 8. (a) Deformation $(\Delta / \mathrm{R})$ versus time curves obtained from circular rings for a P91 steel at $650{ }^{\circ} \mathrm{C}$, and (b) minimum creep strain rate data for a P91 steel at $650^{\circ} \mathrm{C}$ obtained from uniaxial and ring tests, from Ref. [36].

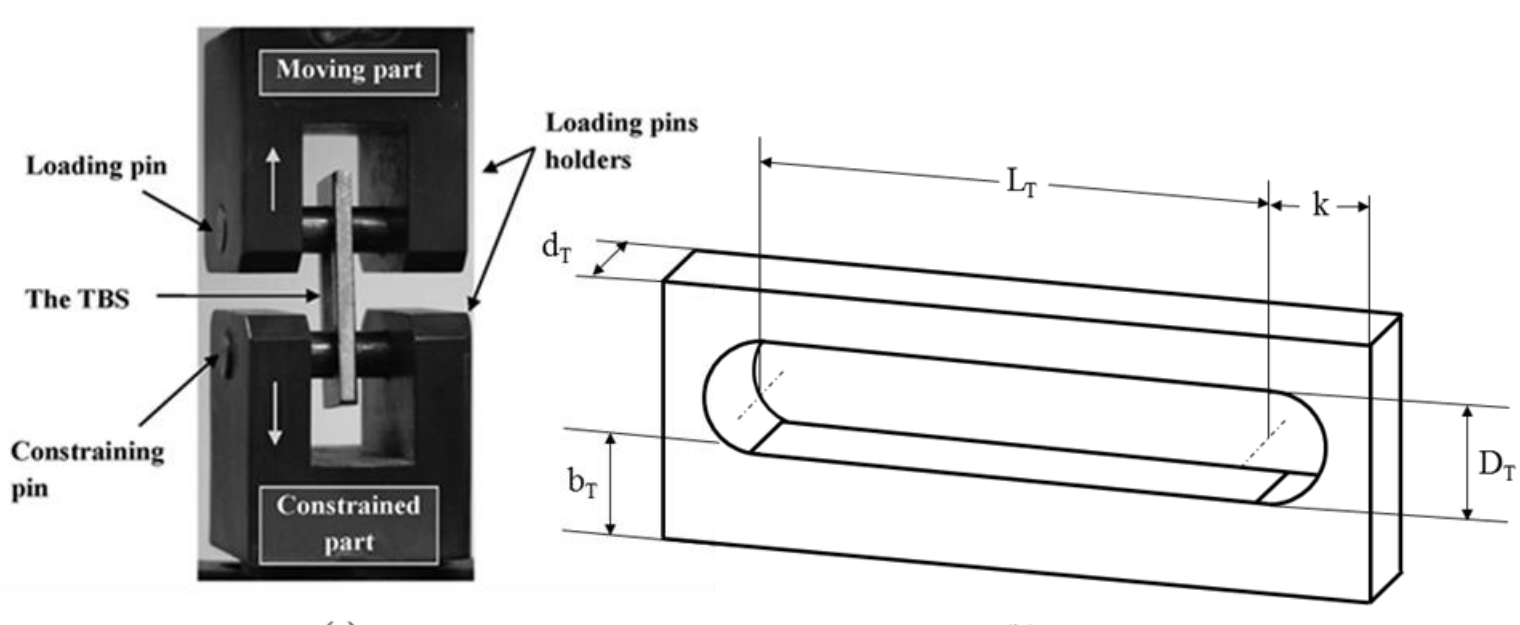

(a)

(b)

Figure 9. (a) Two-Bars experiment setup and loading application; (b) schematic representation of the Two-Bar specimen, adapted from Ref. [39]. 

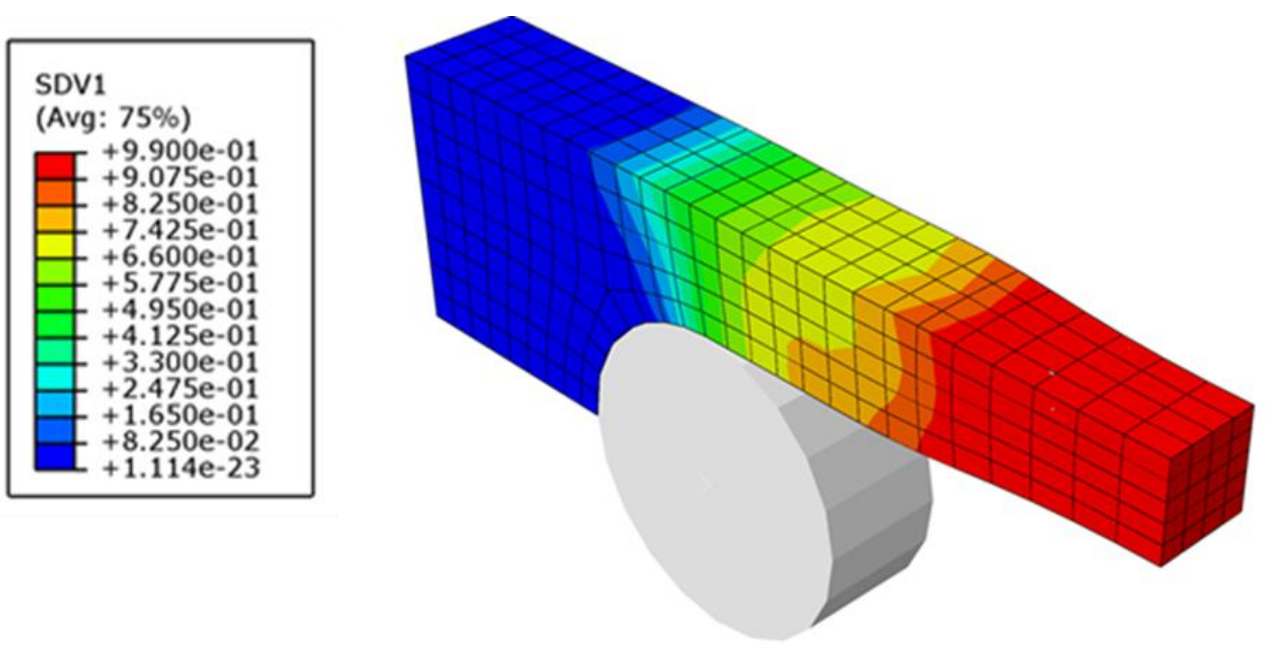

Figure 10. Contour plot of damage parameter, $\omega$, in the TBS for P91 at $600^{\circ} \mathrm{C},\left(\sigma=170 \mathrm{MPa}, \mathrm{t}_{\mathrm{f}}=\right.$ 169 h), from Ref. [38]. Only a quarter of the specimen is modelled due to symmetry. 


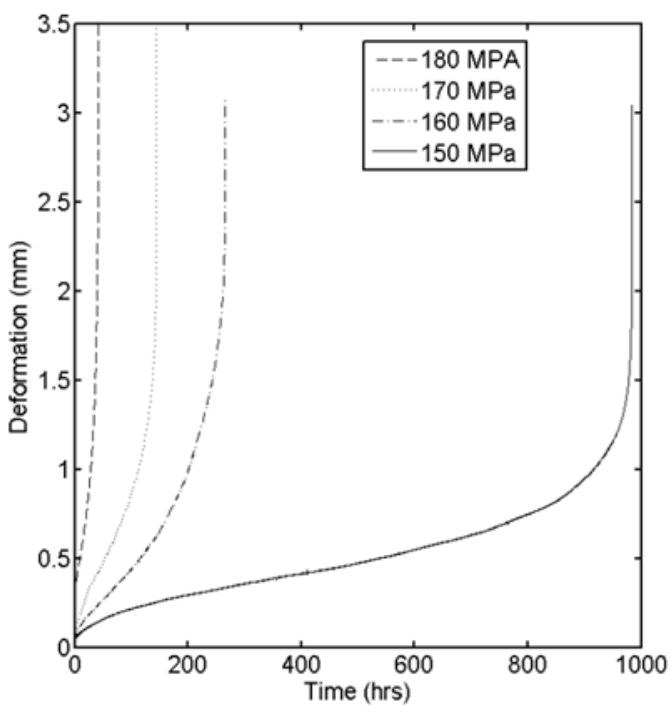

(a)

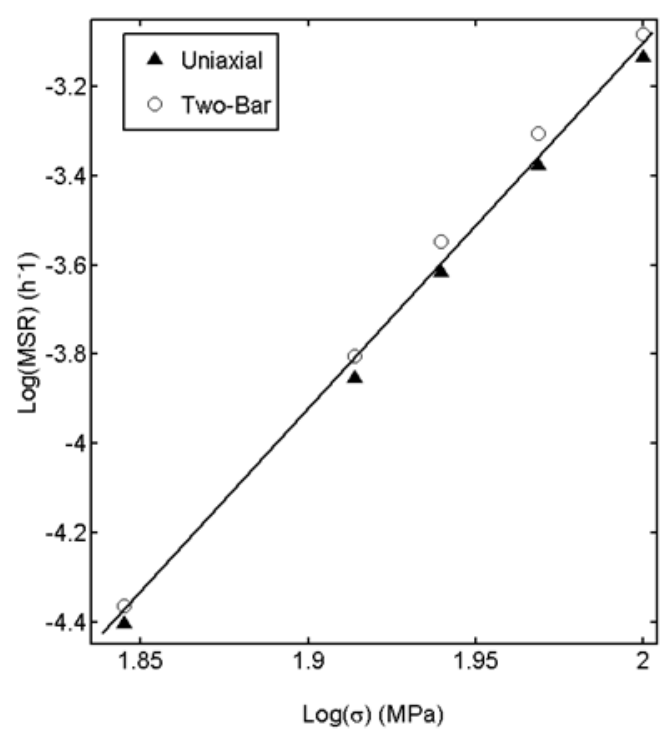

(c)

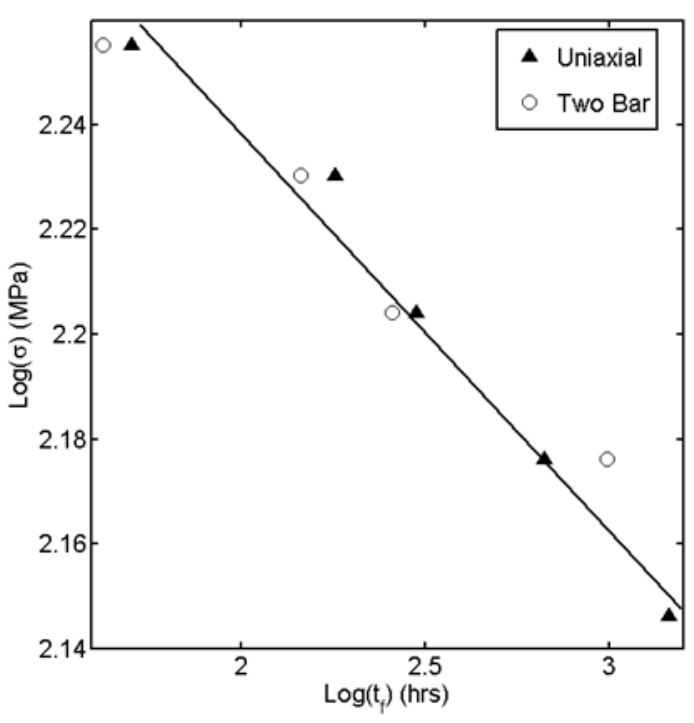

(b)

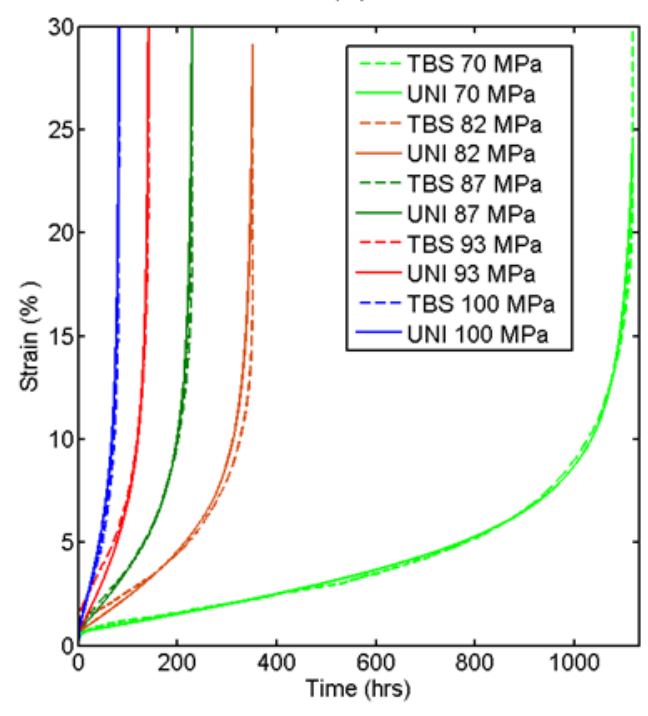

(d)

Figure 11. (a) Deformation versus time curves obtained from two bar specimens for a P91 steel at $600{ }^{\circ} \mathrm{C}$, (b) Creep rupture data and minimum and (c) creep strain rate data obtained from two bar and uniaxial specimens for a P91 steel at $600{ }^{\circ} \mathrm{C}$, from Ref. [27]. (d) Fitted uniaxial and converted (using equation ) two-bar strain versus time curves for a P91 steel at $650{ }^{\circ} \mathrm{C}$, from Ref. [102]. 


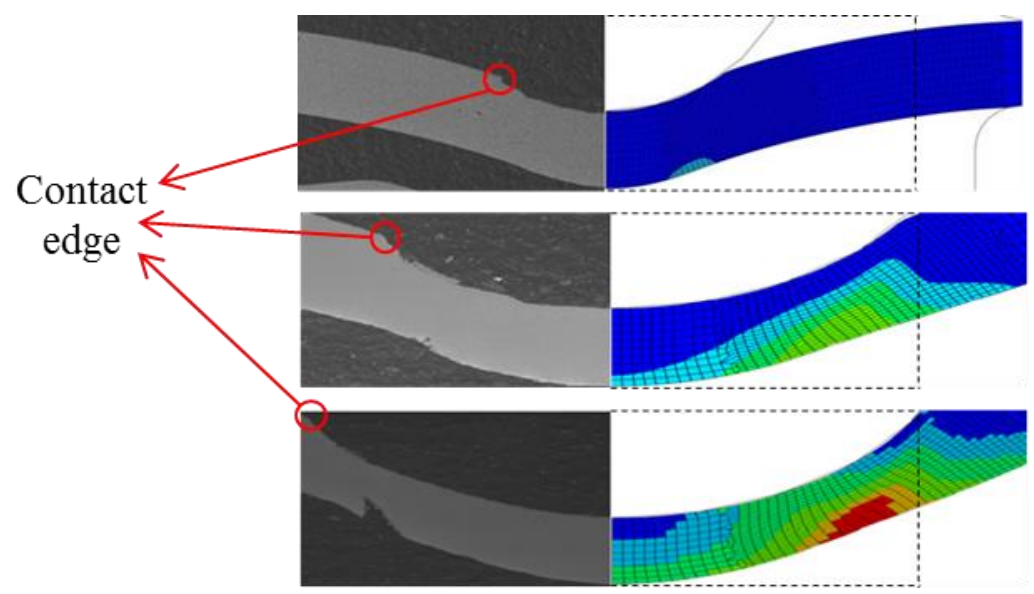

(a) (Avg: $75 \%$ )

DAMAGE

$+9.899 \mathrm{e}-01$
$+9.800 \mathrm{e}-01$
$+9000 \mathrm{e}-01$
$+7.000 \mathrm{e}-01$
$+5.000 \mathrm{e}-01$
$+3.000 \mathrm{e}-01$
$+0.000 \mathrm{e}+00$

(c)

Figure 12. SEM images from ref. [49] for a small punch creep test, for a P91 steel at $600{ }^{\circ} \mathrm{C}$ with a load of $25 \mathrm{~kg}$, interrupted after (a) 2 hours $\left(t / t_{f} \approx 0, \Delta /_{\Delta_{f}} \approx 0.40\right)$, (b) 200 hours $\left(t / t_{f} \approx 0.20\right.$, $\Delta_{\Delta_{f}} \approx 0.62$ ) and (c) after 669 hours $\left(t / t_{f} \approx 0.64, \Delta /_{\Delta_{f}} \approx 0.82\right)$, and FE damage contour plots for a P91 steel at $650{ }^{\circ} \mathrm{C}$ under a load of $200 \mathrm{~N}$, with $R_{s}=1.04 \mathrm{~mm}$ and $t_{0}=0.5 \mathrm{~mm}$.

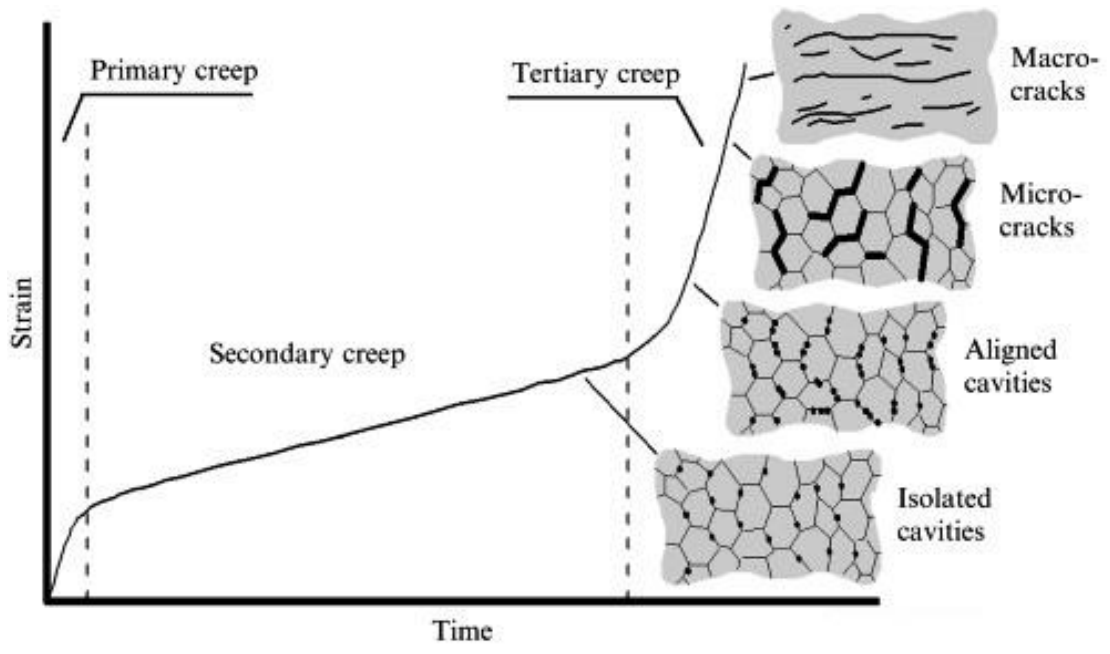

Figure 13. Creep degradation through life, adapted from Ref. [103]. 


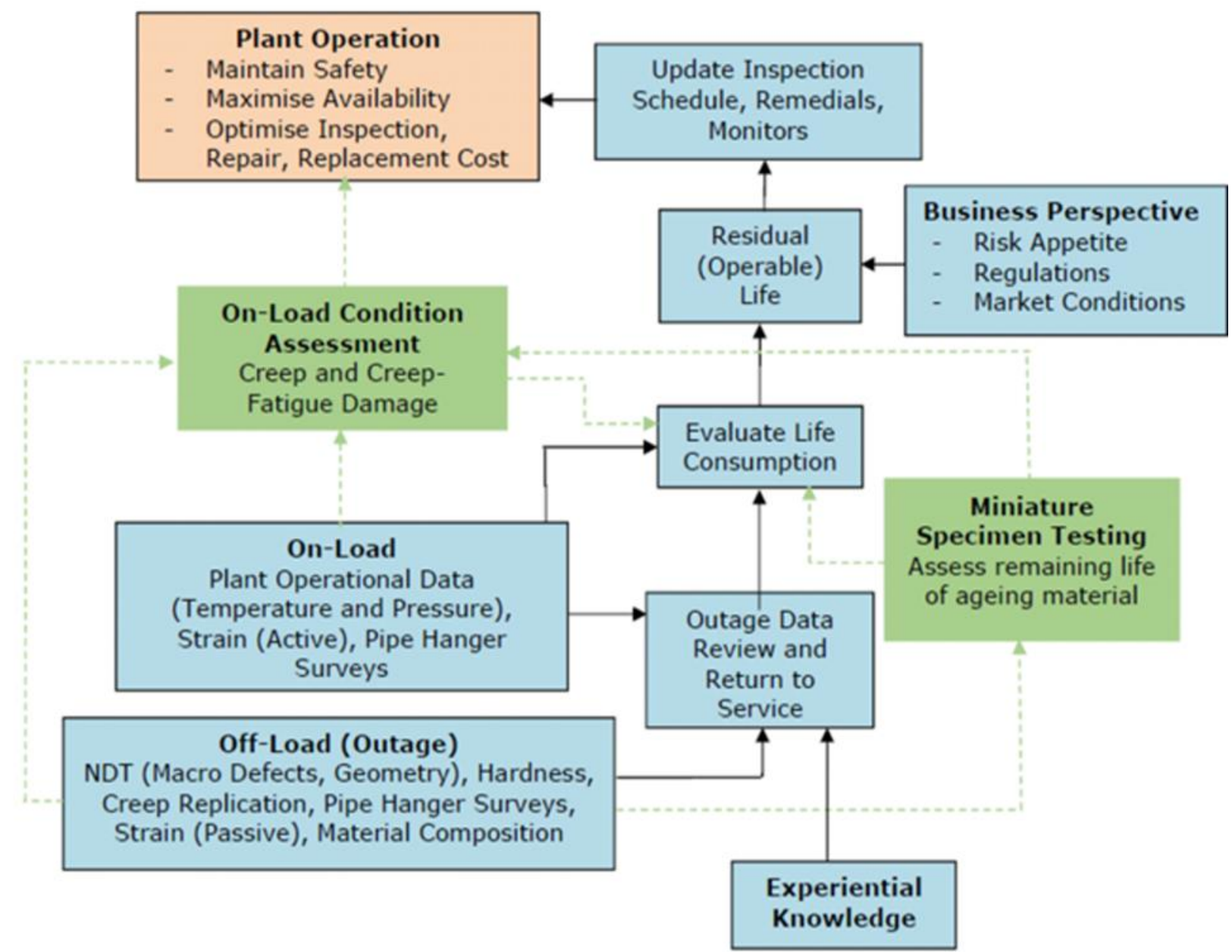

Figure 14. High temperature plant conditon assessment (dotted line represent aspects of data analysis/methods that are not fully utilised. Solid lines represent the current and well established IBA approach).

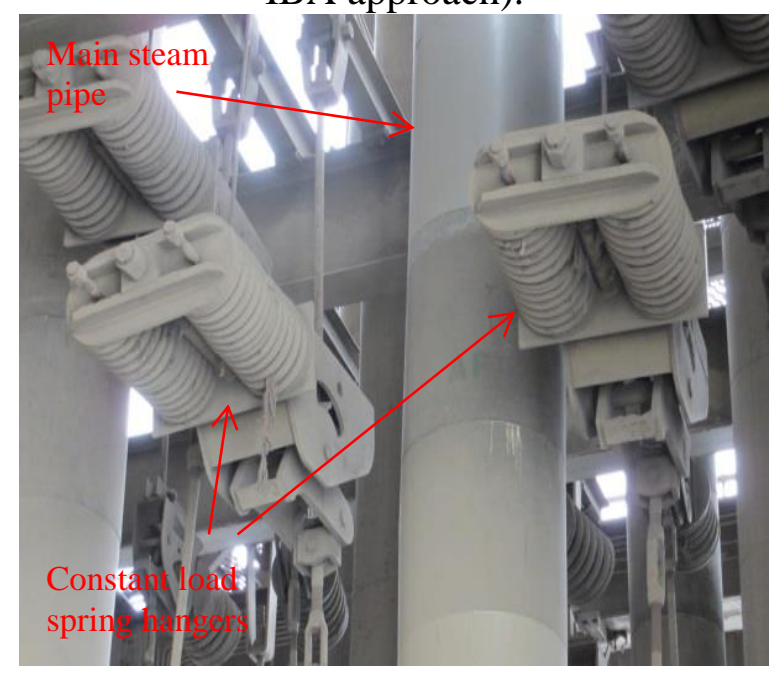

Figure 14. Typical pipe hanger arrangement. 


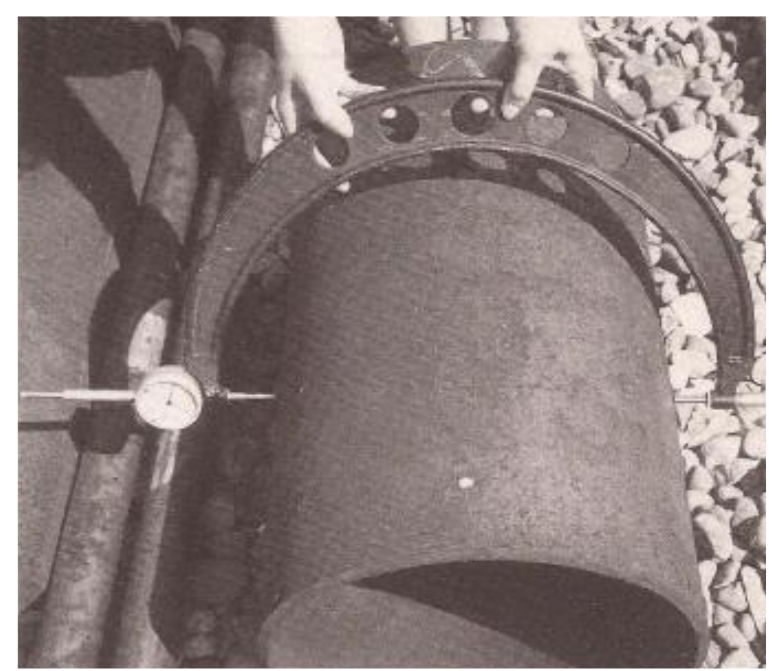

Figure 15. Bow gauge micrometer with dial gauge. 

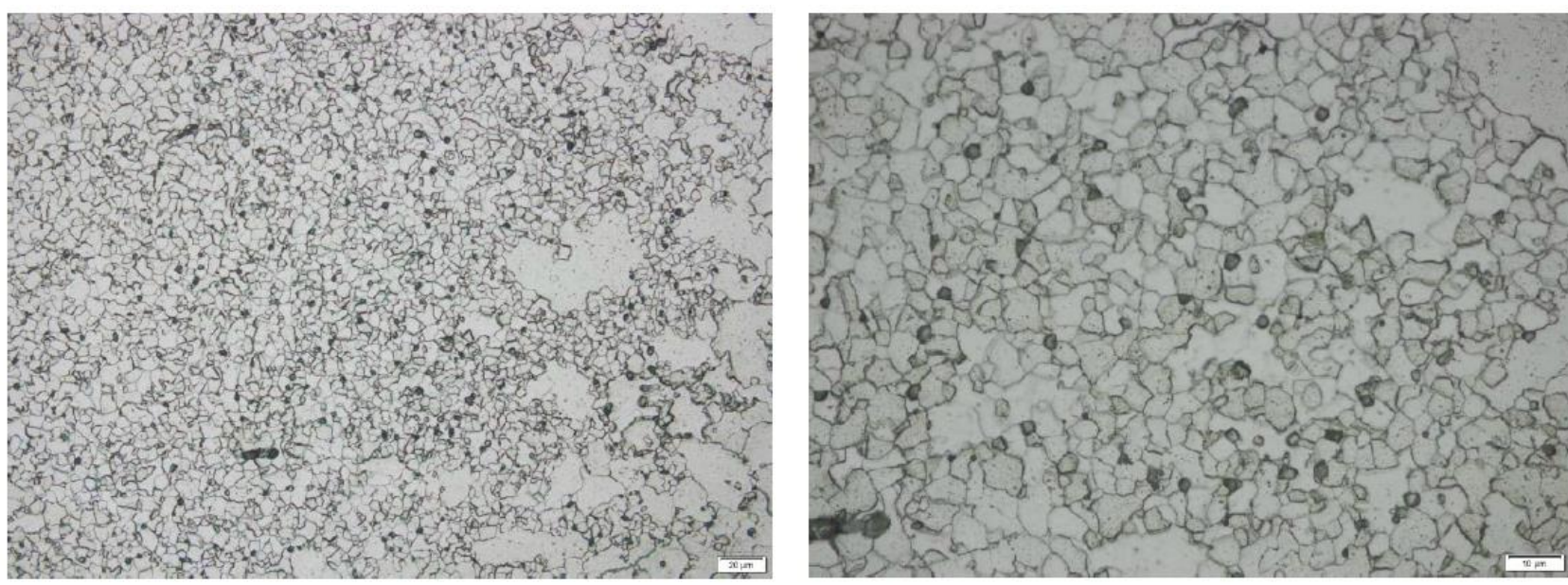

Figure 17. Weld Type IV region of a main steam pipework weld, surface replica taken $5 \mathrm{~mm}$ below the outer surface. Photomicrographs shown at x200 magnification (left) and x500 magnification (right)

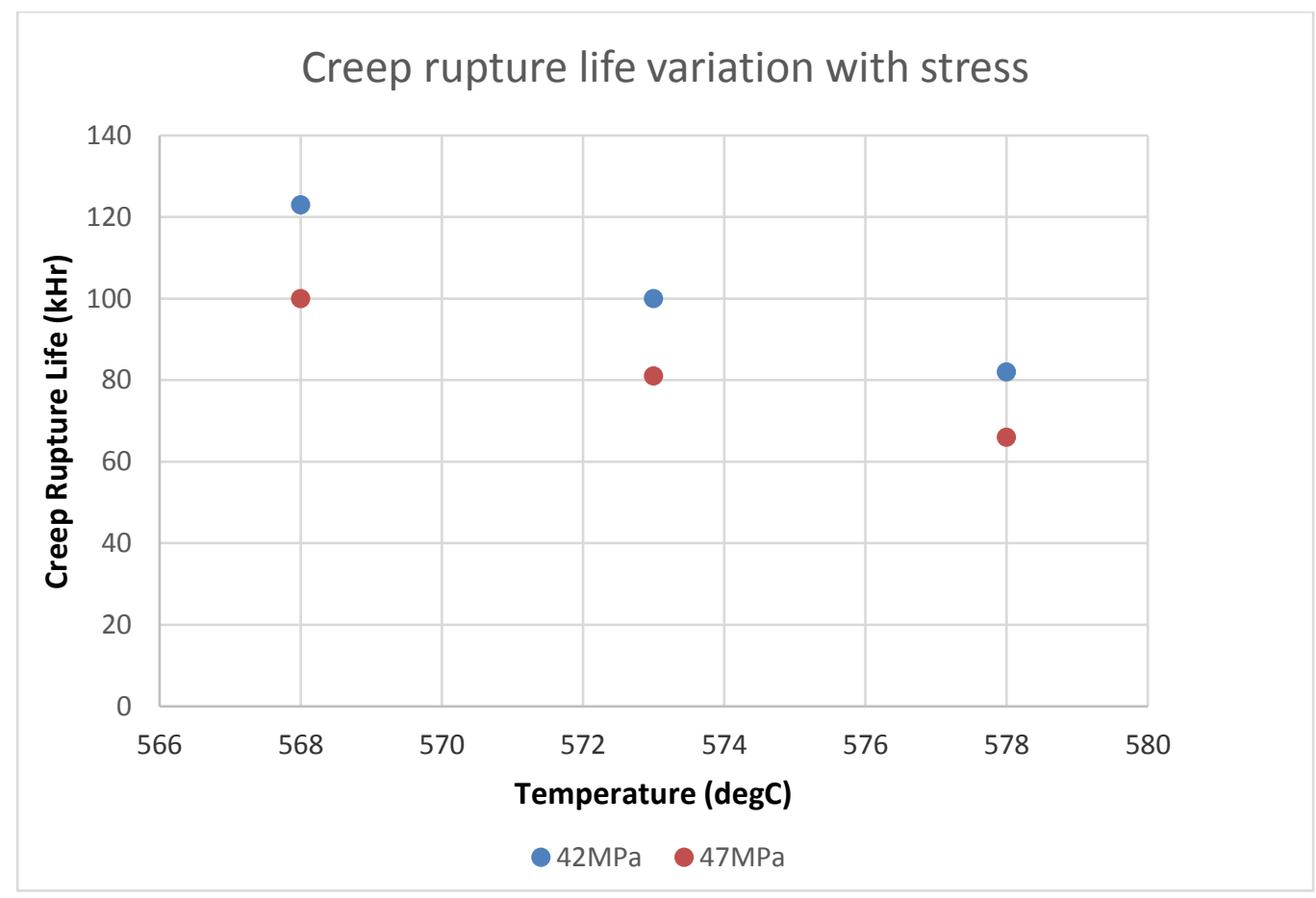

Figure 18. Sensitivity of creep rupture life. 


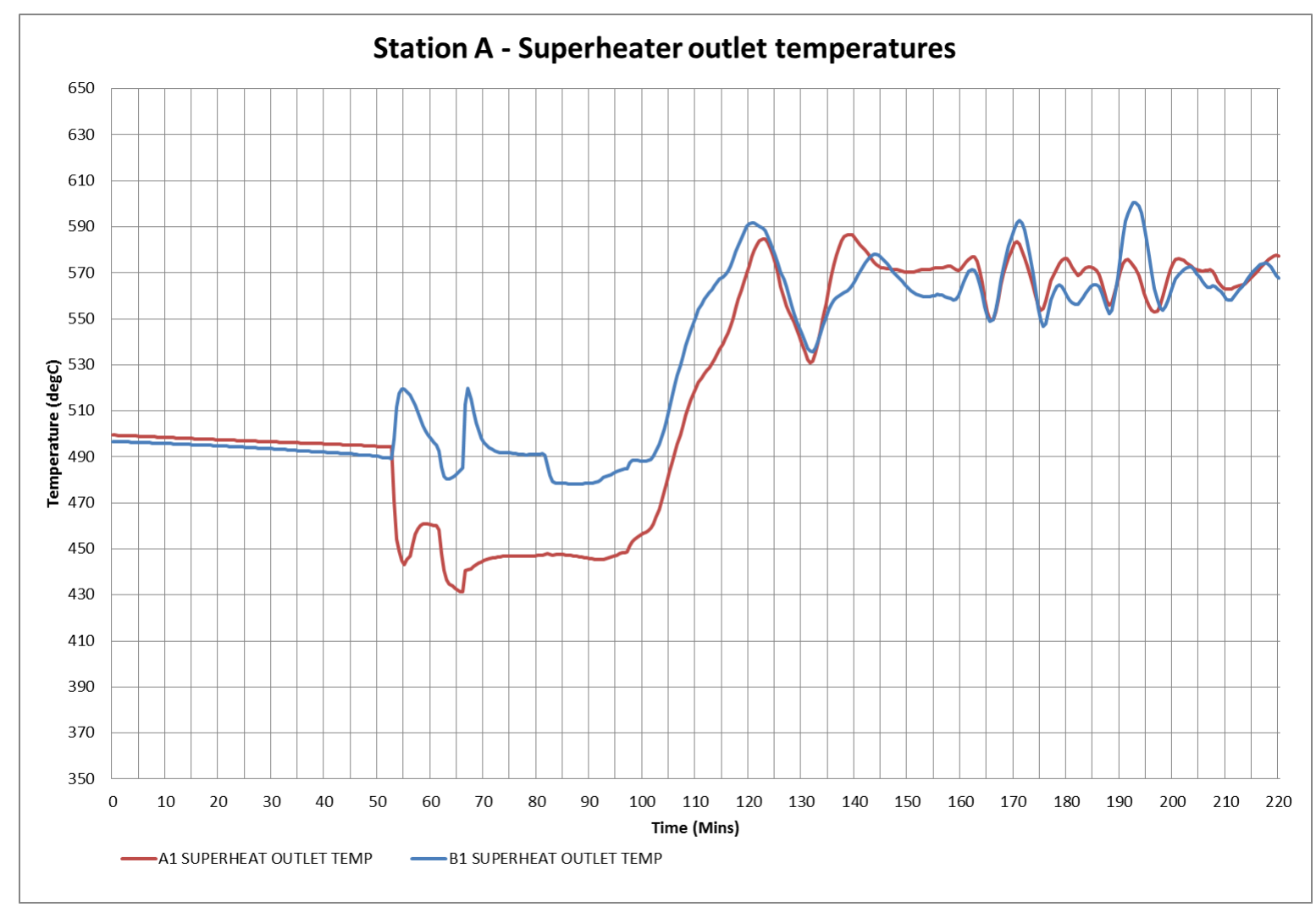

Figure 19. Typical steam temperature trace for two boiler outlet steam legs (A1 and B1)

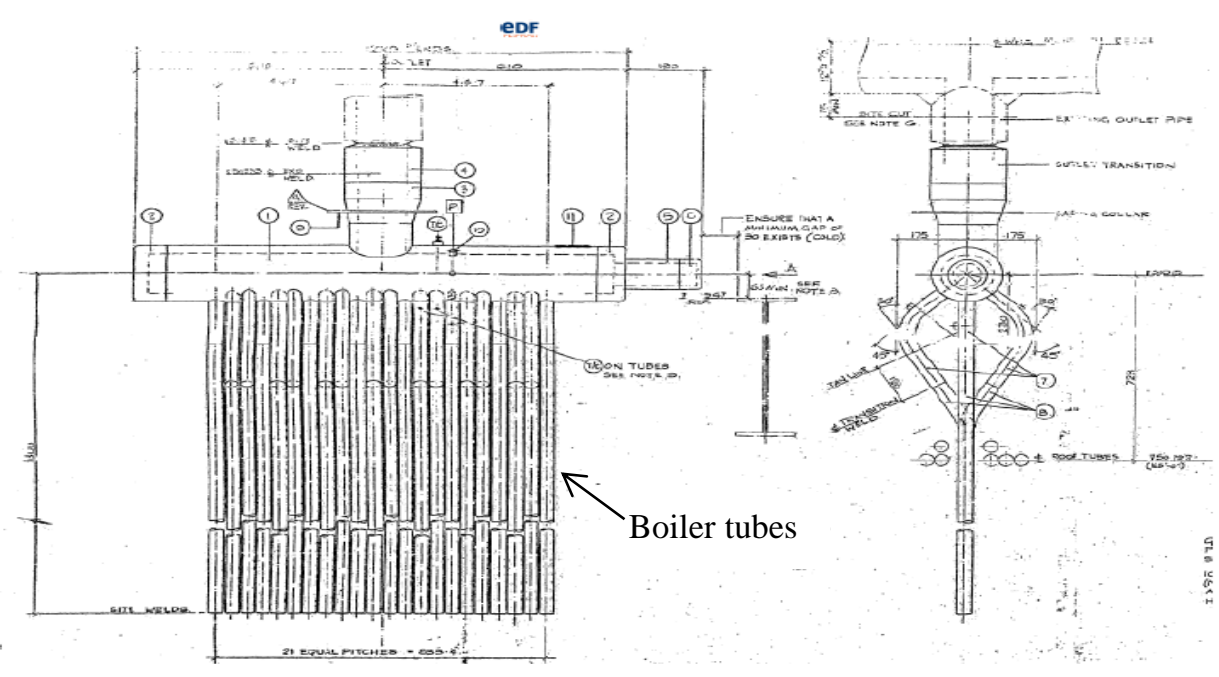

Figure 20. Stub header. 


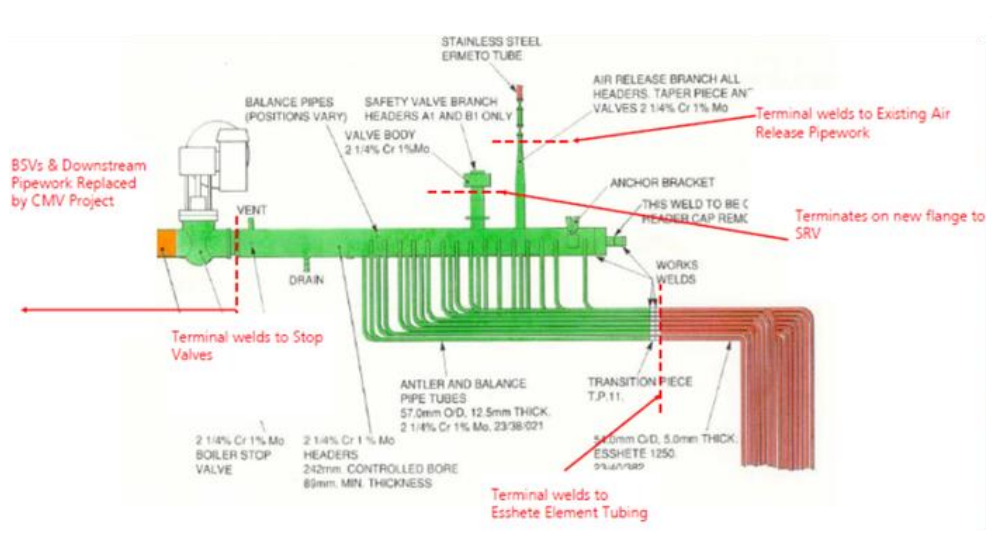

(a)

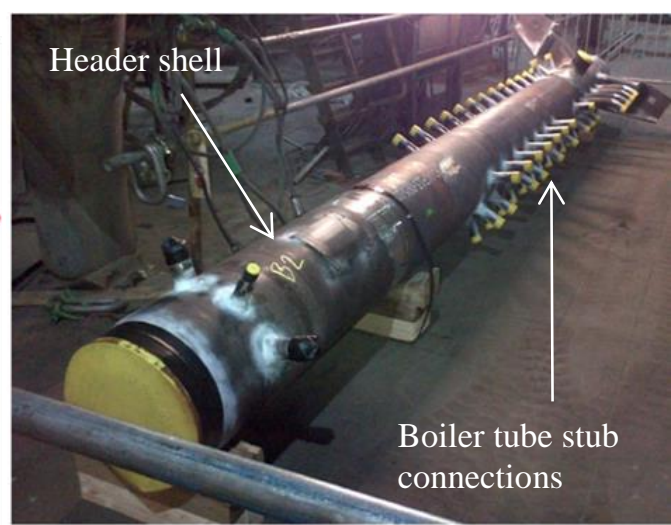

(b)

Figure 21. $6^{\text {th }}$ Stage superheater outlet header (a) schematic component and (b) replacement component.

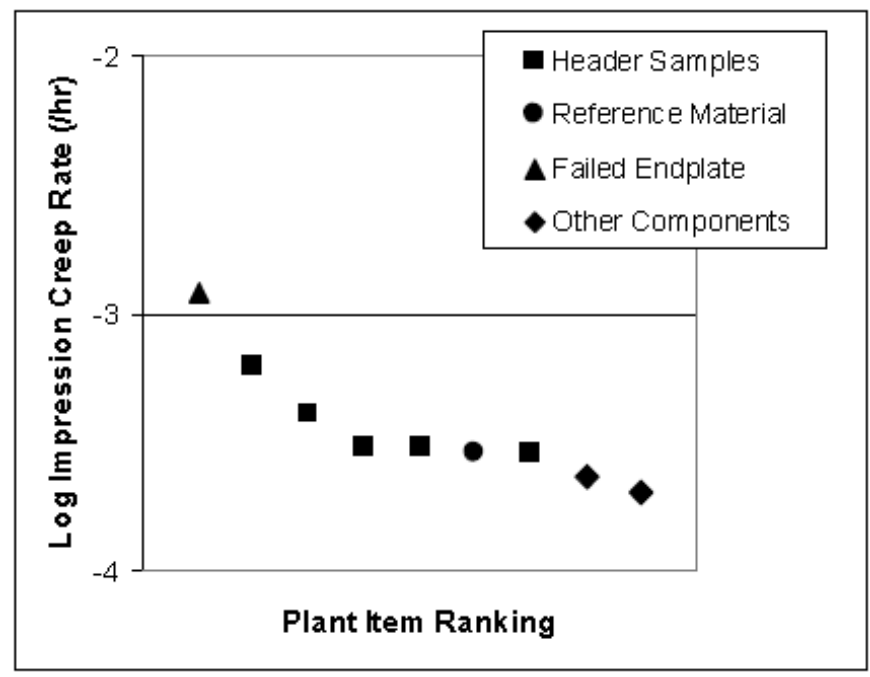

Figure 16. Impression creep strain rates of plant items ranked in order of decreasing MSR, obtained from samples from the suspect header compared to a sample from a weak failed endplate and samples from other components, from Ref. [67]. 


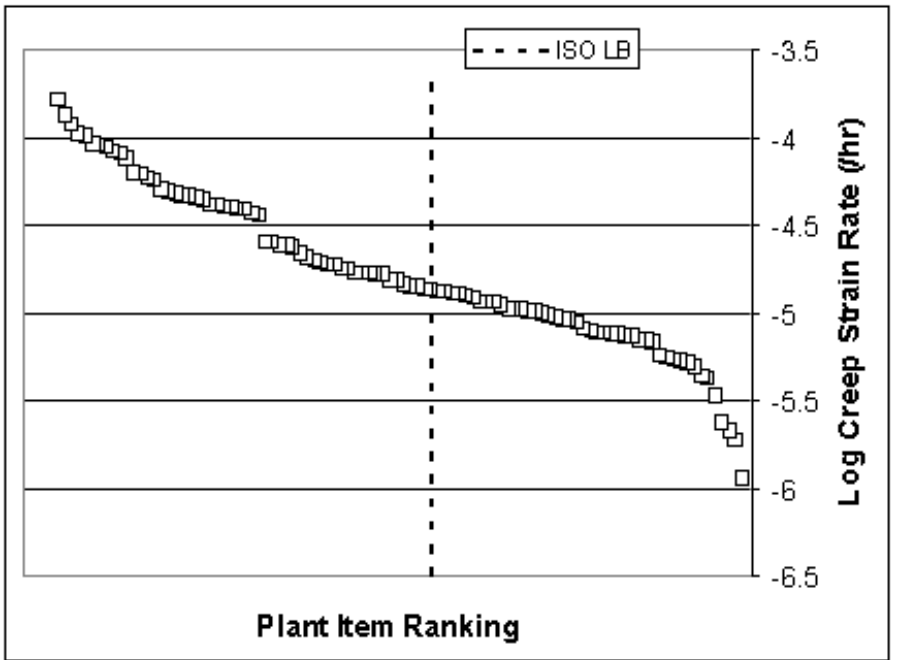

Figure 17. Impression creep strength ranking plot for CMV as-sampled, from Ref. [67].

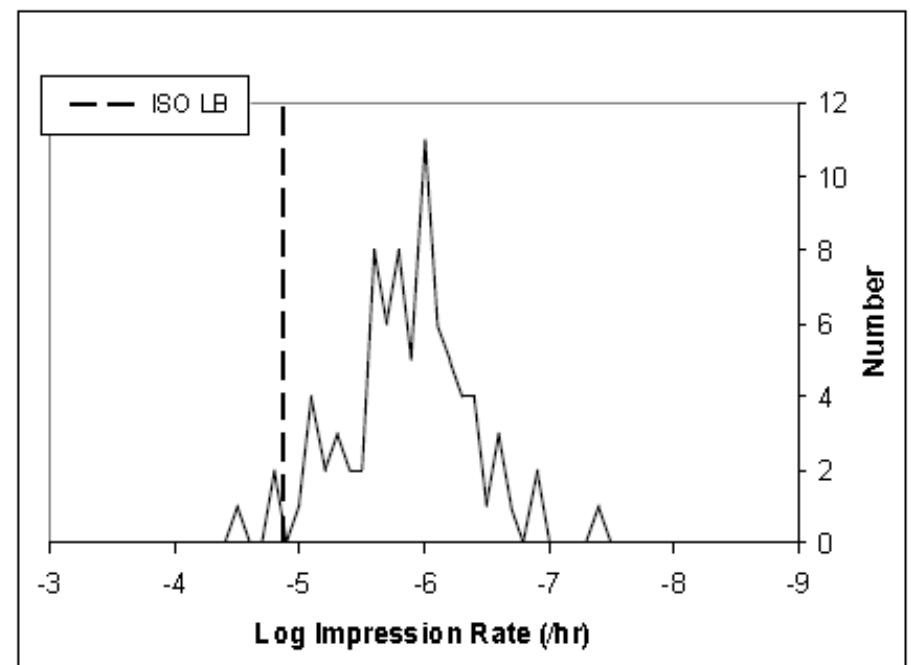

Figure 18. Histogram showing the CMV data, corrected for operating hours at the time of sampling to reflect strength at the start of life, from Ref. [67]. 


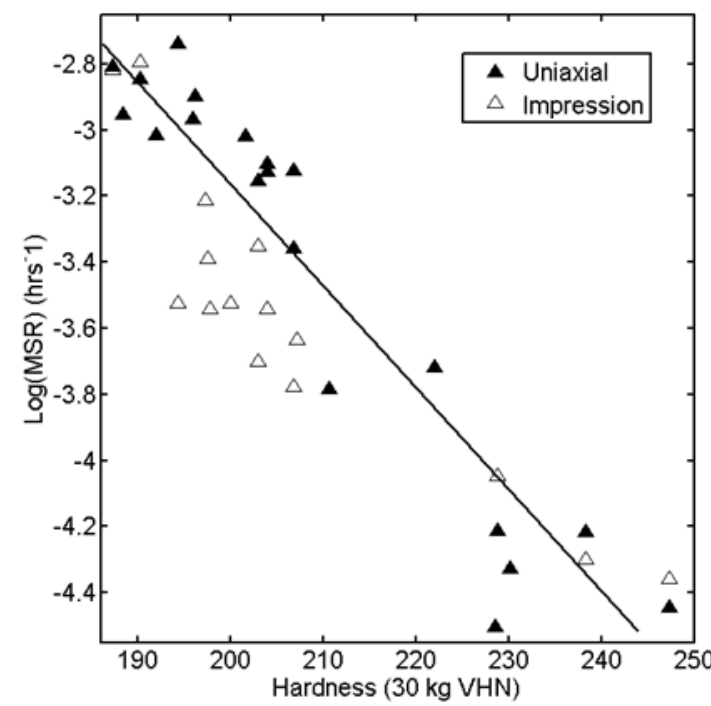

(a)

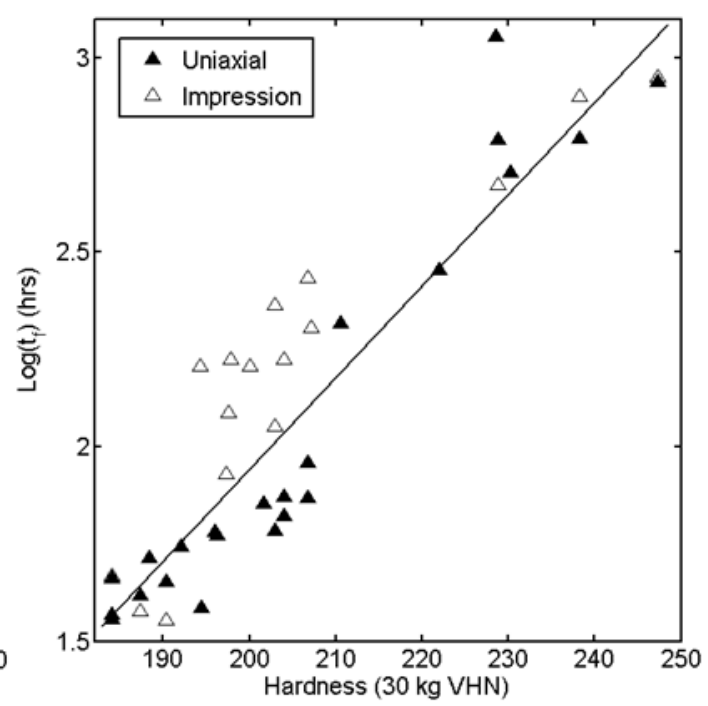

(b)

Figure 19. (a) Variations of minimum creep strain rates at $600^{\circ} \mathrm{C}$ and at a stress of $155 \mathrm{MPa}$, with room temperature hardness for Grade P91 steels (with different service histories) from ref. [12], and (b) variations of uniaxial rupture life, $\mathrm{t}_{\mathrm{f}}$, at $600{ }^{\circ} \mathrm{C}$ and at a stress of $155 \mathrm{MPa}$, with room temperature hardness for Grade P91 steels (with different service histories), from ref. [12].

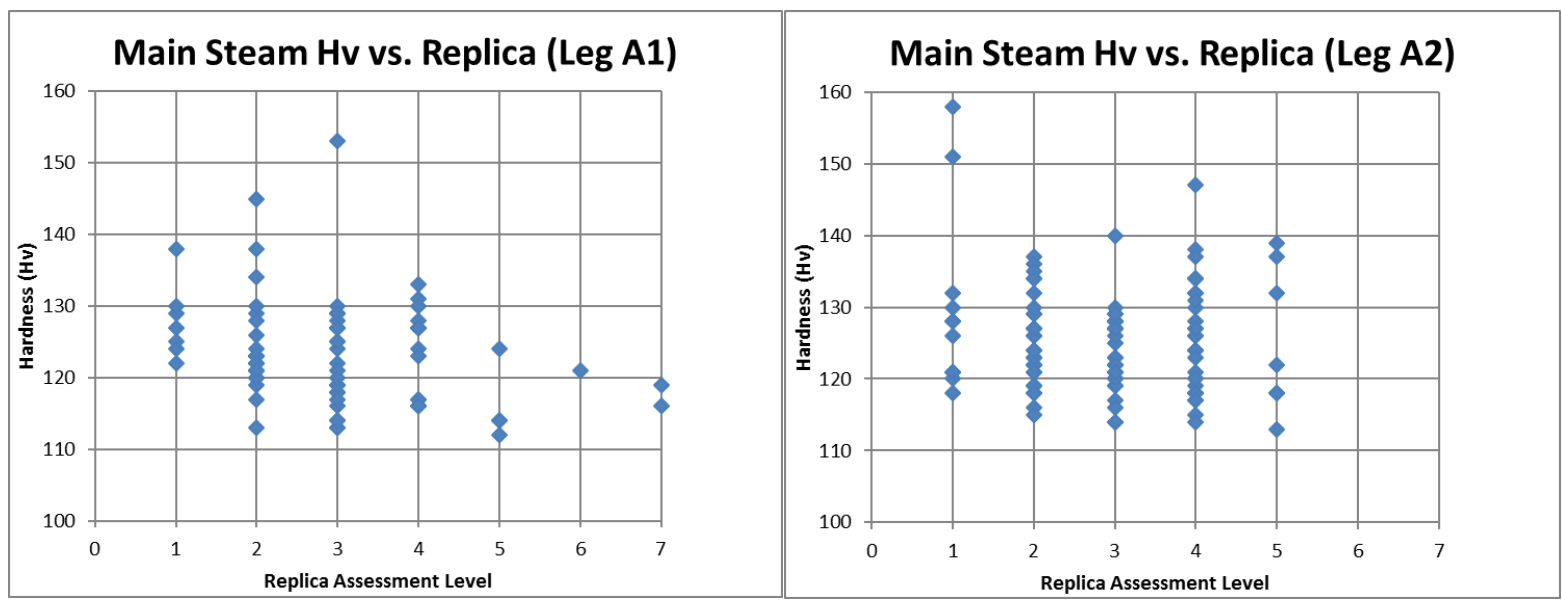

\begin{tabular}{|c|l|c|}
\hline $\begin{array}{l}\text { Replica } \\
\text { Assessment } \\
\text { Level }\end{array}$ & Definition & $\begin{array}{l}\text { Creep Cavities } \\
\text { per } \mathrm{mm}^{2}\end{array}$ \\
\hline 1 & Clear & 0 \\
\hline 2 & Very Isolated & $1-10$ \\
\hline 3 & Isolated & $10-50$ \\
\hline 4 & Low Orientated & $50-250$ \\
\hline 5 & $\begin{array}{l}\text { Orientated (Including } \\
\text { High Orientated) }\end{array}$ & $250-500$ \\
\hline 6 & Grouped & $500-1000$ \\
\hline 7 & Aligned & $1000-1500$ \\
\hline
\end{tabular}

Figure 24. Main steam line parent CMV hardness vs. creep replica assessment level, at 200,000 h 